\title{
NEUES ZUR URBANISTIK DER ZIVILSTÄDTE VON AQUINCUM-BUDAPEST UND CARNUNTUM-PETRONELL
}

\author{
AUSWERTUNG UND ARCHÄOLOGISCHE INTERPRETATION \\ DER GEOPHYSIKALISCHEN MESSUNGEN 2011 UND 2012
}

\author{
STEFAN GROH - ORSOLYA LÁNG - HELGA SEDLMAYER - PAULA ZSIDI \\ Österreichisches Archäologisches Institut, Wien, Franz Klein Gasse 1, Österreich \\ Aquincum Museum, Szentendrei út 135, H-1031 Budapest, Hungary \\ E-Mail: stefan.groh@oeai.at, lang.orsolya@aquincum.hu, \\ helga.sedlmayer@oeai.at, zsidi.paula@aquincum.hu
}

\begin{abstract}
In this paper the new results of an Austrian-Hungarian research cooperation (2011-2014) on the urbanism of the Civil towns of Aquincum and Carnuntum are to be presented. In synthesis of geophysical surveys, the interpretation of archaeological excavations and the reinterpretation of elder evidences, a new picture of the diachronic development of the two Civil Towns from an early vicus to a fortified city can be drawn.

Keywords: Capitals of Pannonian provinces, geophysical prospection, urbanism
\end{abstract}

\section{EINLEITUNG}

Im Rahmen einer Forschungskooperation zwischen dem Österreichischen Archäologischen Institut - ÖAI (Fachbereich Zentraleuropäische Archäologie - ZEA, St. Groh, H. Sedlmayer) und dem Budapest History Museum (S. Bodó) sowie dem BHM Aquincum Museum in Budapest (P. Zsidi, O. Láng) begannen 2011 Forschungen zur Urbanistik der Zivilstädte von Aquincum-Budapest und Carnuntum-Petronell (Abb. 1-2). Die Ausgangslage zu urbanistischen Überlegungen stellen neue, ergänzte digitale Stadtpläne und geophysikalische Prospektionen mit Georadar und Magnetik aller noch unverbauten größeren, zugänglichen Freiflächen in Aquincum und solche mit Magnetik im westlichen Suburbium von Carnuntum dar (Abb.3).

Die prospektierten Flächen in Aquincum erstrecken sich auf Areale innerhalb der Stadtmauern und auf suburbane Gebiete westlich sowie südlich der Stadt. Die Messergebnisse geben wichtige neue Aufschlüsse zu Strukturen mit Streifenbebauung außerhalb der Stadtmauern; intraurban kann erstmals der Südwestteil der Zivilstadt von Aquincum interpretiert werden. Die prospektierten Flächen in Carnuntum erstrecken sich auf Areale entlang der Ausfallstraße im Suburbium-West, wo eine Vicus-Bebauung mit Streifenparzellierung und Gräberbefunde erkannt werden konnten.

Zur Erleichterung der Orientierung innerhalb und außerhalb der Stadtgebiete von Aquincum und Carnuntum werden intraurban vier Regionen 1-4 und extraurban die Begriffe Suburbium-Nord, -West und -Süd definiert. ${ }^{1}$ Der in Aquincum in Nord-Süd-Richtung verlaufende cardo maximus (Straßen A und C) und der die Stadt in WestOst-Richtung durchmessende decumanus maximus (Straße D) ${ }^{2}$ gliedern das Stadtgebiet intra muros in vier Teile, die als die Regionen 1-4 angesprochen werden. Die extramuralen Siedlungsgebiete werden nach den Himmelsrich-

${ }^{1}$ Die im aktuellen Beitrag gewählte Bezeichnung ,Regionen" ist nicht identisch mit den von T. Nagy hypothetisch aufgrund topografischer Gesichtspunkte definierten „Regiones“ (NAGY 1943, 390; NAGY 1973, 122). - Zur Unterscheidung werden die hier für beide pannonischen Hauptstädte, Aquincum und Carnuntum, vorgenommenen Regionsbezeichnungen arabisch nummeriert.

${ }^{2}$ Die Ansprache der Straßen folgt ZsIDI 2008 und LÁNG 
tungen benannt, und zwar das an der Straße A nördlich des Stadttores gelegene Suburbium-Nord mit dem Amphitheater, das der Straße D nach Westen folgende Suburbium-West mit Vicus-Bebauung und das außerhalb des südlichen Stadttores an der Straße C gelegene Suburbium-Süd. Diesem Schema folgt auch die Benennung der Regionen und der suburbanen Gebiete in der Zivilstadt von Carnuntum. Die beiden Hauptachsen der Zivilstadt sind die Limesstraße, also der decumanus maximus, und die Nord-Süd-Straße, der cardo maximus, die sich im Zentrum zwischen Forumsareal und dem „Macellum-Thermen-Komplex“ schneiden (Abb. 4).

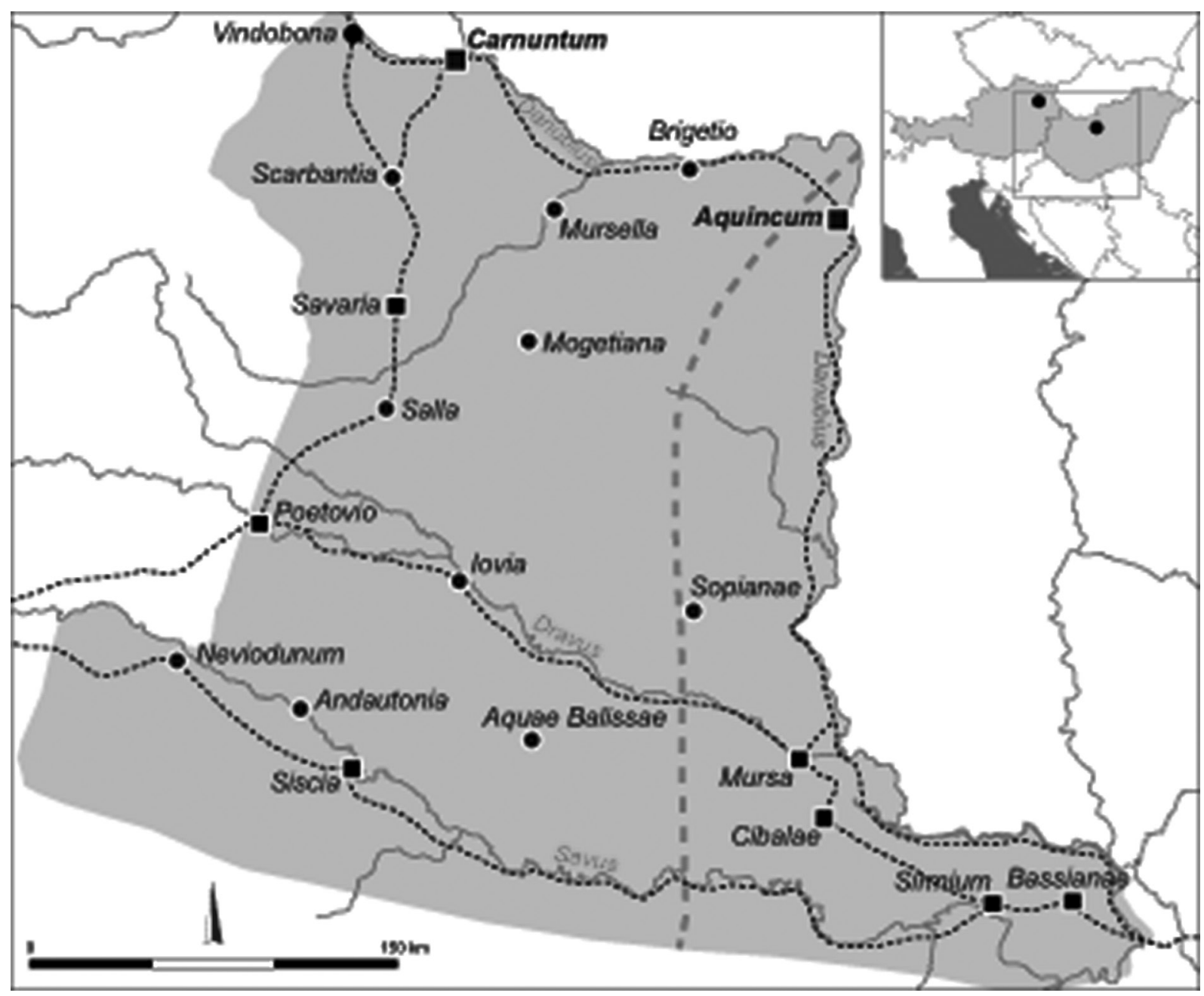

Abb. 1. Aquincum-Budapest und Carnuntum-Petronell: Die Hauptstädte der Provinzen Pannonia Inferior und Pannonia Superior (ÖAI) 


\section{Aquincum}

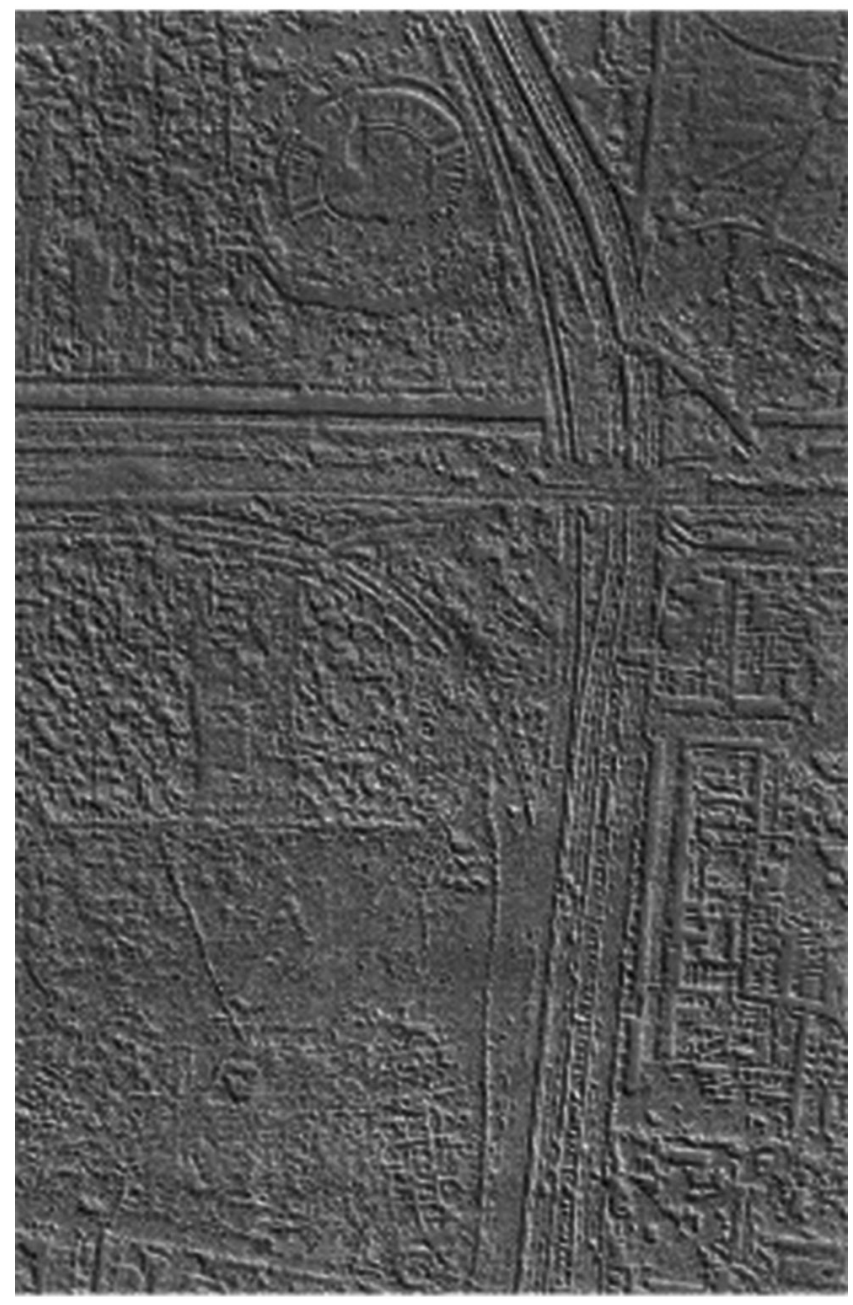

\section{Carnuntum}

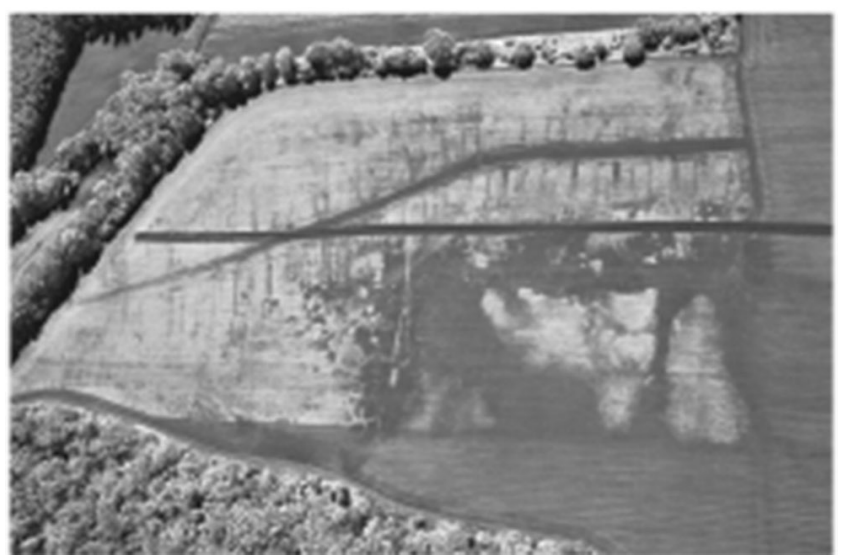

Abb. 2. Prospektionsgebiete im Überblick. LiDAR-Daten der Zivilstadt von Aquincum (BHM) Schwarzweiß-Infrarotbild des Suburbium-West von Carnuntum (nach Doneus 2013, Abb. 15, Ausschnitt) 


\section{Aquincum}

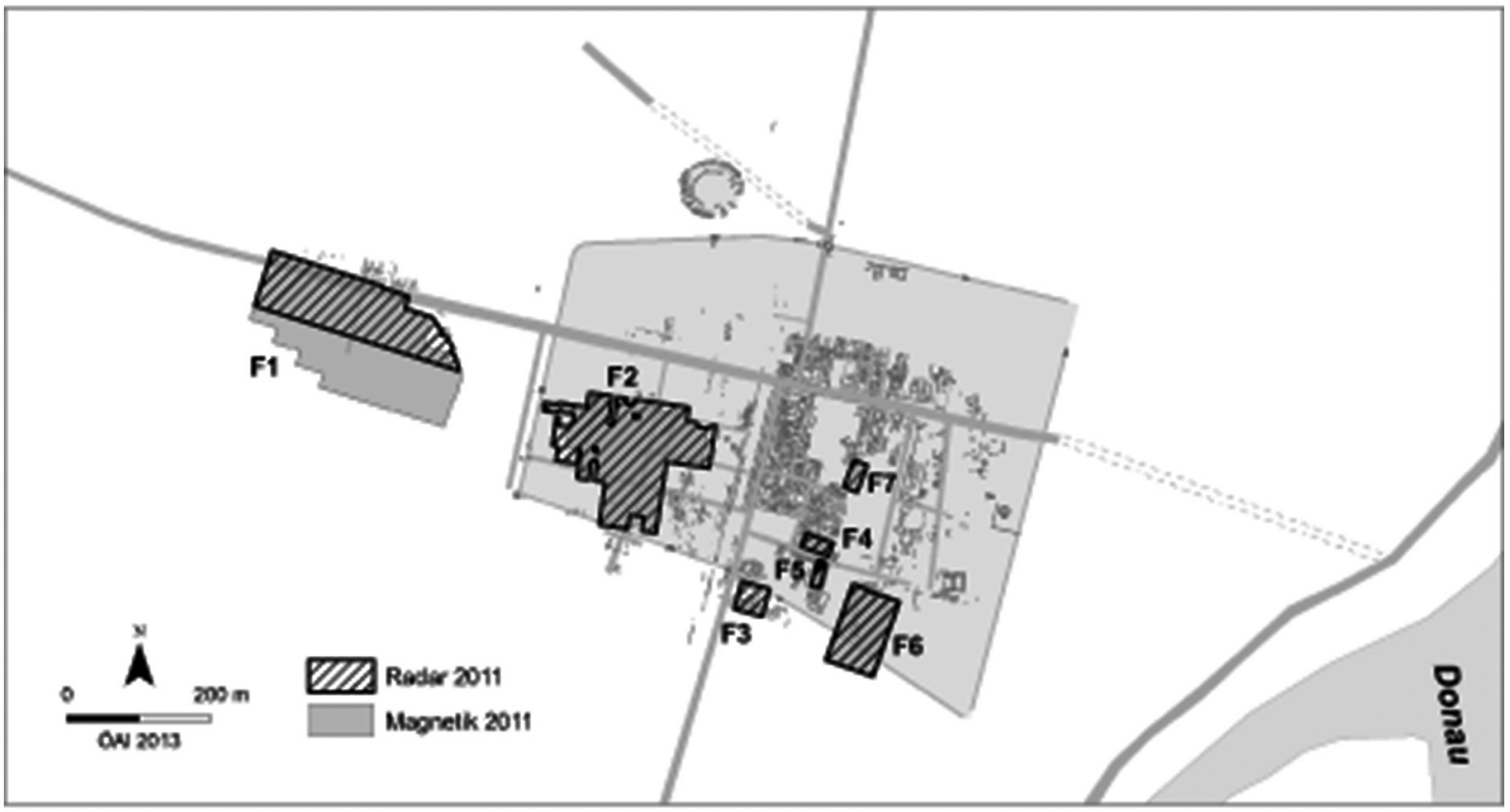

\section{Carnuntum}

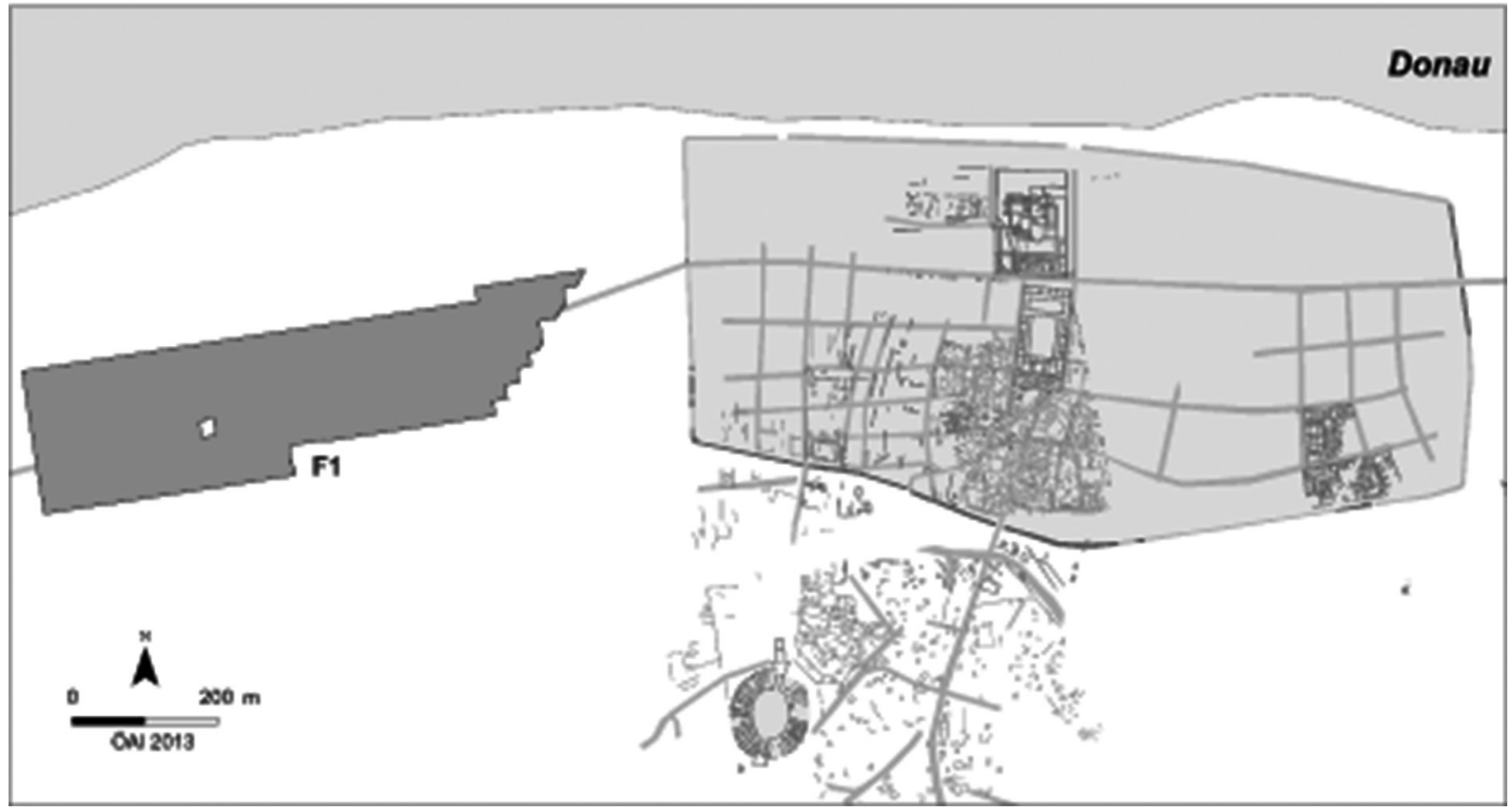

Abb. 3. Aquincum und Carnuntum. Stadtplan der Zivilstadt: Kartierung und Ansprache der geophysikalischen Messflächen 2011-2012 (ÖAI, unter Verwendung von Daten des BHM und der ÖAW) 


\section{Aquincum}

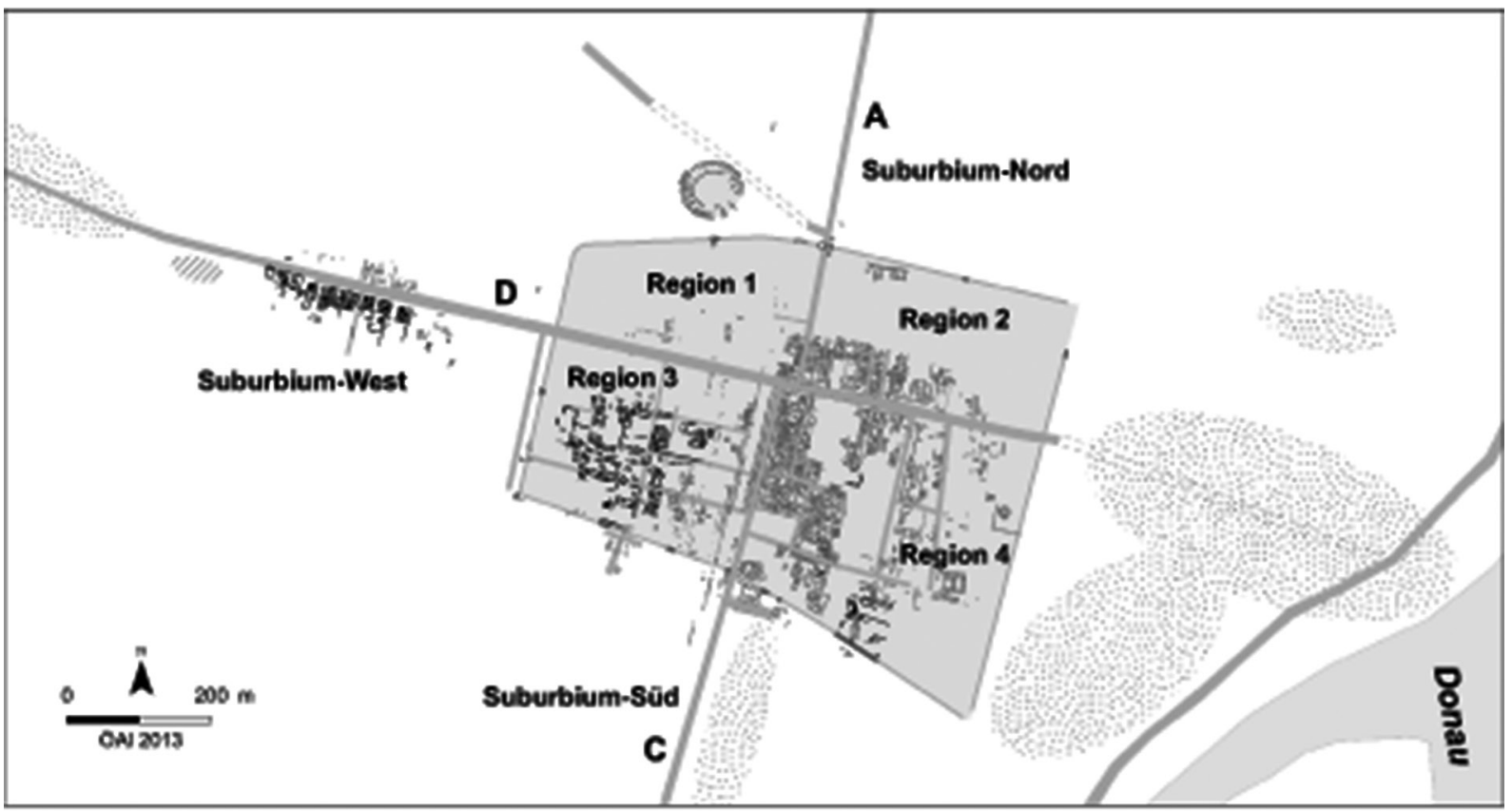

\section{Carnuntum}

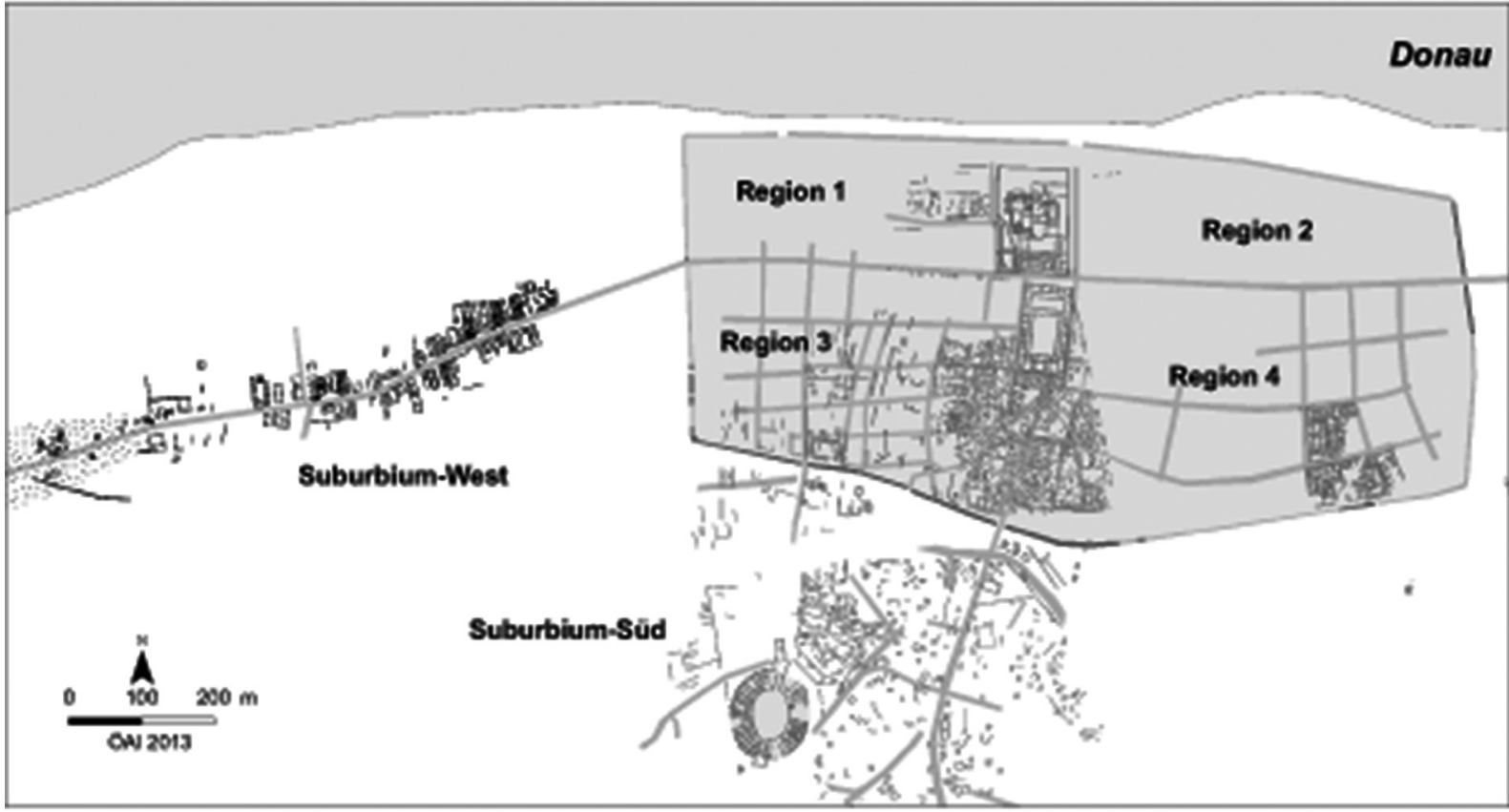

Narer. Geophyel

Maser. Beward

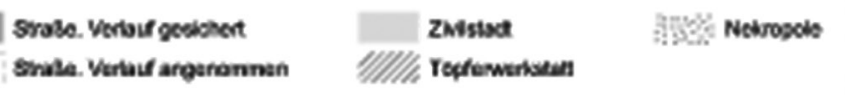

Abb. 4. Aquincum und Carnuntum. Gesamtplan und Ansprache der Stadtgebiete (ÖAI, unter Verwendung von Daten des BHM und der ÖAW) 


\title{
INTERPRETATION DER GEOPHYSIKALISCHEN MESSUNGEN
}

Die geophysikalischen Messungen des ÖAI 2011 in Aquincum erfolgten auf Messflächen im SuburbiumWest (F1) und Suburbium-Süd (F3 und F7) sowie in den Regionen 3 (F2) und 4 der Zivilstadt (F4-7). 5,6 ha konnten mit Georadar und 7,1 ha mit Magnetik untersucht werden. ${ }^{3}$

Die geophysikalischen Messungen des ÖAI 2011 in Carnuntum erfolgten auf der Messfläche F1 im Suburbium-West entlang der Limesstraße.

\section{INTERPRETATION DER GEOPHYSIKALISCHEN BEFUNDE IN AQUINCUM}

\author{
Die Befunde im Suburbium-West der Zivilstadt von Aquincum (Messfläche F1) \\ in Gegenüberstellung mit Befunden der Region 2
}

Die Messfläche F1 befindet sich in einer Entfernung von 115-410 m westlich der Stadtmauer auf und vor allem südlich der aus der Stadt führenden ostwestlichen Hauptstraße, also des decumanus maximus (Straße D). 3,8 ha wurden mit Magnetik und 2 ha mit Georadar untersucht (Abb. 5). ${ }^{4}$

Die Messungen mit Magnetik und Georadar bezeugen die ca. $9 \mathrm{~m}$ breite Trasse der Straße D, die von der Stadtmauer bis mindestens $410 \mathrm{~m}$ nach Westen dokumentiert wurde. Anhand älterer Grabungen ist in diesem Gebiet eine Verbauung auf Streifenparzellen nördlich der Straße belegt (,Streifenhäuser“). Anhand der geophysikalischen Messdaten ist nun auch eine strukturell vergleichbare Bebauung im Süden aufzuzeigen. Der Abstand zwischen den Gebäuden nördlich und südlich der Straße D beträgt ca. 18,7 m, die Breite des Straßenkörpers dürfte zwischen 9-14 m variieren. Die straßenseitigen Fluchten der Gebäude verlaufen nicht linear, sondern springen nach $60 \mathrm{~m}$ von der Westgrenze der Messfläche um ca. $6 \mathrm{~m}$ nach Süden. Daraus kann vielleicht auf eine chronologische Abfolge einzelner Gebäudegruppen geschlossen werden.

Nördlich der Straße D sind Reste von mindestens vier Gebäuden flächig ergraben. Punktuelle archäologische Grabungen indizieren eine durchgehende Verbauung, wie dies nun auch durch die geophysikalischen Messungen für das Gebiet südlich der Straße D zu erkennen ist. Hier können zehn Gebäude flächig erkannt werden. Eine Fortführung der Bebauung gegen Osten zu zeigen ältere Grabungen außerhalb der Messfläche (Tabelle 1).

Es ist möglich, zwei vorherrschende Hausgrößen zu unterscheiden, und zwar annähernd quadratische Grundrisse von ca. $13 \times 16 \mathrm{~m}$ Seitenlänge bzw. ca. $200 \mathrm{~m}^{2}$ Baufläche (Häuser 2, 8 und 9) und längsrechteckige Gebäude von ca. $13 \times 23$ m Seitenlänge bzw. ca. $300 \mathrm{~m}^{2}$ Baufläche (Häuser 5-7, 13-14). Die typologische Einordnung der Grundrisse erfolgt nach der von P. Zsidi 2008 vorgenommenen Gliederung. ${ }^{5}$ Sie unterscheidet Korridorhäuser mit und ohne Zentralraum von Häusern mit Reihen-Grundriss. Soweit die Interpretation der geophysikalischen Messdaten es erlaubt, können die Gebäude des Suburbium-West durchwegs als Korridorhäuser mit und ohne Zentralraum auf Streifenparzellen angesprochen werden. Häuser mit Reihen-Grundriss zeichnen sich durch eine zweireihige Anordnung der Räume ab, die aus den Messdaten, vielleicht mit Ausnahme des Hauses 7, nicht erkennbar ist. Als ein Korridorhaus mit Zentralraum bzw. „Atrium“-Haus mit Korridor ist eventuell das Haus 2 anzusprechen. Anhand der Grundrisse der Häuser 4-10 lässt sich sehr gut die Kombination längsrechteckiger schmälerer Korridore mit quadratischen bis rechteckigen Räumen erkennen.

Die Korridorhäuser werden auf streifenförmigen Parzellen errichtet, wobei keine scharfen Abgrenzungen der einzelnen Parzellen, etwa durch Gräbchen bzw. Zäune oder Grenzmauern, erkennbar sind. Sie könnten durchwegs

${ }^{3}$ Die geophysikalischen Messungen mit Magnetik und Georadar in Aquincum wurden in einer Kampagne vom 5.-15. 9. 2011 unter der örtlichen Leitung von V. Lindinger durchgeführt (A. Langendorf, D. Hagmann, Th. Winklehner, J. Monzon). Die magnetischen Messungen erfolgten mit einem dualen Fluxgate-Gradiometersystem Geoscan FM 256 mit einer Auflösung von 0,1 nT. Das Sampleintervall betrug 0,125 $\mathrm{m}$ und der Traversabstand 0,5 m. Ausgelöst wurde über einen Zeitimpuls bei einer Geschwindigkeit von $0,7-0,8 \mathrm{~m} / \mathrm{s}$. Die Bearbeitung der Rohdaten und Visualisierung der Messergebnisse erfolgte durch V. Lindinger mit der Software Geoplot 3.00 t (Geoscan
Research). Die Georadarmessungen wurden mit dem Georadar GSSI SIR 3000 mit einer $400 \mathrm{MHz}$-Antenne bei einem Traversabstand von 0,5 m und einem Sampleintervall 0,05 durchgeführt (Horchzeit $50 \mathrm{~ns}$. Bandpass-Filter 100-800 MHz. Dielektrizitätskonstante 5. Samp/sca 512. Scans/sec 120). Die Daten wurden mit der Software RADAN 6.5.3.0 bearbeitet.

${ }^{4}$ Die Messgenauigkeit der geophysikalischen Daten liegt höchstens im Dezimeterbereich. Maßangaben werden deshalb immer als Annäherungswerte (circa) verstanden.

${ }^{5}$ ZSIDI 2008. 
Tabelle 1. Gebäude im Suburbium-West der Zivilstadt von Aquincum. Grabungen 1975 (K. Póczy) und 2012 (G. Lassányi) sowie geophysikalische Messungen 2011 (ÖAI) Abb. 5-6, Suburbium-West)

\begin{tabular}{|c|c|c|c|c|}
\hline Haus & Maße (m) & Fläche $\left(\mathbf{m}^{2}\right)$ & Typ & Befund \\
\hline \multicolumn{5}{|l|}{ Süd } \\
\hline 1 & $9 \times 13$ & 117 & $?$ & Geophysik 2011 \\
\hline 2 & $18 \times 22$ & 396 & $\begin{array}{l}\text { Korridorhaus/ } \\
\text { Zentralraum }\end{array}$ & Geophysik 2011 \\
\hline 3 & $17,5 \times 27$ & 472,5 & $?$ & Geophysik 2011 \\
\hline 4 & $14 \times 33$ & 462 & Korridorhaus? & Geophysik 2011 \\
\hline 5 & $14,6 \times 33$ & 481,8 & Korridorhaus & Geophysik 2011/Grabung 2012 \\
\hline 6 & $13,3 \times 22$ & 292,6 & Korridorhaus & Geophysik 2011/Grabung 2012 \\
\hline 7 & $10 \times 23$ & 230 & Reihenhaus & Geophysik 2011 \\
\hline 8 & $13 \times 16,5$ & 214,5 & Korridorhaus & Geophysik 2011 \\
\hline 9 & $12,6 \times 16 / 18 \times 28,5$ & $201,6 / 513$ & Korridorhaus & Geophysik 2011 \\
\hline 10 & $20 \times 16,7$ & 334 & Korridorhaus & Geophysik 2011 \\
\hline \multicolumn{5}{|l|}{ Nord } \\
\hline 11 & - & & $?$ & Grabung 1975 \\
\hline 12 & $20 \times>30$ & & Korridorhaus & Grabung 1975 \\
\hline 13 & $11,5 \times>30$ & & Korridorhaus & Grabung 1975 \\
\hline 14 & $10,2 \times 27$ & & Korridorhaus & Grabung 1975 \\
\hline
\end{tabular}

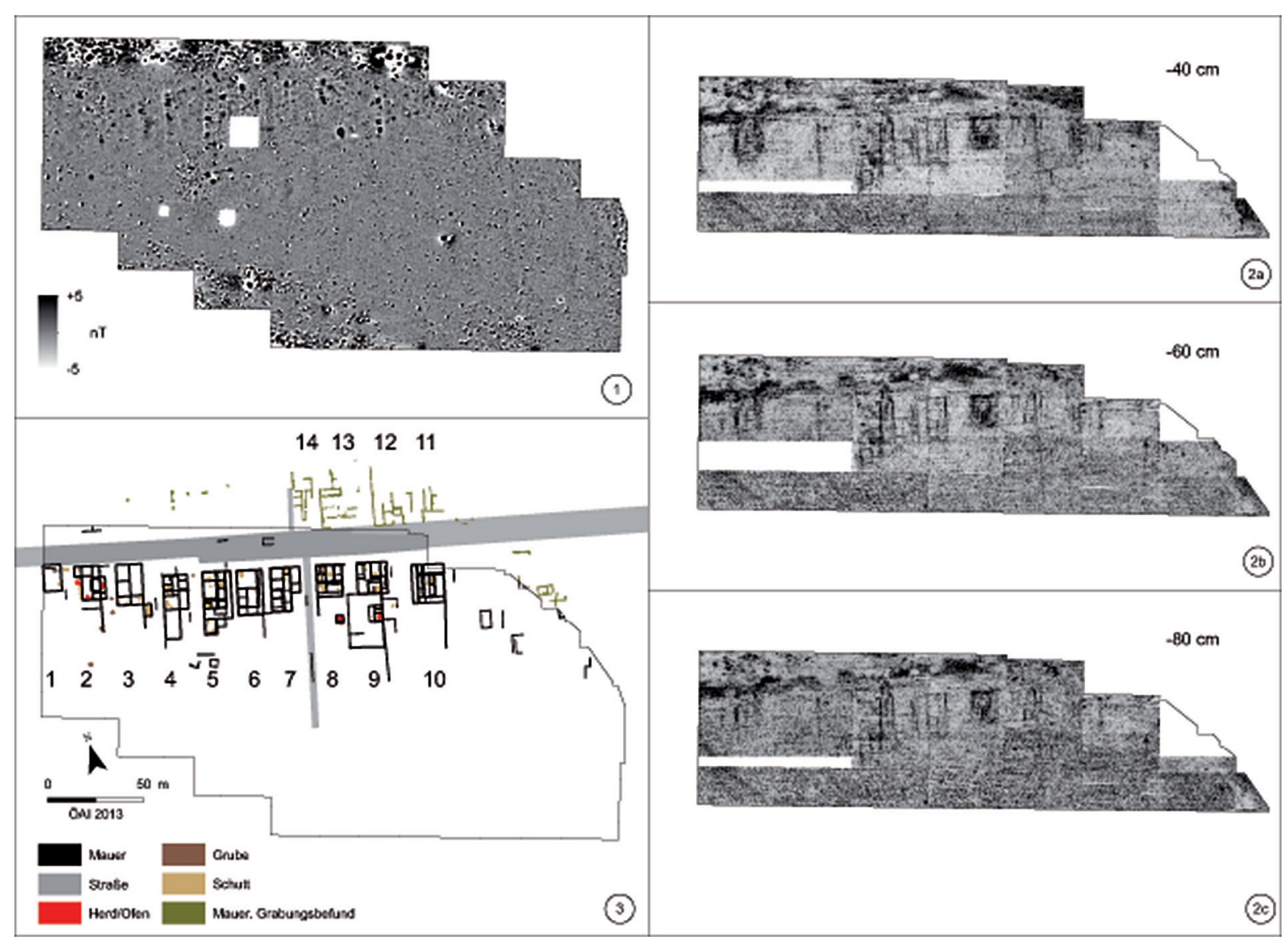

Abb. 5. Zivilstadt von Aquincum. Geophysikalische Messungen 2011 im Suburbium-West (Messfläche F1).

1: Magnetik-Daten; 2: Radar-Daten; 3: Interpretation der geophysikalischen Messdaten (ÖAI, unter Verwendung von Daten des BHM) 

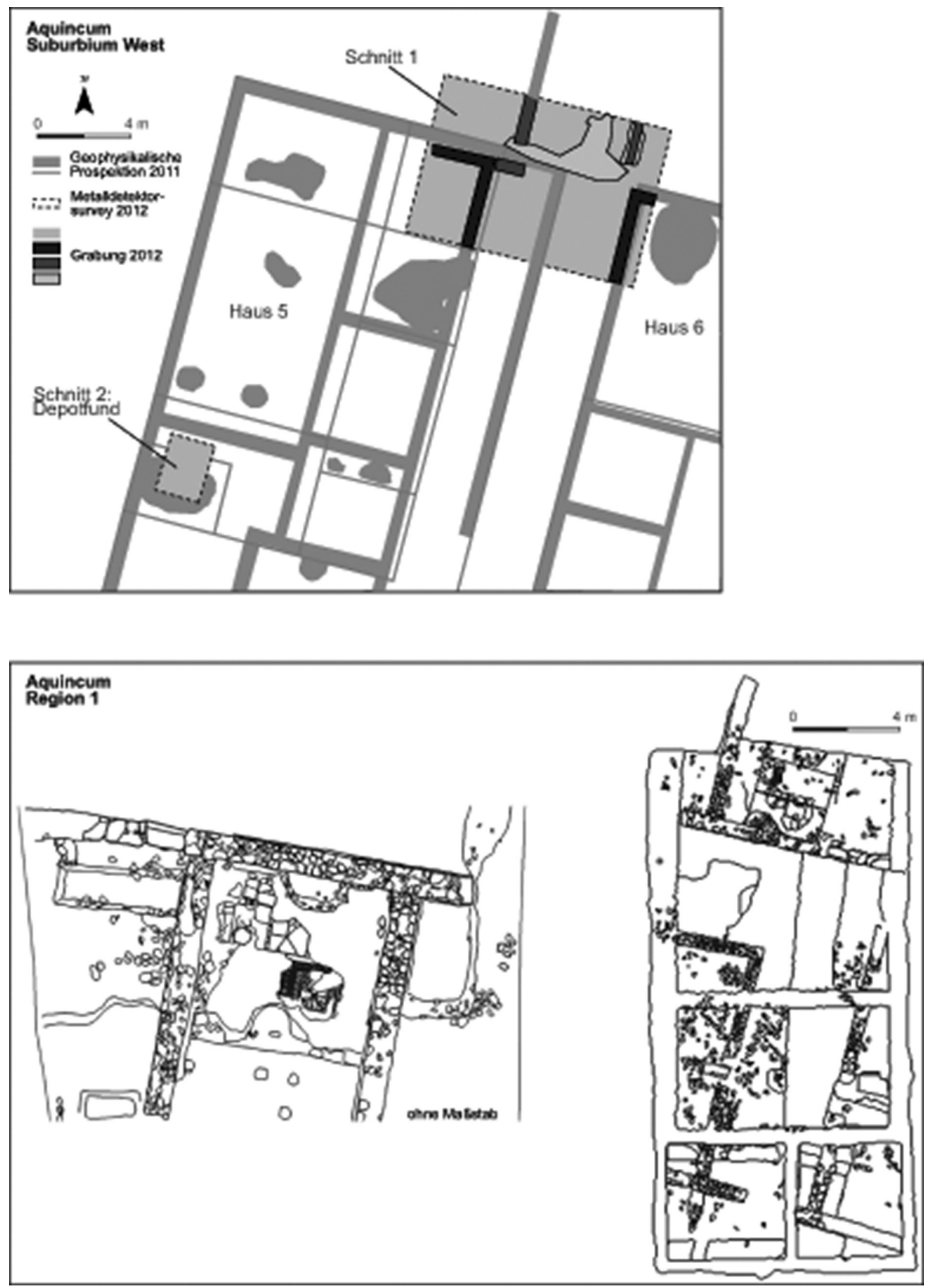

Abb. 6. Zivilstadt von Aquincum. Suburbium-West (Messfläche F1). Geophysikalische Messungen 2011 (ÖAI) und archäologische Grabung 2012 in Haus 5 und 6 (BHM). - Region 1, Gebäude mit aufwändiger Ausstattung: Archäologische Grabung 2008 (BHM, ÖAI, nach Vorlagen in: LASSÁNYI 2013, Abb. 1b; LÁNG 2009b, Abb. 8) 
durch schmale Wege getrennt gewesen sein, wie sie zwischen den Häusern 7-8 und 14 durch die geophysikalischen Messdaten belegt sind. Die durchschnittliche Parzellengröße dürfte ca. $18 \times 50 \mathrm{~m}$ bzw. $900 \mathrm{~m}^{2}$ betragen haben.

Damit sind die extraurbanen Streifenparzellen gleich breit und breiter sowie um 10-20 m kürzer als die intraurbanen (insbesondere nördlich der Straße D in der Region 2 - Haus XXVI - und östlich der Straße C in der Region 4 - z. B. Haus XII).

Im Vergleich mit dem Parzellierungsschema im Nordosten der Zivilstadt Aquincum (Abb. 13) ergeben sich annähernd übereinstimmende Verteilungsmuster der Breitenmaße, wobei sich grob drei Gruppen differenzieren lassen: die kleinste mit 9,0/10,0-11,5/11,9 m, eine mittlere mit 12,6/12,9-13,8/14,6 m und die größte mit 16,7/17,520,0/20,6 m.

In der nordöstlichen Zone der Zivilstadt Aquincum, also in der intraurbanen Region 2, sind im Falle von Streifenhäusern schmale Parzellierungen in ihrer möglichen Ausdehnung an der Wende vom 2. zum 3. Jahrhundert n. Chr. zu beobachten. Rekonstruierte Blöcke messen rund 1 actus $(=\text { circa 35,484 m })^{6}$ in der West-Ost-Erstreckung, während die lichte Weite der Gebäude, d. h. auch der Grundstücke (?), jeweils den Bruchwert 1 actus repräsentieren. ${ }^{7}$

Haus I (sog. basilica) Westflügel: 0,34 actus $(11,9 \mathrm{~m})$.

Haus I (sog. basilica) Mittelteil: 0,28 actus (10,0 m).

Haus I (sog. basilica) Ostflügel: 0,36 actus (12,9 m).

Haus XXVI: 0,57 actus $(\approx 20 \mathrm{~m}$, unsicher $)$.

Haus XXVII: 0,39 actus (13,8 m).

Haus XXVIII: 0,47 actus (16,7 m).

Haus XXIX: 0,37 actus (13 m).

Haus XXX (3. Thermen): 0,58 actus (20,6 m).

Die lichte Weite der Gebäude in der Region 2 betrug durchschnittlich 0,2-0,5 actus ${ }^{8}$ und es ist in dieser Zone von einheitlichen Grundstücksmaßen auszugehen. ${ }^{9}$ Diese Tatsache stimmt gut mit vergleichbaren Parzelleneinteilungen samt Längen- und Breitenmaßen der Bauten in anderen Limesregionen der Westprovinzen überein, so beispielsweise in Vindobona-Wien, Lopodunum-Ladenburg, Bad Wimpfen und dem Munizipium Arae Flaviae-Rottweil. ${ }^{10}$

Die festgestellte Breite der Gebäude in der Zivilsiedlung von Aquincum unterstützt auch die Theorie, dass der östliche Flügel von Haus I (s. o.) einen eigenständigen Baukörper darstellt, zumal davon auszugehen ist, dass hier kein Streifenhaus existierte, das sich über die Breite dreier Flügel (d. h. 1 actus) erstreckt hätte. Die Gesamtlänge der Gebäude in der Region 2 ist in ihrer Nord-Süd-Ausdehnung ungewiss, dürfte aber mindestens 2 actus $(70 \mathrm{~m})$ betragen. Dieses Längenmaß kann vorausgesetzt werden, wenn die nördliche Begrenzung der Parzellen eine römische, West-Ost orientierte Straße definiert, mit wahrscheinlichem Verlauf unter der modernen Keled-Straße.

Im Suburbium-West sind die intensive straßennahe Verbauung und die Präsenz von Hofarealen bzw. Freiflächen in den rückseitig gelegenen Zonen sehr auffällig. Dies unterscheidet die suburbanen von den intraurbanen Korridorhäusern, die Siedlung im Suburbium-West ist daher als Straßenvicus mit Streifenparzellierung anzusprechen.

\footnotetext{
${ }^{6}$ DilKe 1991, 52.

${ }^{7}$ Die Maße wurden den Plangrundlagen entnommen, so dass eine Abweichung von rund $0,1 \mathrm{~m}$ aufgrund ungenügender Grabungsdaten als möglich vorausgesetzt werden kann.

${ }^{8}$ In Zusammenhang mit den oben ausgeführten Überlegungen ist festzustellen, dass bislang die detailreichsten Berechnungen zur Struktur der östlichen Zivilstadt von Aquincum durch E. Márity erfolgt sind (MÁriTY 1992, 67 mit Abb. 2); sie verwendete für die Ansprache der Insulae eine Kombination aus Buchstaben und Zahlen, die auch hier Anwendung findet. E. Márity wies auf die Existenz einer Teilung der Stadtareale hin, so trennt der Aquädukt das Siedlungsgebiet in zwei unterschiedlich große Abschnitte von 1:3 und 2:3; die Insula mit Großem Bad und Macellum (Insula J3) weist ein Verhältnis von 2:3 bei Breite zu Länge auf und diese Proportion ist für die meisten in ihrer Größe gut erfassten Insulae festzustellen. Die Maßeinheit einer Insula betrug laut E. Márity $35 \mathrm{~m}$ in der Breite, während die Länge ein Vielfaches von $35 \mathrm{~m}$ betragen konnte (Maßangaben erfolgten bei E. Márity nur in Meter). Demnach war die Maßeinheit 1 actus.
}

Dieses System ist auch auf das nordöstliche Stadtviertel (Region 2) zu übertragen (Abb. 13). Auf Basis der Berechnungen von E. Márity sind hier demnach folgende Insulae von West nach Ost zu erfassen (MÁrity 1992, Abb. 2): A2: 3 Flügel von Haus I (sog. basilica), wenn es sich um einen Baukörper handelt. - B2: Häuser XXVI-XXVII, getrennt durch schmale Gasse. - C2: Häuser XXVIII-XXIX, getrennt durch schmale Gasse. - D2: Häuser XXX-XXXI (3. Thermen), getrennt durch eine Straße. - E2-I2: sehr unsicher, da nur teilweise ausgegrabener Ostteil des archäologischen Parks.

${ }^{9}$ Die Größe der städtischen Parzellen ist nicht einheitlich, so betragen die Ausmaße in Vindobona zwischen 32 und 38 röm. Fuß: Mosser et al. 2011, 209-210, mit Vergleichsbeispielen.

${ }^{10}$ KortüM 2005, 253; MosSer et al. 2011, 207-208. Streifenhäuser in Bad Wimpfen weisen durchschnittlich eine Breite von 6-12 m und eine Länge von 60-70 m auf: FILGIS 2001, 20. In der Germania Superior (Vicus von Zugmantel) messen Streifenhäuser 5,5-11 m in der Breite und 40,6 m in der Länge: SOMmer 1988, 506. 
Über die jeweilige Funktion einzelner Häuser und die Lebensgrundlagen der Vicani geben stark positive thermoremanent magnetisierte Anomalien in den Räumen und Hinterhöfen der Häuser 2 und 8-9 nähere Auskunft. Jene in den Häusern 2 und 9 dürfen wohl als Feuerstellen (Herde, Backöfen?), die frei stehende, ummauerte im Hinterhof des Gebäudes 8 gelegene Struktur eher als Brennofen interpretiert werden. Letztere wäre im Kontext mit handwerklichen Tätigkeiten zu sehen.

Jüngst wurden mittels systematischer Metalldetektorprospektionen in Kombination mit einer kleinflächigen Grabung die Ostbegrenzung von Haus 5 und die Westbegrenzung von Haus 6 festgestellt, ebenso wie der Verlauf der Straße D (Abb. 5-6, Suburbium-West). Hierbei traf man auf deponierte Eisengeräte ${ }^{11}$ und einen speziellen Typ einer Bronzelampe im Gebäude 5. Der Ausgräber, G. Lassányi, datiert die Aufgabe des Hauses nach der Mitte des 3. Jahrhunderts n. Chr. auf Basis der datierenden Funde. ${ }^{12}$ Die Funktion der Häuser konnte aufgrund des kleinen Grabungsausschnittes zwar nicht definiert werden, allerdings dokumentiert die Deponierung vier landwirtschaftlicher Geräte unterschiedlichen Typs ohne Schäftung im hinteren Gebäudeteil deren Wertschätzung als Gebrauchsgegenstand oder Ware. ${ }^{13}$

Die unter der Leitung von K. Póczy im Suburbium-West nördlich der Straße D durchgeführten Grabungen hatten die Kenntnis von fünf Gebäuden des 3. Jahrhunderts n. Chr. zur Folge, denen sich zu Wirtschaftszwecken dienende Gebäudeteile, also Werkstätten, Läden und Lagerräume anschlossen. ${ }^{14}$ Auf einer Längserstreckung von rund 200 m wurden Räume von Streifenhäusern untersucht, die an die Hauptstraße grenzten. Auf Läden oder Arbeitsräume deuten die Funde von Öfen, Handmühlen und Vorratsgefäßen. Nach K. Póczy könnte auch ein Heiligtum Teil eines Gebäudes gewesen sein, in dessen näheren Umkreis ein Kammergrab und zwei Brandbestattungen angetroffen wurden. Ein Haus könnte aufgrund des Grundrisses als Gaststätte, deversorium, angesprochen werden. ${ }^{15}$

Das ab der Wende vom 1. zum 2. Jahrhundert n. Chr. genutzte Gebiet war Teil einer frühen, entlang der Straße D situierten Straßensiedlung mit Holzbauten und Grubenhütten (s. u., Vicusperiode; Abb. 13), aus der sich in der Folge eine komplexe mehrphasige streifenförmige Verbauung innerhalb und ein Streifenvicus außerhalb der Stadtmauer entwickelten. ${ }^{16}$

Die Ausdehnung des Vicus nach Westen ist durch eine im Jahr 1929 von L. Nagy untersuchte, in ca. $550 \mathrm{~m}$ Entfernung von der westlichen Stadtmauer an der Straße D gelegene Töpferwerkstatt gegeben. Die hier angetroffenen beiden Keramikbrennöfen datieren in traianisch-hadrianische Zeit und indizieren somit die handwerkliche Infrastruktur des frühen Straßendorfes. ${ }^{17}$ Der gesamte frühe Vicus entlang der Straße D dürfte, unter Einbeziehung der Befunde aus der Region 2 (s. u., Vicusperiode), ${ }^{18}$ eine Länge von mindestens $1000 \mathrm{~m}$ besessen haben (Abb. 13).

\section{Die Befunde in der Region 3 der Zivilstadt von Aquincum (Messfläche F2) in Gegenüberstellung mit einem Befund der Region 1}

\section{Befunde der Region 3 (Messfläche F2)}

Die Messfläche F2 befindet sich im Südwesten der Zivilstadt (Region 3); sie wird im Westen und Süden von der Stadtmauer, im Norden von der Straße D und im Osten von der Straße C begrenzt. 2,4 ha wurden mit Magnetik und 2,5 ha mit Georadar untersucht (Abb. 7). ${ }^{19}$

Die Messungen gewähren erstmals einen größeren Einblick in das Straßensystem und die Verbauung der südwestlichen Zivilstadt von Aquincum. Der Stadtteil (Region 3) wird durch eine in nordsüdlicher Richtung verlaufende, ca. 3,5-4 m breite Straße halbiert. ${ }^{20}$ Die beiden Hälften erschloss man durch einen sich in seiner Ausrich-

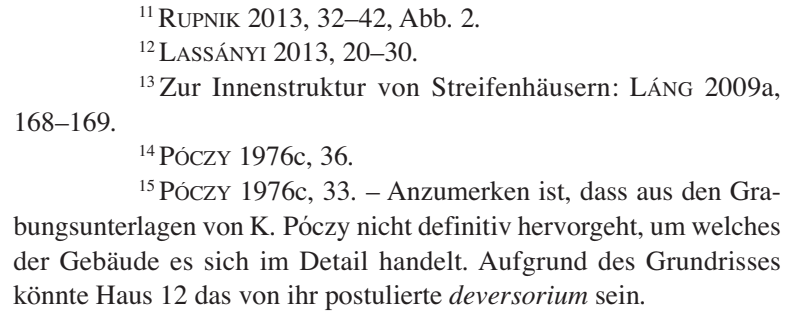

${ }^{15}$ Póczy 1976c, 33. - Anzumerken ist, dass aus den Grabungsunterlagen von K. Póczy nicht definitiv hervorgeht, um welches der Gebäude es sich im Detail handelt. Aufgrund des Grundrisses könnte Haus 12 das von ihr postulierte deversorium sein.

${ }^{16}$ Zsidi 2003b, 143, Abb. 7; Zsidi 2003d, 157, Abb. 1; LÁNG 2009a, 280; LÁNG 2012b; LÁNG 2013c, 235-239, 242-246.

${ }^{17}$ PócZy 1956, 95-102; Zsidi 2005b, 106, Abb. 4 (Kartierung); VÁmos 2010, 67-68, Abb. 1.2.

${ }^{18}$ LÁNG 2009a, 280

${ }^{19}$ Die Messgenauigkeit der geophysikalischen Daten liegt höchstens im Dezimeterbereich. Maßangaben werden deshalb immer als Annäherungswerte (circa) verstanden.

${ }^{20}$ Die Entfernung von dieser Straße zur Straße C beträgt ca. $153 \mathrm{~m}$ und zur Stadtmauer im Westen ca. $159 \mathrm{~m}$. 


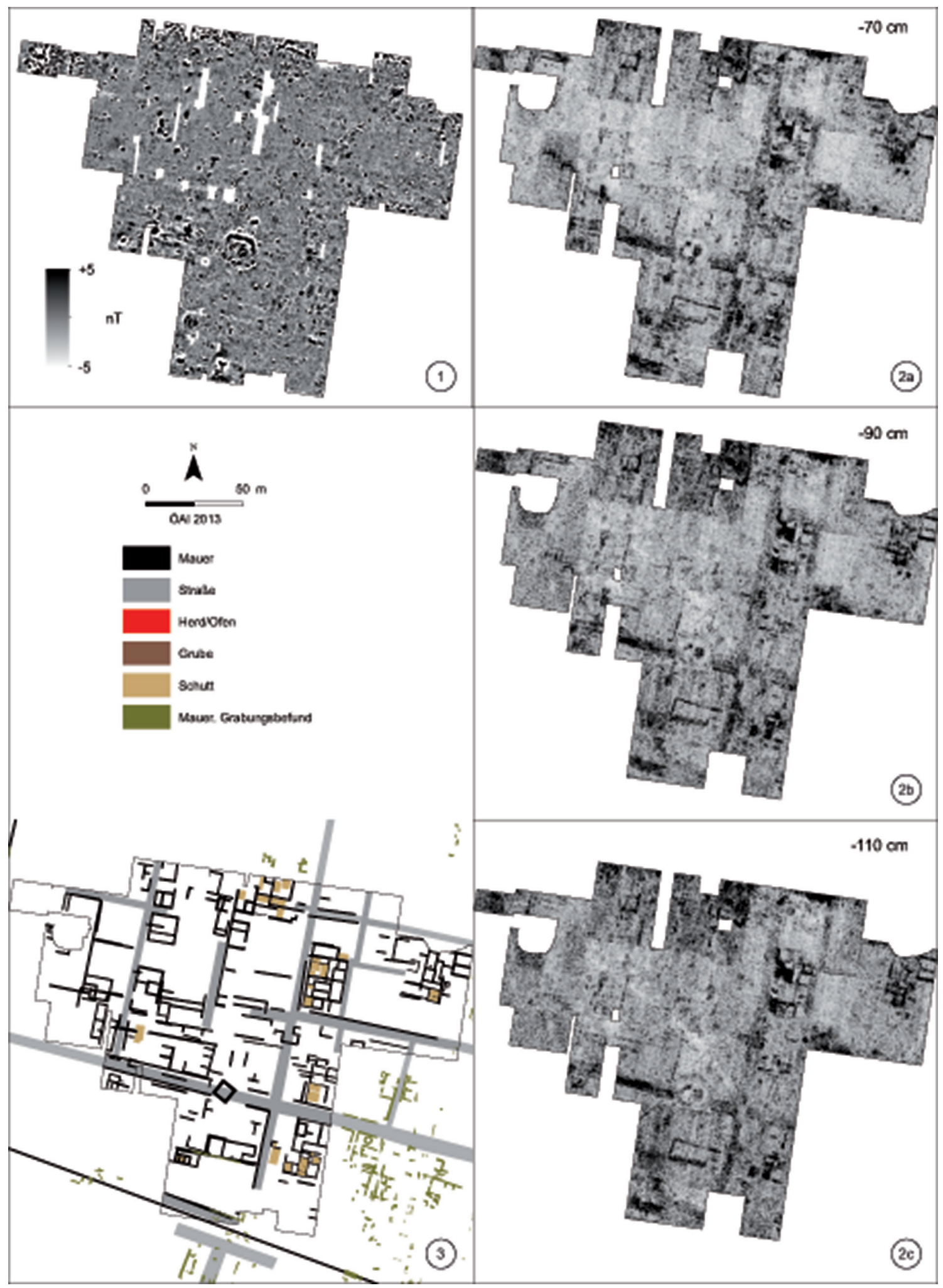

Abb. 7. Zivilstadt von Aquincum. Geophysikalische Messungen in der Region 3 (Messfläche F2).

1: Magnetik-Daten; 2: Radar-Daten; 3: Interpretation der geophysikalischen Messdaten (ÖAI, unter Verwendung von Daten des BHM) 
tung am Verlauf der Straße D orientierenden, annähernd orthogonalen Straßenraster, wobei kein Insulasystem zu erkennen ist. Im Ostteil der Region 3 betragen die Abstände der parallel zum decumanus maximus (D) geführten Straßen 70 - 50 - 44 m, jener der parallel zum cardo maximus (C) geführten Straßen im Westteil der Region 3 ca. $38 \mathrm{~m}$. Eine ca. 4,5 m breite Via sagularis ist im Süden entlang der Stadtmauer erkennbar. Niederrangige Gassen oder Straßen sind in der Region 3 ca. 3 m breit, höherrangige Straßen ca. 4,5 m. Dieser Wert divergiert leicht vom sonstigen Bild in Aquincum mit bis zu 6 m Breite im höherrangigen Bereich (abseits der beiden Hauptverkehrsachsen). Der cardo maximus (C) besitzt im hier dokumentierten letzten Bauzustand einen ca. $8 \mathrm{~m}$ breiten Straßenkörper und jener des decumanus maximus (D) misst ca. 11 m (s. u., zu Straßen).

Der anhand der geophysikalischen Messdaten sichtbare Baubestand erweist sich als sehr fragmentarisch, heterogen und nur schwer strukturell interpretierbar. Das gleiche Bild lieferten archäologische Grabungen im Südwestteil der Region 3. Einzelne Straßenabschnitte wechseln mit Gebäudeteilen, ohne dass zusammenhängende Insulae oder klare Parzellierungsschemata bzw. Haustypen zu erkennen wären. Im Westteil der Region 3 lassen sich einzelne mit Korridoren von den Straßen erschlossene, der Orientierung des Straßenrasters folgende Gebäudeteile unterscheiden. Größere Platzanlagen oder Freiflächen innerhalb einzelner Gebäudekomplexe sind nicht zu sehen, im Gegenteil: Einzelne kaum zu interpretierende Mauerabschnitte dürften eine flächige mehrphasige Bebauung indizieren.

Im zentralen Bereich ist der Grundriss eines ca. $20 \times 32 \mathrm{~m}$ großen Gebäudes erkennbar, das sich in eine nördliche und südliche Hälfte teilen lässt und dort jeweils einen kürzeren Zubau/Annex besitzt. Große, annähernd quadratische Räume werden von hakenförmigen Korridoren und kleineren rechteckigen/quadratischen Räumen flankiert. Die Funktion des Gebäudes lässt sich anhand des Grundrisses nicht klären, allerdings könnten die jüngst durch Metalldetektorprospektionen angetroffenen Münzen und ein Büstengewicht in Form einer Frauenfigur auf eine (partielle) wirtschaftliche Nutzung deuten. ${ }^{21}$

Allgemein ist eher von der Präsenz von Korridor-, Reihen- und Mehrraumhäusern, denn von Atrium- oder Peristylhäusern auszugehen. Die Situation erinnert sehr stark an die derzeit bekannte Verbauung des Südwestteiles bzw. der Region 3 der Zivilstadt von Carnuntum. ${ }^{22}$

Großflächige Grabungen wurden in der Region 3 von Aquincum in der südwestlichen Zone von K. Póczy und Gy. Hajnóczi 1966 und 1972 durchgeführt. ${ }^{23}$ Nördlich des Südabschnitts der Stadtmauer wurden eine West-Ost und eine Nord-Süd orientierte Straße festgestellt, an deren Kreuzung Gebäudestrukturen mit Läden angetroffen wurden. Die Ausgräber unterschieden vier Bauperioden: Die älteste Nutzung während des ausgehenden 1. Jahrhunderts n. Chr. konnte nur in einem kleinen Bereich nachgewiesen werden. Auf eine hadrianische und eine severische Bauperiode folgte die jüngste zu Beginn des 4. Jahrhunderts n. Chr.

\section{Befunde der Region 1}

Im Unterschied zu den Befunden der Region 3, die aufgrund der oben interpretierten Daten (Abb. 7) in keinem Fall Atrium- oder Peristylhäuser dokumentieren, ist ein solches Verbauungsmuster in der im Norden angrenzenden Region 1 anhand eines Grabungsbefunds zu erfassen.

In der nordöstlichen Zone der Region 1, nördlich der Straße D und auf Höhe des Forums, wurde jüngst eine wahrscheinlich um einen Innenhof gruppierte Gebäudestruktur mit mindestens zwei Nutzungsperioden untersucht (Abb. 6, Region 1). ${ }^{24}$ Während der ersten Periode wurde ein leider nur teilweise ergrabener Bau in Fachwerk errichtet, ausgestattet mit Terrazzoboden. In die zweite Periode datieren mehrere Räume mit farbigem Wandverputz, der sich teilweise auch an den Außenwänden feststellen ließ.

Ein großer, 3,5 m breiter und mindestens 8,3 m langer, Nord-Süd orientierter Raum der 2. Bauperiode war im Aufgehenden mit Fresko und Stuckatur sowie in der Sockelzone mit Marmorvertäfelung ausgestattet. Der Raum verfügte über eine Fußbodenheizung und der Eingangsbereich war mit großen Platten Carrarer Marmors dekoriert,

${ }^{21}$ Der Metalldetektorsurvey ist noch nicht abgeschlossen; erste Ergebnisse werden in einem Vorbericht publiziert: ZsIDILASSÁNYI 2014.
${ }^{22}$ Vgl. dazu eine Zusammenstellung der Hausgrundrisse der Zivilstadt von Carnuntum: CenCiC 2003, 17-18, Abb. 3.

${ }^{23}$ PÓCZY 1967, 32-33; PÓCZY-HAJNÓCZI 1968, 22-23.

${ }^{24}$ LÁNG 2009b, 18-29. 
die mit roten Marmorstreifen alternierten. Gegen Norden zu schloss an die Zone mit Marmor ein polychromer Mosaikboden an, dessen geometrische und florale Ornamente ursprünglich höchstwahrscheinlich Teil eines großen Teppichmusters waren. Das Mosaik wies mehrere Reparaturstellen und Störungen auf. Ein weiterer beheizter Raum mit gröberem Verputz schloss im Westen an.

Aufgrund des Fundmaterials kann die 2. Bauperiode in die erste Hälfte und mittleren Jahrzehnte des 3. Jahrhunderts n. Chr. datiert werden. Das Ende der Nutzung indiziert ein Kanal unbekannter Bestimmung, der die Wände des älteren Bauzustands durchschnitt.

Die Funktion des besonders reich ausgestatteten Gebäudes der 2. Bauperiode kann aufgrund der architektonischen Charakteristika und der topografischen Situation in zweierlei Hinsicht gedeutet werden: Die Fußbodenheizung, der dicke hydraulische Verputz mehrerer Wände und die Innendekoration können entweder auf ein - nahe dem Forum situiertes - Bad deuten oder auf ein privates Wohnhaus.

\section{Die Befunde in der Region 4 und im Suburbium-Süd der Zivilstadt von Aquincum (Messflächen F3-7)}

Die Messflächen F4-7 befinden sich im Südosten der Zivilstadt; sie werden großräumig im Osten und Süden von der Stadtmauer, im Norden von der Straße D und im Westen von der Straße C begrenzt. Die Fläche F3 ist östlich des südlichen Stadttores im Suburbium-Süd situiert. 0,9 ha wurden mit Magnetik und 1,1 ha mit Georadar untersucht (Abb. 8).

Die Messergebnisse auf den Flächen F4-6 verdichten bzw. ergänzen das Bild der hier bereits ergrabenen Befunde. In den Flächen F3 und F7 sind ein 18 und ein 71 m langer Abschnitt der südlichen Stadtmauer erkennbar. Die Mauerbefunde der außerhalb der Stadtmauer untersuchten Fläche F3 stimmen mit den dort bereits archäologisch verifizierten Hausgrundrissen überein. Auf der Fläche F7 sind größere hallenartige Grundrisse im Straßenraster und ein schräg zum Raster gelegenes Gebäude erkennbar. Diese Befunde scheinen im Norden nicht mit den ergrabenen Mauern übereinzustimmen. Im Südteil können die bekannten Mauern durch eine in ostwestlicher Richtung verlaufende Begrenzungsmauer ergänzt werden. Zwischen der letzten bekannten Straße und der Stadtmauer ist, in Analogie zur Region 3, keine weitere Querstraße erkennbar.

Die fünf Messungen wurden in partiell archäologisch untersuchten und kartierten Flächen (Region 4: F3-5) sowie in archäologisch größtenteils nicht untersuchten Arealen (F6-7) durchgeführt. Grabungen erfolgten während der späten 1960er und in den 1970er Jahren in mehreren Etappen und es liegen nicht in allen Fällen geodätisch exakte Pläne vor.

Die Messfläche F3 deckt einen Südabschnitt der Stadtmauer und Gebäude außerhalb der Befestigung im Suburbium-Süd ab. T. Nagy legte hier 1947-1948 Suchschnitte an, ${ }^{25}$ O. Láng untersuchte im Jahr 2010 ein kleinflächiges, aber zusammenhängendes Areal in der Nordwestecke des nördlichen Flügels im sog. deversorium (Haus XLI). ${ }^{26}$ Der aktuelle Plan des Gebäudes basiert primär auf einer Zusammenstellung von Befunden aus schmalen Suchgräben (s. u. Abb. 11). T. Nagy deutete die Strukturen als Baukomplex um einen U-förmigen Hof mit der Funktion einer Gaststätte (deversorium). Seiner Meinung nach erfolgte die Errichtung während der ersten Hälfte des 2. Jahrhunderts n. Chr., mit nachträglichen Anbauten späterer Zeitstellung. Die jüngsten Untersuchungen erbrachten demgegenüber das Ergebnis, dass die Nordwestecke und somit wohl der gesamte Nordteil an der Wende vom 2. zum 3. Jahrhundert n. Chr. entstanden und das Fundament des Gebäudes in die bereits verfüllte fossa im Vorfeld der (noch bestehenden) Stadtmauer reichte. Die Fragen, ob der nördliche und südliche Flügel Teil eines Gebäudes waren, in welcher Bauphase diese gemeinsam bestanden oder ob es sich um separate Bauten handelt, könnten nur durch Kontrollgrabungen geklärt werden.

J. Szilágyi untersuchte im Jahr 1943 ein Wohnhaus mit reich ausgestattetem Hof im Areal der Fläche F4. ${ }^{27}$ Zwar wurde der Grundriss in den Stadtplan von Aquincum integriert, eine detaillierte Beschreibung der Befunde fehlt allerdings und auch die Funde wurden nicht publiziert. Nur die Bruchstücke aufwändigen Freskodekors aus der Planierschicht des Gebäudes wurden rekonstruiert und von M. Németh gemeinsam mit Fragmenten aus einer

${ }^{25}$ NAGY 1948, 121-122.

${ }^{26}$ LÁNG 2011c, 18-25.

\footnotetext{
${ }^{27}$ SZILÁGYi 1950, 84, 89, Abb. 1.
} 


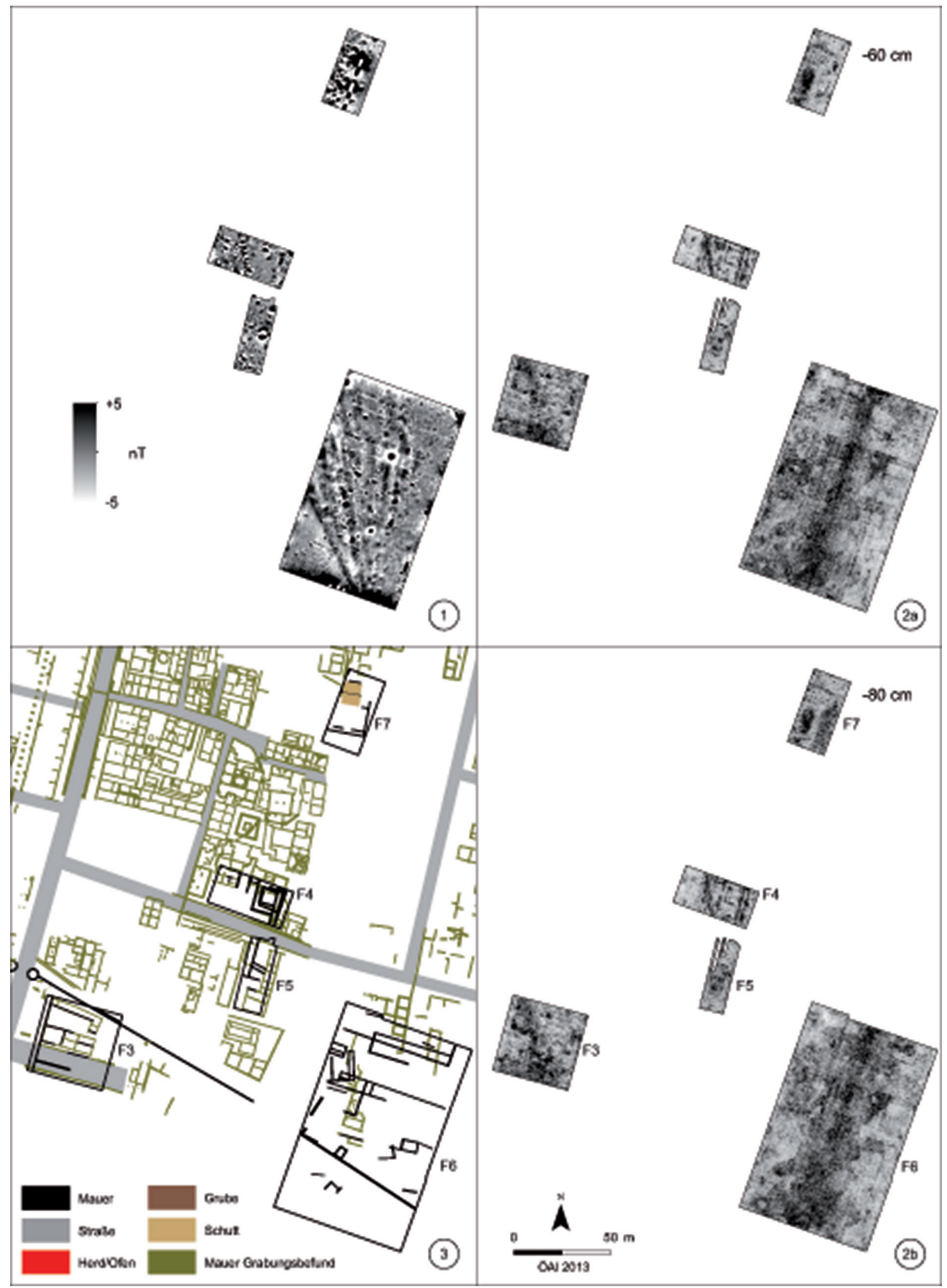

Abb. 8. Zivilstadt von Aquincum. Geophysikalische Messungen in der Region 4 und im Suburbium-Süd (Messflächen F3-7). 1: Magnetik-Daten; 2: Radar-Daten; 3: Interpretation der geophysikalischen Messdaten (ÖAI, unter Verwendung von Daten des BHM) 
kurzen Untersuchung des Jahres 1969 publiziert. ${ }^{28}$ Darstellung und Komposition der rekonstruierten Wandmalerei deuten auf die Datierung der frühen Bauphase des Hauses im zweiten Viertel des 2. Jahrhunderts n. Chr.

Nur einige Mauern wurden bei älteren Untersuchungen im Areal F5 angetroffen. ${ }^{29}$ Diese gehören zu Streifenhäusern entlang der Straße G. Große Teile der Flächen F6 und F7 sind bislang archäologisch nicht untersucht. Ein Gebäude mit Apsis wurde im Zuge der Anlage des Sportplatzes im Jahr 1928 untersucht und von L. Nagy als Bad angesprochen. ${ }^{30}$ Der Grundrissplan ist in Teilen im Westen der Messfläche F6 zu erkennen $(A b b .8 / F 6)$. Eine Befundbeschreibung existiert, mit der Feststellung, dass aufgrund des durch eine Quelle gespeisten Grundwassers die Grabungen vorzeitig beendet werden mussten.

\section{INTERPRETATION DER GEOPHYSIKALISCHEN BEFUNDE IN CARNUNTUM}

\section{Die Befunde im Suburbium-West der Zivilstadt von Carnuntum (Messfläche F1)}

Die Situation in der Zivilstadt von Aquincum lässt sich direkt mit jener in Carnuntum vergleichen, wo bereits bei früheren geophysikalischen Messungen und anhand der Interpretation von Luftbildern die Strukturen eines Vicus im Suburbium-West zu erkennen waren. ${ }^{31}$ Im Jahr 2012 wurden im Zuge des Forschungsprojektes vom Fachbereich Zentraleuropäische Archäologie (ZEA) des ÖAI geophysikalische Messungen mit Magnetik auf einer Fläche von 12,9 ha in dem der Stadtmauer im Westen vorgelagerten Areal vorgenommen (Abb. 9). ${ }^{32}$

Die Befunde ähneln jenen des Suburbium-West von Aquincum: Eine durchgehende Vicus-Bebauung auf streifenförmigen Parzellen ist nördlich und südlich der ca. 7,5 m breiten Limesstraße bis in eine Entfernung von ca. $600 \mathrm{~m}$ von der westlichen Stadtmauer der Zivilstadt zu erkennen. Danach (ca. bei Meter $680 \mathrm{ab}$ der Stadtmauer) schließt eine Nekropole mit einzelnen Grabgärten und Grabbauten an, die in den Daten bis zur westlichen Grenze des Messgebietes über eine Strecke von $250 \mathrm{~m}$ zu verfolgen ist. ${ }^{33}$

Die Vicus-Bebauung überlagert ältere Holz-Erde-Strukturen. Im Nordteil der Messflächen sind Grabenstrukturen und der Teil von zumindest einem, wenn nicht mehreren temporären Lagern zu erkennen. Ein ca. $240 \mathrm{~m}$ breites und mindestens $105 \mathrm{~m}$ langes, über 26 ha großes Lager besitzt gerundete Ecken („Spielkartenformat“) und reicht mit seiner Südostecke (in der Ergänzung) entweder bis zur Limesstraße, die genau in diesem Bereich schräg nach Nordosten biegt, oder sogar über sie hinaus. Im Lagerinneren sind großflächige (sekundäre?) Materialentnahmegruben auszumachen, wie sie im näheren Umfeld überregionaler Straßen oft anzutreffen sind. ${ }^{34}$ Die Grabenstruktur könnte als frühes temporäres Militärlager interpretiert werden und eine vortraianische (?) militärische Nutzung des Gebietes westlich der Zivilstadt indizieren. Auch für den westlichen Teil der Zivilstadt von Aquincum wird eine vormunizipale (flavische) Wehranlage postuliert. ${ }^{35}$

Die Vicus-Bebauung setzt sich aus durchschnittlich 7-9 m breiten und $30 \mathrm{~m}$ langen Gebäuden auf ca. 50-70 m langen Parzellen zusammen. Die Gebäude sind nach typologischen Kriterien als Ein-/Zweiraum-, Korridor- und Reihenhäuser anzusprechen. Südlich der Limesstraße ist die Bebauung weniger intensiv als auf der flussnahen Nordseite, zur Zivilstadt hin verdichtet sich die Bausubstanz. Es lassen sich mehrere Gruppen von Gebäuden mit leicht divergierenden Orientierungen unterscheiden, die als Indizien für funktionale Einheiten oder die chronologische Entwicklung des gesamten Vicus zu interpretieren sind. Im Westteil des Vicus sind zwei Straßen erkennbar,

\footnotetext{
${ }^{28}$ NÉMETH 1973, 115-120.

${ }^{29}$ BudRég 1950, 308, Plan der Häuser Nr. XXXVIII, XXXIX.

${ }^{30}$ NAGY 1937, 263; NAGY 1942c, 552

${ }^{31}$ HUMER 2006a, Katalogbd., 152, Abb. 214; GUGL 2013, 78-80, Abb. 42-43.

${ }^{32}$ Die geophysikalischen Messungen mit Magnetik in Carnuntum wurden in einer Kampagne vom 11.-23. 5. 2012 unter der örtlichen Leitung von V. Lindinger durchgeführt (Mitarbeiter: A. Gorbach, D. Hagmann, A. Langendorf, K. Lappé, Th. Winklehner). Die magnetischen Messungen erfolgten mit einem dualen Fluxgate-Gradiometersystem Geoscan FM 256 mit einer Auflösung von 0,1 nT. Das
}

Sampleintervall betrug $0,125 \mathrm{~m}$ und der Traversabstand $0,5 \mathrm{~m}$. Ausgelöst wurde über einen Zeitimpuls bei einer Geschwindigkeit von $0,7-0,8 \mathrm{~m} / \mathrm{s}$. Die Bearbeitung der Rohdaten und Visualisierung der Messergebnisse erfolgte durch V. Lindinger mit der Software Geoplot 3.00 t (Geoscan Research).

${ }^{33}$ Aufgrund der fehlenden Georadar-Messungen wird von einer detaillierten Interpretation der Hausgrundrisse Abstand genommen.

${ }^{34} \mathrm{Vgl}$. dazu die Situation bei den an der Bernsteinstraße errichteten temporären Lagern von Strebersdorf im Burgenland: GROH 2009, 179, Abb. 3.

${ }^{35}$ ZsIDI 2003c, 128, Abb. 1-2. 


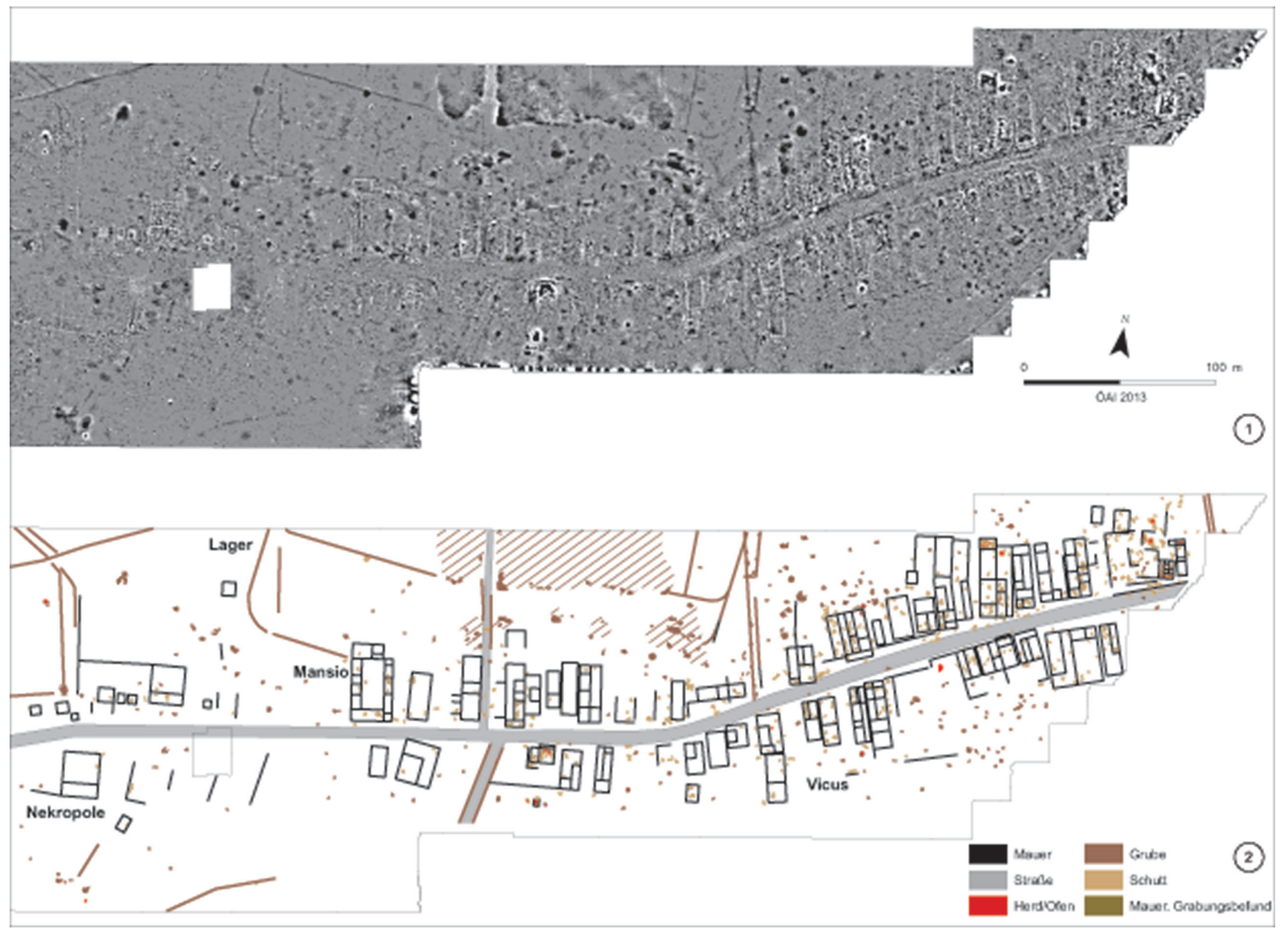

Abb. 9. Zivilstadt von Carnuntum. Geophysikalische Messungen 2012 im Suburbium-West (Messfläche F1). 1: Magnetik - Daten (Ausschnitt). 2: Interpretation der geophysikalischen Messdaten (ÖAI)

die leicht versetzt das Hinterland erschließen. Die nördliche, ca. 3,5 m breite Straße zielt auf die Materialentnahmegruben und die Donau. Der überwiegende Teil der Siedlung wird jedoch höchstens durch einfache, zwischen den Gebäuden gelegene Wege und Gassen strukturiert.

Im Süden der Messfläche F8 ist ein Teilabschnitt der aus der Flur Gstettenbreite in Richtung Zivilstadt unterirdisch geführten Wasserleitung ersichtlich.

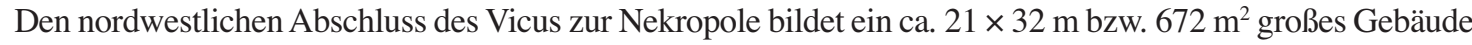
mit einem ca. 7,5 $\times 16$ m bzw. $120 \mathrm{~m}^{2}$ großen Zubau, dessen Funktion anhand des Grundrisses als Straßenstation oder Mansio erklärt werden könnte. Um einen $12 \times 26,5$ m bzw. $318 \mathrm{~m}^{2}$ großen Innenhof gruppieren sich auf beiden Längsseiten kleinere rechteckige Räume, zur Straße hin scheint sich eine Halle zu öffnen (Abb. 10-11). Diese Baustruktur findet eine Analogie im Gebäude B der in 11 röm. Meilen Distanz von Vindobona-Wien in Nordwestpannonien gelegenen Straßenstation von Biedermannsdorf; das $24 \times 31,5$ bzw. $756 \mathrm{~m}^{2}$ große, im 3. Jahrhundert n. Chr. errichtete Gebäude B zeichnet sich durch einen zentralen Innenhof und Raumreihen, die sich um diesen gruppieren, aus $(A b b .11) .^{36}$

Auch in und um Aquincum wurden Gebäude als deversoria oder mansiones angesprochen, deren exakte funktionale Bestimmung jedoch meist ungewiss ist. Eine dieser Strukturen (Haus XLI) wurde von T. Nagy in den Jahren 1946-1947 außerhalb des südlichen Stadttores festgestellt (Abb. 10.2, Abb. 11): ${ }^{37}$ Das weitläufige Gebäude (ca. $20 \times 25 \mathrm{~m}$ ) im Suburbium-Süd war am cardo maximus (Straße C) errichtet und wies mehrere, um einen Innenhof gruppierte Räume auf. Unter den Funden lagen mehrere Fragmente von Fenstergläsern vor. Ein frei liegender Back-

\footnotetext{
${ }^{36}$ GROH 2013, 174-175, Abb. 92; vgl. dazu auch die StraBenstationen von Vetoniana-Pfünz, Immurium-Moosham und Riom.
}

${ }^{37}$ NAGY 1948, 121-122. 


\section{Aquincum}

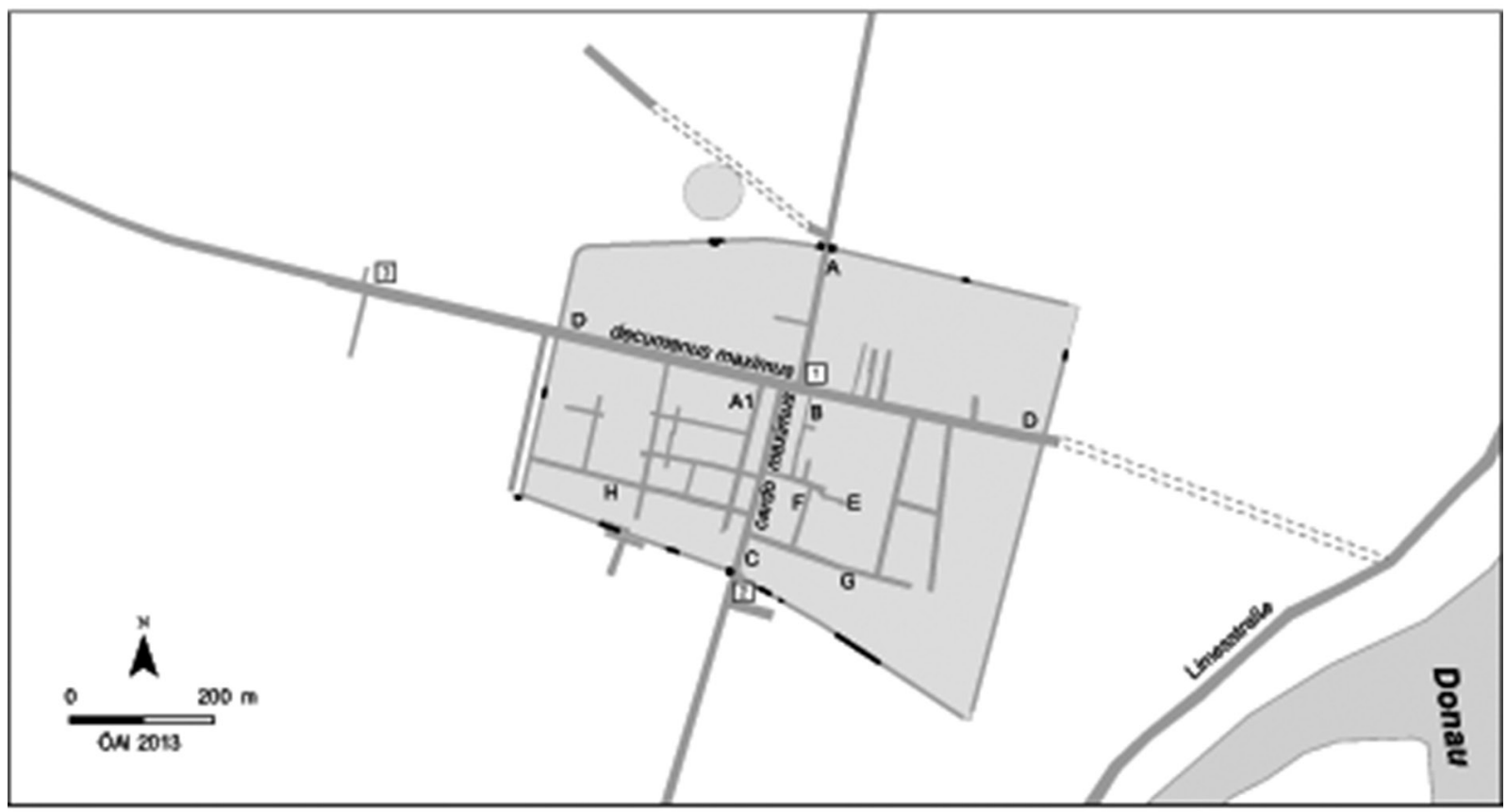

Carnuntum

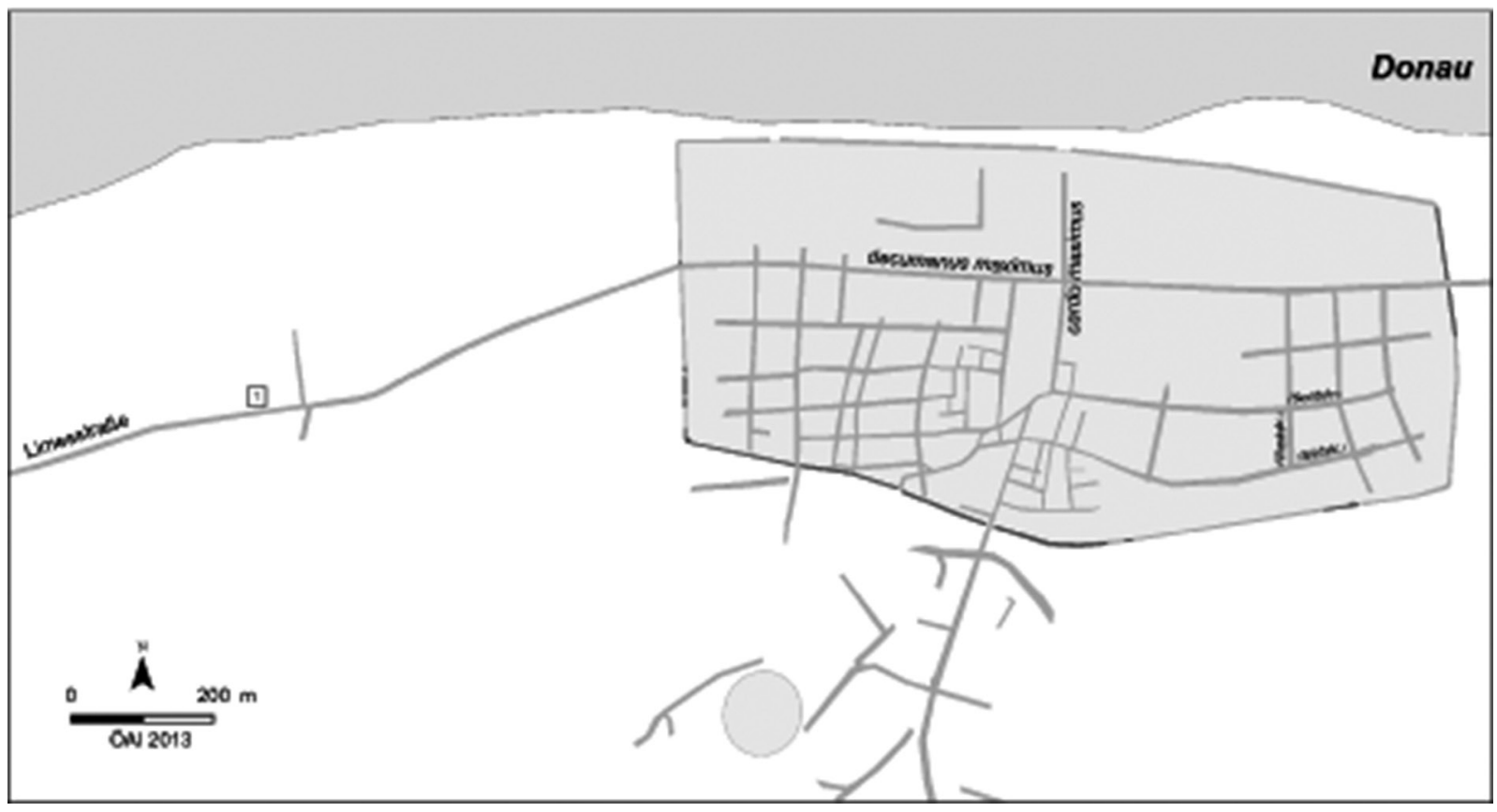

Abb. 10. Straßennetz und Stadtmauer der Zivilstädte von Aquincum und Carnuntum. Kartierung von Rast- und Gasthäusern. Aquincum. 1: Region 2, Westteil von Haus 1, Gaststätte (Mansio?); 2: Suburbium-Süd, Haus XLI, fragliches deversorium; 3: Suburbium-West, mögliches deversorium. Carnuntum. 1: Suburbium-West, Mansio (ÖAI, unter Verwendung von Daten des BHM und der ÖAW) 


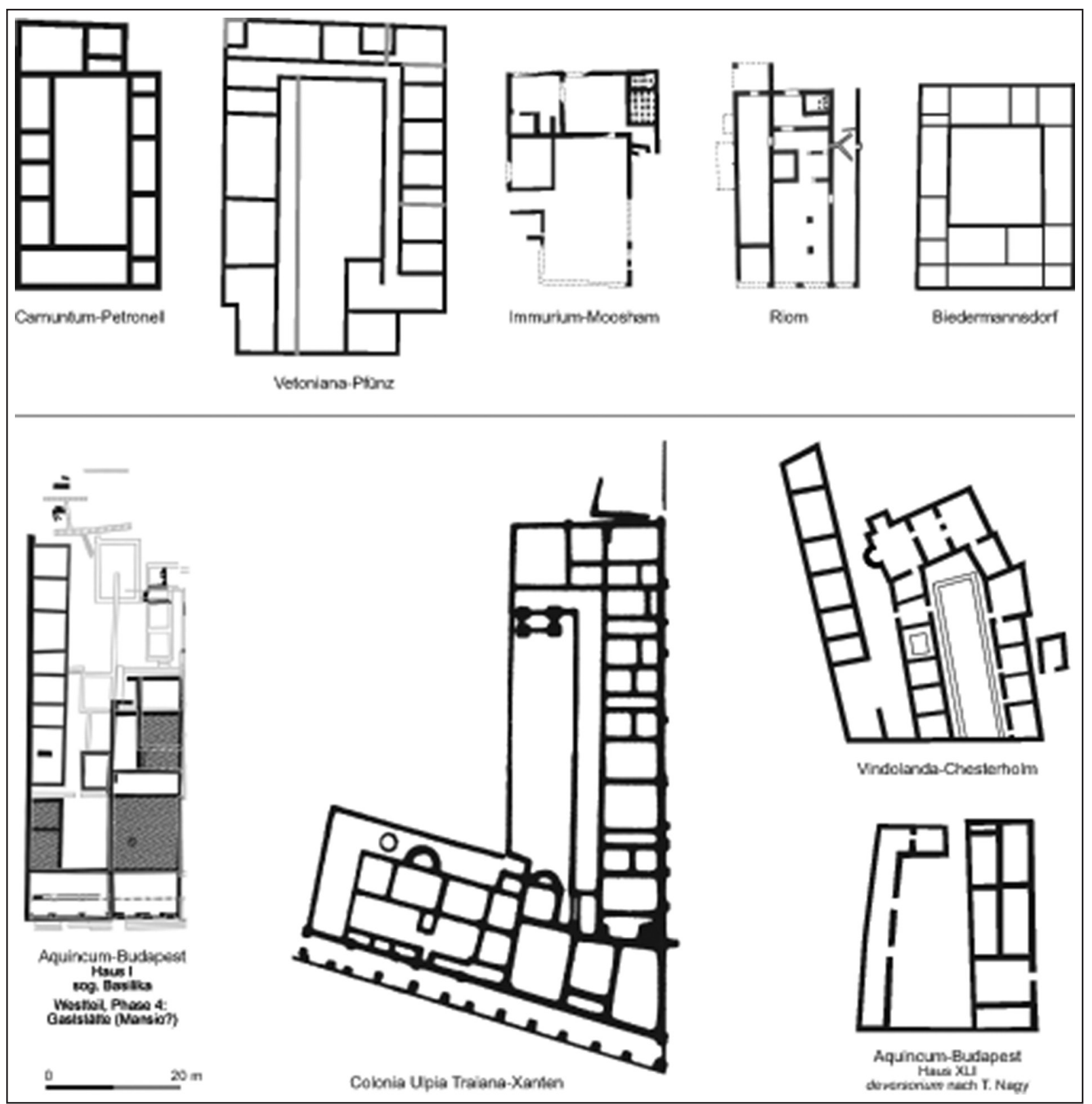

Abb. 11. Rast- und Gaststätten mit Vergleichsbefunden. Mansio im Suburbium-West von Carnuntum, Gaststätte (Mansio?) in der Region 2 von Aquincum (Westteil von Haus I), fragliches deversorium im Suburbium-Süd (Haus XLI) (BHM, ÖAI, unter Verwendung von Vorlagen in: DruRY 1982, Abb. 14.2; GROH 2013, Abb. 93; ZIELING 1995, Abb. 140)

ofen und - laut T. Nagy - Abdrücke von Klinen in einem Raum (triclinium?) wurden im straßenabgewandten Teil des Komplexes festgestellt. Zumal nur kleinflächige Grabungsschnitte in diesem Areal angelegt wurden, ist der Gesamtplan eher hypothetischer Natur. Es wäre demnach auch eine andere Interpretation der Strukturen denkbar, nämlich nicht als ein einzelnes Gebäude, sondern als mehrere Streifenhäuser (s. o., zum Suburbium-Süd von Aquincum) ${ }^{38}$

Nordöstlich der Zivilstadt von Aquincum wurde eine längliche Baustruktur, gleichfalls mit Innenhof und zudem mit aufwändiger Freskodekoration vor einigen Jahren am Donauufer ausgegraben, die wahrscheinlich nahe

\footnotetext{
${ }^{38}$ Im Detail: LÁNG 2013a.
} 
der Limesstraße situiert gewesen war. Das Gebäude wurde im 2.-3. Jahrhundert n. Chr. genutzt und später abgetragen, um Baumaterial für den nahe errichteten Wachturm des 4. Jahrhunderts n. Chr. zu erlangen. ${ }^{39}$

Eine Struktur (Haus I; Abb. 10.1, Abb. 11), am cardo maximus (Straße A) in der Region 2 gelegen, wurde lange als Basilika der Stadt interpretiert. Jüngste Untersuchungen und eine Neubewertung von Fundmaterial und Befundplänen lassen darauf schließen, dass es sich beim westlichen und mittleren Gebäudeflügel mit höherer Wahrscheinlichkeit, zumindest in der ältesten Phase, um ein mit Dekor ausgestattetes öffentliches Gebäude, möglicherweise eine Unterkunft (mansio?) handelt. Der Grundriss sowie zum Teil die topografische Situation und signifikantes Fundmaterial legen eine Deutung in diesem Sinn nahe. ${ }^{40}$

\section{EIN VERGLEICH DER BEIDEN ZIVILSTÄDTE VON AQUINCUM UND CARNUNTUM}

\section{Struktur der Städte}

Geophysikalische Messungen, Grabungen und Fundbearbeitungen der letzten Jahre erlauben es, ein neues Licht auf die Struktur und Entwicklung der beiden Zivilstädte von Aquincum und Carnuntum zu werfen. ${ }^{41}$ Die Nachweise von an den beiden Hauptstraßen bzw. decumani gelegenen Straßendörfern (Vici) lässt auf ähnliche Entstehungsmuster schließen. Beide Städte entwickeln sich an bzw. am Kreuzungspunkt wichtiger Überlandrouten in der zweiten Hälfte bzw. im letzten Drittel des 1. Jahrhunderts n. Chr. In Carnuntum sind die in ostwestlicher Richtung, parallel zur Donau verlaufende Limesstraße (= decumanus maximus) und die vom Forum nach Süden zur Bernsteinstraße einbindende Hauptachse (= cardo maximus), in Aquincum die in nordsüdlicher Richtung verlaufende Limesstraße am rechten Donauufer und der in nordwest-südöstlicher Richtung durch das Solymártal führende Verkehrsweg (= decumanus maximus $[\mathrm{D}])$ bestimmend (Abb. 10, Abb. 12). Entlang der Hauptverkehrswege dürften sich erste Straßensiedlungen mit Streifenhäusern herausgebildet haben $(A b b .13)$, die an den Kreuzungspunkten vielleicht zu ersten Siedlungsagglomerationen führten. In beiden Zivilstädten treffen die beiden Hauptachsen nicht orthogonal, sondern leicht versetzt aufeinander. In Aquincum wird der cardo maximus westlich des Macellums um ca. $25 \mathrm{~m}$ nach Westen versetzt weitergeführt und der Forumskomplex eben an diesem Kreuzungspunkt in der Region 1 angenommen.

Im Fall von Aquincum ist darauf hinzuweisen, dass der cardo maximus sich aus zwei Straßen unterschiedlicher Breite zusammensetzt. Die Breite des südlichen Abschnitts des cardo maximus (Straße C) beträgt im letzten Befundzustand 7,7 m, hatte aber ursprünglich rund 10,7 m betragen. ${ }^{42}$ Die nördliche Fortsetzung des cardo maximиs, die Straße A, welche den Forumskomplex im Osten flankierte, maß 6,0-6,5 $\mathrm{m}$ in der Breite. Es handelte sich demnach um eine niederrangigere Straße, die durch das nördliche Stadttor zum 700 m entfernten Quellgebiet des Aquädukts mit Heiligtum (Rómaifürdő) führte. Der weitere Verlauf ist ungewiss. ${ }^{43}$ Als Hauptverkehrsrouten sind demgegenüber die Straße D und die Route östlich der Stadt entlang des Donauufers zu werten (Abb. 10). ${ }^{44}$

Die den Forumskomplex im Westen säumende Straße A1 ist mit 7,3-8,1 m (soweit messbar) etwas breiter als die Straße A, allerdings wurde die Trasse mittig durch den Aquädukt in zwei Hälften geteilt. Die auf Pfeilern errichtete Wasserleitung querte die Stadt Nord-Süd orientiert, ausgehend vom Ursprung in der genannten Quellfassung und endend im Legionslager. Die beiderseits des Aquädukts geführte Straße A1 endete im Norden und Süden jeweils an der Stadtmauer. ${ }^{45}$ Die Wasserleitung war ein äußerst bestimmendes Element für die Zivilstadt von Aquincum, mit Einfluss auf die Siedlungsstruktur und Kommunikation der durch sie getrennten Stadthälften.

${ }^{39}$ LÁNG 2013b.

${ }^{40}$ LÁNG 2013a.

${ }^{41}$ Für die Erstellung des digitalen Stadtplans von Carnuntum wurden uns dankenswerter Weise durch PD Dr. Ch. Gugl, Österreichische Akademie der Wissenschaften in Wien (ÖAW), Daten zur Verfügung gestellt.

${ }^{42}$ Teile einer frühen Portikus, welche die ursprünglich weitere Straße säumte, sind an der Westseite der Straße C innerhalb des Archäologischen Parks zu sehen. Die Rekonstruktion basiert auf den hier in einer Kontrollgrabung untersuchten Tabernen: NÉMETHHAJNÓCZI 1976, 423.
${ }^{43}$ Nach der von L. NAGY in seiner Studie zur Topografie der Zivilstadt von Aquincum geäußerten These könnte diese Straße zum vicus Vindonianus im Gebiet des heutigen Békásmegyer geführt haben: NAGY 1942a, 370.

${ }^{44}$ ZsIDI 2002, 131, Abb.1.

${ }^{45}$ Ein Zusammentreffen der nördlichen Stadtmauer und des Aquädukts wird an der Kreuzung Szentendrei- und Pókstraße aufgrund von Kontrollgrabungen durch K. Póczy rekonstruiert (Vorbericht: PóCZY 1976a, 424). Jüngste Grabungen belegen Pflastersteine beim Aquädukt außerhalb der südlichen Stadtmauer (HAvas 2005, 52, 60). Diese könnten auch zum Schutz als Abstandshalter gedient haben: PócZY 1995, 470 

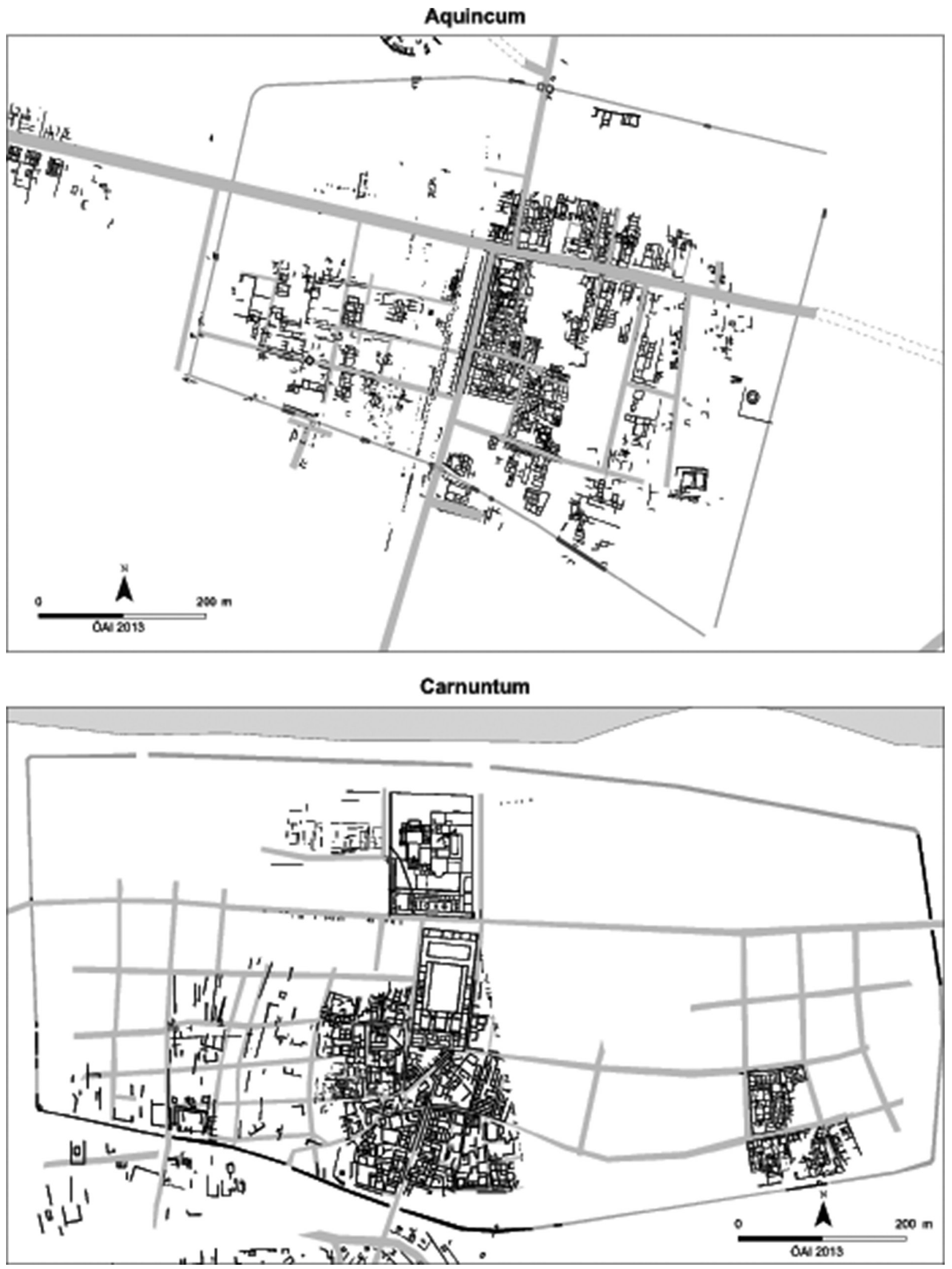

Abb. 12. Aquincum und Carnuntum. Pläne der Zivilstädte (ÖAI, unter Verwendung von Daten des BHM und der ÖAW) 
In Carnuntum zielt der cardo maximus südlich des Forums um ca. $27 \mathrm{~m}$ nach Westen versetzt schräg aus der Stadt (Abb. 10, Abb. 12). Ein älterer Straßenbefund lässt jedoch darauf schließen, dass dieser Cardo ursprünglich gerade oder leicht schräg durch die Stadt zur Donau führte und erst beim Bau des neuen Stadtzentrums mit Forum, Basilika und Tempel in der mittleren Kaiserzeit nach Osten verlegt worden ist (s. u.).

Das durch geophysikalische Prospektionen erfasste Forum und die nördlich daran anschließende Basilika der Zivilstadt Carnuntum waren in eine Insula von 64,5-65 m Breite und $142 \mathrm{~m}$ Länge eingepasst (Abb. 12). Der Forumsplatz selbst maß 34,5 $\times 57 \mathrm{~m}$ und war demnach deutlich weitläufiger als jener in Aquincum (s. u.). ${ }^{46}$ Die Forumsinsula war rund doppelt so groß wie die Insulae der Region 4 der Zivilstadt Carnuntum. ${ }^{47}$

Die Entstehung des Forums möchte M. Kandler mit der Erhebung Carnuntums zum Munizipium unter Hadrianus in Verbindung bringen. ${ }^{48}$ Es ist allerdings festzustellen, dass konkrete Informationen zur Errichtung eines öffentlichen Gebäudes für die mittleren Jahrzehnte des 2. Jahrhunderts n. Chr. ausschließlich für die Thermen im Osten der Zivilstadt vorliegen. ${ }^{49}$ Ihre Größe von $1800 \mathrm{~m}^{2}$ entspricht exakt einem Fünftel der Fläche der ForumsBasilika-Insula. Möglicherweise resultieren diese metrischen Abhängigkeiten aus einem zeitgleich in den mittleren Jahrzehnten des 2. Jahrhunderts $\mathrm{n}$. Chr. entwickelten urbanistischen Baukonzept.

Bemerkenswert ist, dass der zweite monumentale städtebauliche Komplex, der innerhalb einer mit Umfassungsmauer umgebenen Insula von $14283 \mathrm{~m}^{2}$ in frühseverischer Zeit ein Macellum, eine Schola, eine Palästra und die Großen Thermen vereinte, nicht in einem mit dem Forum übereinstimmenden Insularaster errichtet wurde ${ }^{50}$ Die Fläche von etwas weniger als 1,5 ha entsprach $3 \%$ des ummauerten Stadtgebiets und maß somit mehr als drei Insulae in der östlichen Zivilstadt. ${ }^{51}$ Die wahrscheinlich ältere Forums-Basilika-Insula mit einer Gesamtausdehnung von 0,9 ha war somit um rund $5000 \mathrm{~m}^{2}$ kleiner konzipiert und wies eine Abweichung um $3^{\circ}$ von der nördlich gelegenen Insula des severischen „Macellum-Thermen-Komplexes“ auf.

Mit den Baumaßnahmen frühseverischer Zeit dürfte der Bauboom im Zentrum der Colonia Carnuntum ein Ende gefunden haben, jedenfalls ist festzustellen, dass auf der Insula nördlich der Umfassungsmauer des „Macellum-Thermen-Komplexes“ keinerlei städtische Verbauung größeren Ausmaßes mehr erfolgte.

Das Forum der Zivilstadt Aquincum ist am Kreuzungspunkt des decumanus und cardo maximus (Straßen C, A und D) in der Region 1 situiert (Abb. 13, oben) und nur partiell archäologisch untersucht. Die nördliche und westliche Begrenzung des rechteckigen, Nord-Süd orientierten Areals ist bislang unbekannt, zumal sie sich unter modernen Straßen befindet. Im Zuge archäologischer Untersuchungen des 19. Jahrhunderts meinte man hier eine Palästra identifizieren zu können. ${ }^{52}$ Nachgrabungen in den frühen 1970er Jahren erbrachten den Nachweis von fünf Bauperioden..$^{53}$

Die älteste Nutzung des Areals datiert an das Ende des 1. Jahrhunderts n. Chr., als hier Grubenhäuser und Werkstätten (wahrscheinlich) als Teil des West-Ost orientierten Vicus bestanden. Eine Gebäudestruktur, ausgestattet mit einem Wasserbecken, wurde zu Beginn des 2. Jahrhunderts n. Chr. errichtet und in weiterer Folge erweitert und umgebaut.

Um die Mitte des 2. Jahrhunderts n. Chr. wurde ein Temenos mit Podiumstempel und südlich gelegenem Keller eingerichtet. Der Bauzustand des 2.-3. Jahrhunderts n. Chr. weist einen Eingang von Süden her in jener Portikus auf, die sich entlang des decumanus maximus (Straße D) erstreckte. Die Nutzung kleinteiliger, um diesen Eingang gruppierter Strukturen möglicherweise als Amtsräume ist bislang nicht geklärt. Der nördlich an den Eingang grenzende langrechteckige Raum zeigte Spuren von Statuenbasen. An diesen schloss der große, $30 \mathrm{~m}$ lange, mit Steinplatten gepflasterte Forumsplatz an. Umgeben war dieser an drei Seiten von Mauern mit Quaderverkleidung, profiliertem Gesims und Halbpfeilern. Ein länglicher, an der Ostseite des Platzes situierter Baukörper mit Heizkanal und Wandmalerei könnte als Kurie gedient haben. Die Basis eines Altars (?) befand sich am Nordende des Forumsplatzes; von dort führte eine Treppe zu dem bislang noch nicht untersuchten Podiumstempel. Marmorfragmente einer Statue der Viktoria und ein Säulenkapitell mit dem Abbild des Jupiter Ammon entdeckte man in

\footnotetext{
${ }^{46}$ KANDLER 1999, 366-368; HuMER-KANDLER 2003, 12 ; KANDLER et al. 2006, 282-283, Abb. 2-3; MASCHEK 2011, 36.

${ }^{47}$ MASCHEK 2011, 36

${ }^{48}$ KANDLER 2000, 49.

${ }^{49}$ PACHER-KoneCNy 2012, 129.
}

\footnotetext{
${ }^{50}$ KANDLER 2000, 49

${ }^{51} \mathrm{Zu}$ Insulagrößen: MASCHEK 2011, 35-36.

${ }^{52}$ KUZSINSZKY 1890, 104.

${ }^{53}$ Póczy-Hajnóczi 1971, 27; Póczy 1970, 182.
} 

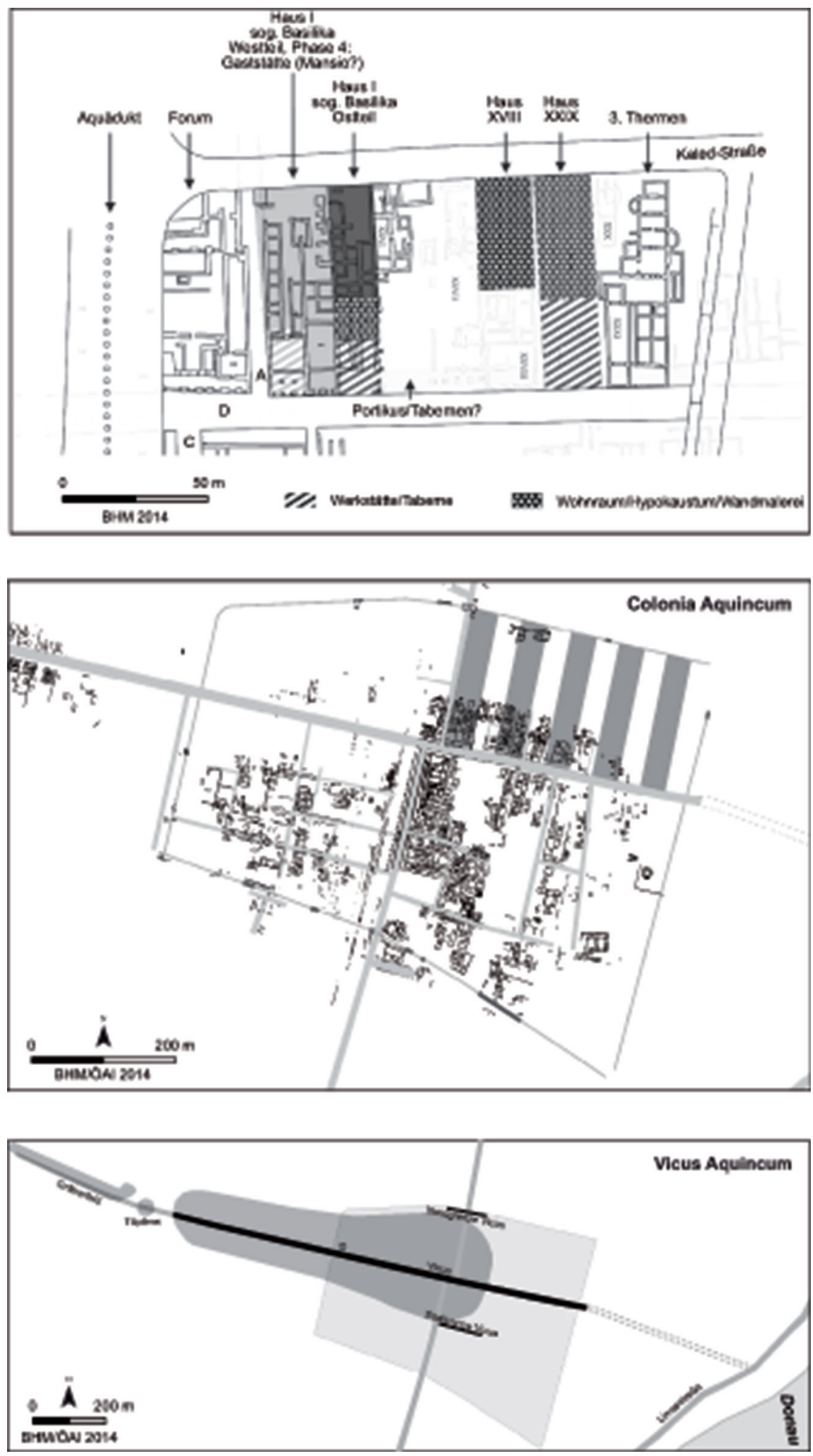

Abb. 13. Der Vicus von Aquincum an der West-Ost orientierten Hauptverkehrsroute (Straße D) und das streifenförmige Parzellierungsschema der Stadt (BHM, ÖAI) 
Vorhof und Portikus des Tempels. ${ }^{54}$ Fragmente der Skulpturenausstattung, Altäre und anderen Bauelemente wurden im Zuge eines völligen Umbaus während des 4. Jahrhunderts n. Chr. im Keller des Tempels verfüllt.

Die nur fragmentarisch bekannten Straßenraster der beiden Zivilstädte ähneln sich in vielerlei Hinsicht. Es kann kein orthogonaler Raster für die gesamten Stadtgebiete definiert werden, vielmehr scheinen einzelne Regionen, vielleicht durch chronologisch differierende Entwicklungsphasen bedingt, interne Raster zu besitzen. Für die Region 4 der Zivilstadt von Carnuntum zeigte dies D. Maschek auf. Er geht von Stadtplanung und Parzellierung des Baulandes in flavischer Zeit aus, ${ }^{55}$ mit einer grundlegenden Zenturiation in Blöcken von idealtypischen $66,625 \times 66,326 \mathrm{~m}(225 \times 224$ röm. Fuß $)$ und einer darauf folgenden Unterteilung in kleinere, 13,5-14 m breite Streifenparzellen.

In Carnuntum sind jedoch südlich, westlich und östlich des Forums deutlich kleinteiligere Straßenstrukturen sichtbar ( $A b b .12)$, die vielleicht als Indizien für eine erste dorfähnliche Ansiedlung gewertet werden können, die bereits vor der Zenturiation bestanden haben könnte.

Ein Teil des Stadtquartiers südlich des Forums wurde großflächig, auf rund $7600 \mathrm{~m}^{2}$ bereits im späten 19. Jahrhundert freigelegt. ${ }^{56}$ Hier konnte Wohnarchitektur an orthogonalen, $4,1 \mathrm{~m}$ breiten und spitzwinkelig verlaufenden, 2,4 m breiten, gepflasterten Straßenzügen dokumentiert werden. ${ }^{57}$ Eine aus diesem Stadtviertel gegen Nordosten führende Straße band in den cardo maximus ein und begrenzte eine zwickelförmige Stadtfläche mit einem kleinen Tempel nächst dem Eingang zum Forum. Dieses Fanum war in seiner Orientierung nicht auf die Ausrichtung der zentralen Platzanlage im Stadtzentrum abgestimmt. M. Kandler vermutete aufgrund dieser vom Raster des Forums abweichenden Anordnung der Straßen und Gebäude in diesem südlichen Wohnviertel einen alten Siedlungskern des vormunizipalen Vicus. ${ }^{58}$

In Aquincum ist entlang des decumanus maximus (D) in der Region 2 eine Fortführung der Streifenparzellierung erkennbar (Abb. 13). Die Straßenraster der Regionen 3 und 4 dürften strukturell jenen in Carnuntum ähneln. P. Zsidi spricht von einer frühen Absteckung - Zenturiation mit größeren Blöcken -, wie sie nun durch die neuen Messungen auch für die Region 3 bezeugt sind. Es lässt sich jedoch kein einheitliches Schema erkennen: Eine „Normbreite“ könnte ca. 38-40 m betragen haben, die Längen variieren zwischen 70 - 50 - $44 \mathrm{~m}$. In der Region 3 ist keine Parzellierung in Streifenparzellen erkennbar. Hier könnten Unterschiede zur bisherigen Annahme bestehen, dass es eine frühe Zenturiation in größere Blöcke und eine spätere/severische Parzellierung in Streifen innerhalb der Blöcke gegeben habe. ${ }^{59}$

Die westliche suburbane Bebauung beider Zivilstädte kann hier erstmals verglichen werden. Sowohl in Aquincum als auch in Carnuntum reicht sie im Westen entlang der Ausfallstraße bis ca. $600 \mathrm{~m}$ von der Stadtmauer. Beide Siedlungen sind als Vici mit Streifenhäusern anzusprechen (Abb. 5, Abb. 9), wobei die durchschnittlichen Parzellenbreiten und -längen in Carnuntum mit 7-9 m bzw. 50-70 m deutlich schmäler und länger als in Aquincum sind (13-18 m bzw. $50 \mathrm{~m}$ ). In Aquincum besitzen die Gebäude eher rechteckige/quadratische Grundrisse und sind kürzer als in Carnuntum. In Carnuntum endet die Verbauung des Vicus im Westen mit einem Gebäude, das als Mansio interpretiert wird, und geht dann in eine die Limesstraße flankierende Nekropole über. In Aquincum ist dieser Randbereich nicht für Messungen zugänglich.

Die Grabungsbefunde und geophysikalischen Messungen indizieren in Aquincum handwerkliche Tätigkeiten als Lebensgrundlage der Vicani. Als älteste Befunde sind Reste einer traianisch-hadrianischen Töpferwerkstätte im äußersten Westen des Vicus zu werten; die Steingebäude werden bislang in das 3. Jahrhundert n. Chr. datiert. Fraglich ist, ob die frühen Holz-Erde-Befunde einer dorfähnlichen Siedlung in der Region 2 von Aquincum als Evidenzen für einen Straßenvicus ab traianischer Zeit zu werten sind, der sich von der Töpferwerkstatt im Westen bis in das spätere Stadtzentrum erstreckte. Demnach wäre die hier präsente Streifenparzellierung als älteste Absteckung in der Zivilstadt von Aquincum zu werten und stimmte - in manchen Details - auch mit der späteren Struktur überein. ${ }^{60}$
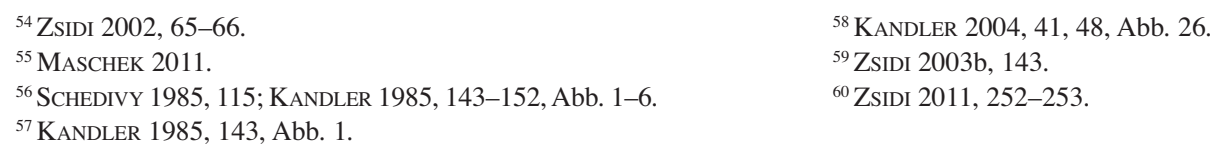


\section{Vicusperiode}

In der ältesten römischen Siedlungsperiode ist für die Entwicklung von Aquincum ein Fokus auf die West-Ost orientierte Hauptstraße (Straße D) festzustellen, der durch archäologische Untersuchungen jüngster Zeit bekräftigt werden konnte $(A b b .13)$. In Carnuntum sind bislang nur Hypothesen zur frührömischen Entwicklung zu postulieren, zumal signifikante archäologische Befunde ausreichender Zahl bislang nur am südöstlichen Rand des Vicus untersucht wurden.

Aquincum. In Aquincum ist eine frühe dorfähnliche Siedlung mit Grubenhäusern, deren Bewohner als Handwerker und Bauern noch stark keltischen Traditionen verpflichtet waren, an der Straße D in der Region 2 belegt. ${ }^{61}$

Der Typ eines Handwerkervicus mit Grubenhütten und anderen Grubenstrukturen, der sich nicht aus einer einheimischen Vorgängersiedlung entwickelte, wurde erstmals in den 1960er Jahren als Vorläufer der Zivilstadt identifiziert. ${ }^{62}$ Basierend auf den Grabungsergebnissen von P. Zsidi wurde seit dem ausgehenden 20. Jahrhundert eine Siedlung militärischen Charakters (Lager?) postuliert, aus der sich später der zivile Vicus entwickelt hätte. ${ }^{63}$

Jüngere Forschungen konnten keine weiteren Erkenntnisse über die Ausdehnung, Funktion und innere Gliederung der Siedlung erzielen, zumal eine Auswertung großflächiger Grabung noch ausständig ist. ${ }^{64}$

Nichtsdestotrotz liegen neue Informationen zur frühen Geschichte von Aquincum vor, basierend auf einer Neubewertung diverser, im nordöstlichen Siedlungsabschnitt durchgeführter kleinerer und größerer Kontrollgrabungen, die Restaurierungsarbeiten der Mauern vorausgegangen waren.

Diesen Forschungsergebnissen zufolge dürfte sich der früheste Kern der Siedlung ( $A b b$. 13) in diesem Areal befunden haben, also in der nordöstlichen Zone entlang der West-Ost orientierten Hauptstraße (Straße D), deren Trasse möglicherweise bereits in prähistorischer Zeit als Verkehrsweg genutzt wurde. Diese Straße führte vom Solymártal zu einer günstigen Flusspassage der Donau. ${ }^{65}$ Anhand der in jüngerer Zeit erfolgten genauen Studie des Fundmaterials aus diesem Siedlungsabschnitt ${ }^{66}$ und unterstützt durch ältere Forschungsergebnisse ${ }^{67}$ kann die älteste Besiedlung (Phase 1) im westlichen, höher gelegenen Viertel lokalisiert werden; sie datiert in das letzte Viertel des 1. Jahrhunderts $\mathrm{n}$. Chr. In die dünne Humusstrate, die den sandigen Unterboden bedeckte, waren einige wenigen Grubenhäuser, Abfallgruben und Gräben eingetieft, welche die West-Ost verlaufende Hauptstraße begrenzten. Rund ein Jahrzehnt später, in Phase 2, wurden die bislang nur verstreut angelegten Wohn- und Wirtschaftsstrukturen in einer dorfähnlichen Siedlung neu organisiert. ${ }^{68}$ Begleitet wurden diese Maßnahmen von starken Veränderungen der Landschaft: Ein Areal wurde mit einer bräunlich schwarzen, lehmhaltigen Schicht bedeckt, die in die eingetieften Siedlungsstrukturen der Phase 1 verfüllt wurde, ebenso wie in die Senken der Sanddünen; darüber hinaus wurde der ursprünglich steil zum Fluss abfallende Abhang verändert. Man erzielte so ein weitläufiges Siedlungsareal in der Zone des späteren Hauses I. Eine Expansion der Ansiedlung gegen Ost zu konnte auf diese Weise vorgenommen werden, wobei allerdings häufige Überflutungen in diesem neu gewonnenen Abschnitt das Leben erschwerten; dünne Sandschichten unter dem Haus XXIX bezeugen dies. ${ }^{69}$

Festzustellen ist, dass die Siedlungsstrukturen und Funde dieses nordöstlichen Areals eine zivile Ansiedlung bezeugen und ein militärischer Charakter nicht nachzuweisen ist. ${ }^{70}$ Es handelte sich demnach um eine Zivil-

\footnotetext{
${ }^{61}$ LÁNg 2011b, 30.

${ }^{62}$ NAGY 1971, 59-81; PócZY 1970, 189, 191; PócZY-ZSIDI 1992, 39.

${ }^{63}$ ZsIDI 2002, 34-35; ZsIDI 2004, 189. K. Póczy nahm hier hypothetisch ein Auxiliarkastell an: PócZy 2004, 58, 109.

${ }^{64}$ Zusammenfassung der frühen Geschichte und des Rechtsstatus der Siedlung: Póczy 2003b, 125.

${ }^{65}$ Bereits T. Nagy vermutete die Bedeutung der West-OstStraße für die Siedlungsentwicklung: NAGY 1971, 66. Zum Kreuzungspunkt jüngst: Zsidi 2007, 67. Als ausschlaggebende Faktoren für die Position eines Vicus sind die Nähe zu einem Fluss und die Verbindung zum existierenden Verkehrsnetz zu werten: RoRISON 2001, 1920. K. Póczy vermutete eine domitianische Zeitstellung der West-Ost-Straße (= Straße D): Póczy 2004, 108.

${ }^{66}$ LÁNG 2012b; LÁNG 2013c, 235-236, 242-244.
}

\begin{abstract}
${ }^{67}$ Laut älteren Forschungen könnte die älteste Phase vespasianisch (NAGY 1964, 48), spätflavisch (GABLER 1977, 147, Anm. 23) oder domitianisch (NAGY 1942a, 372) datieren.

${ }^{68}$ Basierend auf älteren Forschungen nahm E. Márity eine dorfähnliche Siedlung mit „lateinischer“ Kultur an: E. MÁRITY, Colonia Septimia Aquincum (Civil Town of Aquincum), unpublizierte Studie im Nachlass von E. Márity, BTM RA H.1927-2006, 6.

${ }^{69}$ Dieses Bild kann zudem durch die Befunde von Grubenhäusern und Werkstätten vervollständigt werden, die bei Kontrollgrabungen unter dem Forum von K. Póczy entdeckt wurden (bislang nur in Vorberichten vorgelegt). Ihrer Meinung nach wurden groß angelegte Baumaßnahmen in diesem Areal erst in traianischer Zeit initiiert: PócZy 1970, 182; Póczy 2004, 108, 155-156.

${ }^{70}$ ZsIDI 2002, 34. Die kurzen Grabenabschnitte und Palisaden, die sie mit einem Militärlager in Verbindung bringt, könnten auch anders gedeutet werden (s. u.)
\end{abstract}


siedlung mit dem Rechtsstatus eines Vicus im Gebiet der civitas Eraviscorum. Verwaltungstechnisch könnte diese Siedlung dem Zentrum der Civitas, im Gebiet der Wasserstadt (Viziváros) ${ }^{71}$ untergeordnet gewesen sein, aber - wie dies bereits von L. Nagy und T. Nagy angenommen wurde - es gab keine einheimische Vorläufersiedlung: ${ }^{72}$ Die Nachuntersuchung der nordöstlichen Zone beweist römische oder romanisierte Lebensweise, wie dies unter anderem Gebrauchsgegenstände wie Terra Sigillata, Räucherschalen, Öllampen, Glaslöffel etc. indizieren. Ein späteisenzeitlicher Einfluss ist allerdings aufgrund der Grubenhäuser zu erfassen. ${ }^{73}$

Die Struktur der frühen Siedlung, speziell der Phase 2, lässt bereits auf eine übergeordnete Planung schließen: Grubenhäuser wurden parallel in Reihen und im rechten Winkel zur West-Ost-Straße angelegt. Vergleichbare Strukturierungen können auch in anderen pannonischen Vici, bei denen es sich allerdings um Lagerdörfer handelt, ${ }^{74}$ festgestellt werden. Sie deuten auf ein geplantes, vereinheitlichtes System von Parzellierungen und waren, zumindest in Aquincum, mit einer intensiven Überformung der Landschaft verbunden.

Im Zuge einer Aktualisierung der von T. Nagy entwickelten Hypothesen zur Geschichte, Struktur und Ausdehnung des Vicus Aquincum ${ }^{75}$ ist davon auszugehen, dass eine dorfähnliche Straßensiedlung ${ }^{76}$ die West-Ost orientierte Straße D säumte mit Befunden und Funden möglicherweise in Reihen ${ }^{77}$ angelegter Grubenhäuser, mit einer hufeisenförmigen Struktur ${ }^{78}$ und mit Abfallgruben. ${ }^{79}$ Genauere Funktionsbestimmungen der Häuser sind unklar, obwohl die ältere Forschung davon ausgegangen ist, dass hier eine Gerberei betrieben wurde, worauf ein parallel zur Straße geführter Graben deuten sollte. ${ }^{80}$ Eine Grube wurde als Glasofen identifiziert. ${ }^{81}$ Zudem wurde ein Ofen mit Rauchabzug an der nördlichen Peripherie des Areals durch T. Nagy dokumentiert. ${ }^{82}$

Diverse Analogien sind für die Form des Vicus Aquincum beizubringen, so die Befunde im Bereich der Zivilstadt von Vindobona-Wien ${ }^{83}$ und die Vici in den germanischen Provinzen, wo die Strukturen auch nach der Munizipalisierung erhalten blieben, z. B. im Munizipium Arae Flaviae-Rottweil. ${ }^{84}$ Bliesbruck in Gallien ist auch als Vergleichsbeispiel heranzuziehen, wo eine schrittweise Entwicklung der langrechteckigen Parzellen an der Hauptstraße im westlichen, durch Handel und Handwerk geprägten Siedlungsteil zu beobachten ist. ${ }^{85}$ Auch im gallischen Vicus von Malain sind langrechteckige, vor allem als Werkstätten genutzte Siedlungsstrukturen auf die Hauptstraße ausgerichtet. ${ }^{86}$

Die Grenzen des Vicus Aquincum (Abb. 13) sind schwer zu bestimmen, zumal nur wenige großflächige Grabungen außerhalb der nordöstlichen Zone in anderen Arealen der Zivilsiedlung ausgeführt wurden. Allerdings sind Abschnitte V-förmiger Gräben an mehreren Punkten zu Tage getreten, die eine Begrenzung des Vicus darstellen könnten, auch wenn „befestigte“ Vici in Pannonien bislang rar - aber in anderen römischen Westprovinzen durchaus üblich sind. ${ }^{87}$ Demzufolge ist die Nordbegrenzung durch einen West-Ost orientierten Graben definiert, der

${ }^{71}$ KovÁCs 1997-1998, 289; ZsIDI 2002, 33. Ursprünglich vermutete T. NAGY in der Vorläufersiedlung der Zivilstadt das Zentrum der civitas: Nagy 1973, 125.

${ }^{72}$ NAGY 1942a, 372; NAGY 1964, 48; NAGY 1971, 59; NAGY 1973,125

${ }^{73}$ Die Situation ist auch mit Auxiliarvici vergleichbar: KoVÁCS 1999, 147-148;

${ }^{74}$ Albertfalva, Matrica, Intercisa, Vetus Salina: KovÁcs 1999, 145-148; jüngst, im Nordteil des Vicus von Albertfalva: BESZÉDES 2011, 59.

${ }^{75}$ T. Nagy datierte die Phase 2 des Vicus an den Beginn des 2. Jahrhunderts n. Chr., also etwas später als es hier angenommen wird: NAGY 1971, 75.

${ }^{76}$ Auch „linear-ribbon“-Typ genannt: RoRISON 2001, 33.

${ }^{77}$ In manchen Vici sind mehrere Reihen an zwei Straßen angeordnet (,extended ribbon“-Typ), so z. B. in Bliesbruck: RoRISON 2001, 33-34.

${ }^{78}$ Zur möglichen Funktion dieser Struktur: LÁNG 2011a, $143-156$.

${ }^{79}$ Grubenhäuser in mehreren hintereinander angeordneten Reihen können für andere pannonische Vici angenommen werden: KovÁCs 1999, 152.
${ }^{80}$ NAGY 1964, 16. Der V-förmige Graben wurde von T. Nagy als „Grube $\alpha$ “ bezeichnet. Seiner Meinung nach könnte die „rostrote Verfärbung“ der Struktur auf eine Gerberei deuten. Allerdings ist eine solche Färbung auch als Resultat regelmäßiger Aktivität einer Wasserzufuhr zu deuten; so weist auch die Nordmauer von Raum 59 des Hauses XXIX eine ,rostrote Färbung“ auf (beobachtet durch O. Láng). Es liegen keine Informationen über naturwissenschaftliche Analysen der Ablagerungen von „Grube $\alpha$ “ vor.

${ }^{81}$ Basierend auf der Grabungsdokumentation des Jahres 1991 von E. Márity. Zahlreiche Glasgefäßfragmente wurden in der Grube angetroffen, woraus allerdings nicht mit Bestimmtheit auf eine Produktion zu schließen ist; es könnte sich einfach um eine Abfallgrube handeln.

302.

${ }^{82}$ Ohne Beschreibung oder Erläuterung: NAGY 1971, 64, $30,36,42$.

\footnotetext{
${ }^{83}$ Kronberger 2009, 56-59; MÜLLER-MADER et al. 2011,
}

${ }^{84}$ SOMMER 1999, Abb. 1.

${ }^{85}$ Petit 2001, 39, Abb. 6; Rorison 2001, 209, Abb. 41.

${ }^{86}$ RORISON 2001, 135.

${ }^{87}$ KovÁcs 1999, 37, 156. Im Fall von Vindobona (2. Jahrhundert n. Chr.): MÜLLER-MADER et al. 2011, 47. 
unter der jüngeren Stadtbefestigung von P. Zsidi angetroffen wurde. ${ }^{88}$ Die Verfüllung des Grabens bildet gleichfalls homogener, kompakter schwarzer Lehm, der auch zur Verfüllung der Strukturen der Phase 1 verwendet worden war.

Die südliche Begrenzung könnte ein weiterer, West-Ost orientierter Graben bilden, der unter dem Südteil des späteren Macellum und dem sog. Haus des Victorinus parallel zur Straße E verlief. ${ }^{89}$ Die Fortsetzung des Grabens gegen Westen zu ist bislang unbekannt. In diesem Zusammenhang ist auch eine Anmerkung von T. Nagy zu verstehen: Seiner Meinung nach reichte die frühe Siedlung nicht über die Straße E hinaus, zumal Funde des 1. Jahrhunderts n. Chr. zwar sekundär in Schichten angetroffen wurde, so im Bereich des Collegium Centonariorum und im sog. Malerhaus, jedoch ein zugehöriger Nutzungshorizont nie festgestellt werden konnte. ${ }^{90}$ Die West- und Ostbegrenzung des Vicus sind schwer definierbar. Im Westen ist, abgesehen von kleinen Arealen, das Siedlungsgebiet nicht archäologisch untersucht. Allerdings ist der früheste Friedhof der Siedlung, der sog. Aranyhegyi-Fluss-Friedhof (dessen gesamte Ausdehnung bislang unbekannt ist), parallel und etwas nördlich der westöstlichen Hauptstraße situiert und markiert hier die Westgrenze des Vicus. ${ }^{91}$ Diese topografische Position von Nekropolen, z. B. peripher an der Siedlungsgrenze, ist typisch für Vici. ${ }^{92}$ Eine kleine Töpferei (sog. Militärdepot- oder Aranyhegyi-FlussWerkstatt), die von flavischer Zeit bis in das erste Jahrzehnt des 2. Jahrhunderts n. Chr. datiert, könnte gleichfalls die Westgrenze der Siedlung markieren, worauf bereits vor langem K. Póczy hingewiesen hat. ${ }^{93}$

Auch die Ostbegrenzung des Vicus ist aufgrund des Mangels an Grabungsbefunden schwer erfassbar: Das Gelände fiel hier steil zur Donau ab, allerdings könnten sich die archäologischen Strukturen einer frühen Besiedlung tief unter dem modernen Niveau befinden. Die hier befindliche Gasfabrik samt zugehörigen Gebäuden war hinderlich für eine Erforschung des Areals. ${ }^{94}$ Der Mangel an frührömischen Befunden und signifikanten Funden wie Terra Sigillata, Amphoren oder Mortarien unter dem mittelkaiserzeitlichen Haus XXIX könnte darauf deuten, dass dieses Areal in der Vicusperiode (Phase 1-2) Peripherie war und erst im Verlauf der Phase 3 ausgebaut wurde, als die Siedlung gegen Osten zu expandierte.

In Aquincum ersetzt man am Beginn des 2. Jahrhunderts n. Chr. die Grubenhäuser durch komplexere Bauten in Leichtbauweise und investiert in Infrastrukturprojekte wie die Errichtung des Aquädukts (traianisch-hadrianisch, s. u.). Die Befunde aus einer Töpferwerkstatt im Suburbium-West von Aquincum aus traianisch-hadrianischer Zeit bezeugen diese Entwicklung auch im äußersten Westen des Vicus.

Carnuntum. Vor der Monumentalisierung des Stadtzentrums von Carnuntum im Abschnitt des „ThermenMacellum-Komplexes“ bestand nördlich des decumanus maximus eine Verbauung mit Wohn- oder Wirtschaftsgebäuden. Fundamentmauern in Stein, bodenebene Feuerstellen mit Ziegelsetzung, Estrich- und Ziegelböden und (verstürzter) Wandverputz ${ }^{95}$ sind charakteristisch für die bis in antoninische Zeit bestehenden Baustrukturen. Die Befunde konzentrieren sich auf das Areal entlang des Hauptverkehrswegs und erstrecken sich vom decumanus maximus bis etwa 33 m nach Norden. Funde eines Webgewichts sowie verworfener Schlacken aus der Metallverarbeitung könnten auf eine partielle Nutzung des Areals durch Handwerker deuten.

${ }^{88}$ Jüngst: ZsIDI 2002, 34. Der Graben wurde als Teil einer Befestigung eines frührömischen Lagers angenommen, zumal zu diesem Zeitpunkt die Existenz von Grubenhäusern und anderer römischer Siedlungsstrukturen der nordöstlichen Zone noch nicht bekannt war.

${ }^{89}$ MADARASSY 1991, 33 und Grabungsdokumentation des Jahres 1960 von M. Kaba (BTM RA ltsz.: 353-77). P. Zsidi identifizierte den Graben als Abwasserkanal innerhalb der Siedlung: ZsidI 1990, 164, Anm. 15.

${ }^{90}$ Ebenso ist es unwahrscheinlich, dass ein Grabensegment (?), das P. Zsidi unter der jünger datierenden südlichen Stadtbefestigung feststellte und das sie als Teil einer militärischen Befestigung deutete, die südliche Begrenzung der frührömischen Siedlung darstellte: ZsIDI 2004, 189

${ }^{91}$ Ein Zusammenhang des von flavischer Zeit bis um die mittleren Jahrzehnte des 2. Jahrhunderts n. Chr. belegten Friedhofs mit dem Vicus wurde bereits von K. Póczy angenommen: PóczYZsIDI 1992, 39; ZsiDI 2002, 36. Jüngste Grabungsergebnisse deuten auf eine Nutzung des Friedhofs auch nach der Mitte des 2. Jahrhunderts: LASSÁNYI 2005, 81-90; LASSÁNYI-BECHTOLD 2006, 73-78.

${ }^{92}$ Die topografische Situation ist in den Vici von Yutz oder Florange-Daspich-Ebange (Gallia) sehr ähnlich: RoRISON 2001, 45.

${ }^{93}$ NAGY 1942b, 629-630; PÓCZY-ZSIDI 1992, 39-40. Eine Rettungsgrabung des Jahres 2013 im Bereich der westlichen Stadtmauer erbrachte den Nachweis mehrerer Grubenhäuser, verfüllt mit der oben erwähnten schwärzlichen Lehmschicht. In dieser wurde u. a. frührömische glasierte Ware angetroffen. Es erscheint möglich, dass das frühe Siedlungsareal sich über die später durch die Stadtmauer definierte Grenze in westlicher Richtung erstreckte: LÁNG 2014.

${ }^{94} \mathrm{~S}$. o. Die Nähe zur östlichen Siedlungsgrenze ist indiziert durch die Tatsache, dass in der schwarzen Lehmschicht unter dem Haus XXIX nur wenige Strukturen und hauptsächlich Abfallmaterial (Tierknochen und sehr wenige Gefäßfragmente) angetroffen wurden. Quellwasseraktivität ist auch hier zahlreich zu beobachten.

${ }^{95}$ Swoboda-Milenović 1959, 34-36, Abb. 4, Taf. 6. 2-4. 
Die Position dieses Siedlungsteils nördlich des decumanus maximus ist vergleichbar mit den entlang der Straße D dokumentierten Strukturen in Aquincum, die ebenda mit hoher Wahrscheinlichkeit den Nukleus der Zivilsiedlung darstellen. Allerdings ist in Carnuntum keine vergleichbare, auf diesen Hauptverkehrsweg fokussierte Herausbildung eines Vicus zu postulieren. Es ist zwar davon auszugehen, dass die unter dem „Thermen-MacellumKomplex“ erfassten Baubefunde in das zentrale Hauptverkehrsnetz eingebunden waren, allerdings primär über einen Nord-Süd orientierten Straßenzug. Diese Straße definierte bereits im 1. Jahrhundert n. Chr. eine Hauptachse, und zwar als Strang eines sich zwickelförmig gegen Südwesten zu im Winkel von $36^{\circ}$ teilenden Verkehrsweges im Siedlungszentrum. Hypothetisch ist davon auszugehen, dass mit der im Verlauf des 2. Jahrhunderts n. Chr. erfolgten Schaffung des Forumskomplexes eine Umleitung bzw. Adaptierung dieser Südwest-Nordost verlaufenden Hauptstraße (cardo maximus) erfolgte, wobei die Trasse nunmehr entlang der Ostbegrenzung der in ein älteres Siedlungsgefüge eingepassten Insula mit Forum und Basilika verlief.

Geht man modellhaft davon aus, dass in Carnuntum Flächen innerhalb eines zwickelförmigen Straßensystems den Ausgangspunkt des Vicus darstellten, ist ein deutlicher Unterschied zur oben beschriebenen Entwicklung in Aquincum, basierend auf einer Straßensiedlung des ,linear-ribbon“-Typs, herauszustreichen.

Außerhalb des Zentrums der Zivilsiedlung Carnuntum ist eine systematische Erschließung der Vicusareale mittels Parzellierungen bereits im späteren 1. Jahrhundert n. Chr. zu erfassen. Einfache Holz-/Fachwerkbauten wurden in der Region 4 während des letzten Viertels des 1. Jahrhunderts n. Chr. auf streifenförmigen Parzellen von 13,5-14 m Weite errichtet. ${ }^{96}$ Eine Verbauung lässt sich allerdings zu diesem frühen Zeitpunkt nicht flächig, sondern nur partiell erfassen, so durch in Holz errichtete, parallel zur Straße orientierte Portiken und durch mehrräumige Lehmziegelarchitektur mit zugehörigen Feuerstellen in den Arealen abseits der Straße. ${ }^{97}$ Grubenhütten konnten nicht festgestellt werden.

Bemerkenswert sind hinsichtlich einer frühen infrastrukturellen Konzeption die bereits in der ältesten Siedlungsphase vorhandenen hallenartigen Holzkonstruktionen, die parallel zur „Südstraße“ verlaufen und die eine bauliche Trennung zu den abseits des Verkehrswegs errichteten rechteckigen Baustrukturen darstellen. ${ }^{98}$ Die Gefäßkeramik aus der Verfüllung der Balkengräbchen legt eine Datierung der Siedlungsperiode I von der zweiten Hälfte des 1. bis zum ersten Viertel des 2. Jahrhunderts n. Chr. nahe. ${ }^{99}$ Weitere Hallenbauten bestanden auch unter dem sog. Valetudinarium. ${ }^{100}$

Im Verlauf des 2. Jahrhunderts n. Chr. wurde einfache Holz-/Fachwerkarchitektur im südöstlichen Stadtteil (Region 4) der Zivilstadt Carnuntum durch Lehmziegelbauweise auf Sockelmauerwerk substituiert.

\section{ZUR ENTWICKLUNG AUSGEWÄHLTER STÄDTISCHER INFRASTRUKTUR}

Mit der Teilung der pannonischen Provinz in die westliche Pannonia Superior und die östliche Pannonia Inferior unter Kaiser Traianus zu Beginn des 2. Jahrhunderts n. Chr. dürfte eine Verlegung des Statthaltersitzes vom Landesinneren an den Limes - nach Carnuntum und Aquincum - verbunden gewesen sein. Eine Forcierung der beiden Zivilsiedlungen von Aquincum und Carnuntum außerhalb der um das Legionslager abgesteckten Leugenzone ${ }^{101}$ lässt sich allerdings erst mit dem unter Kaiser Hadrianus zuerkannten munizipalen Status erfassen. In Carnuntum dürfte in diese Zeit die Errichtung öffentlicher Thermen in der Oststadt (Region 4) fallen. In Aquincum erfolgten der Ausbau des Wasser- und Kanalsystems sowie der Verkehrswege mit ersten gepflasterten Straßenzügen und die Errichtung der Stadtmauer. ${ }^{102}$

Bemerkenswert ist, dass ein Aufschwung der urbanistischen Entwicklung der beiden Zivilstädte auch aufs Engste mit der persönlichen Geschichte regierender römischer Kaiser in Bezug stand. Aquincum erfuhr einen deutlichen Investitionsschub bereits in der ersten Hälfte des 2. Jahrhunderts n. Chr., was mit hoher Wahrscheinlichkeit darauf zurückzuführen ist, dass der 117 n. Chr. zum Kaiser ernannte Hadrianus in seinem cursus honorum mehrfach

${ }^{96}$ MASCHEK 2011, 34-35.

${ }^{97}$ JoBST-RudolF 1987, 189-195, Abb. 5 und 32; MASCHEK-HuMER 2006, 690-691, Abb. 101; BAIER 2008, 28-30, Abb. 2; MASCHEK 2011, 34-35.

${ }^{98}$ Humer-KONECNy 2002, 656-658, Abb. 571; HuMERKONECNY-MASCHEK 2004, 98-102, Abb. 8; BAIER 2008, 28-30, Abb. 2.
${ }^{99}$ PetZneK 2006, 149-153, Taf. 1/1-5, 6/2-3, 12/1-2, 13/2, 14/3-9, 14/12-17; wahrscheinlich Intrusionen: Taf. 14/10, 14/18; RAUCHENWALD 2006, 281-282, Taf. 1-2.

${ }^{100}$ Konecny 2008, 28.

${ }^{101}$ GugL 2012; PISO 1991.

${ }^{102}$ ZSIDI 1990, 143-169. 
führende Ämter in Unterpannonien bekleidete. Er war in jungen Jahren Militärtribun der in Aquincum stationierten Legio II Adiutrix und in der von Traianus neu geschaffenen Provinz legatus praetorius in Pannoniam inferiorem. ${ }^{103}$

Vor diesem Hintergrund verwundert es nicht, dass der infrastrukturelle Ausbau in Aquincum offenkundig im Verlauf des frühen 2. Jahrhunderts n. Chr. schneller als in Carnuntum erfolgte. Dies resultiert aber naturgemäß auch aus der besonderen topografischen Situation der Hauptstadt von Niederpannonien, die in diesem Abschnitt der mittleren Donau konkurrenzlos das städtische Zentrum bildete (Abb. 1). Die Zivilstadt von Carnuntum war demgegenüber in eine durch die Bernsteinstraße erschlossene Siedlungslandschaft traditionsreicher städtischer Zentralorte (Scarbantia-Sopron, Savaria-Szombathely) eingebunden, die seit dem frühen bis mittleren 1. Jahrhundert $\mathrm{n}$. Chr. von hoher Bedeutung für die Entwicklung von Oberpannonien waren ( $A b b .1)$.

Als Folge der Akklamation des Statthalters von Oberpannonien, Septimius Severus, zum Kaiser des römischen Reichs durch die pannonischen Truppen erfuhren die Hauptstädte Carnuntum und Aquincum einen deutlichen Investitionsschub. Mit der Erhöhung in den Rang von Kolonien erfolgten Verbesserungen bzw. Neustrukturierungen der öffentlichen Infrastruktur. So wurde in Carnuntum erstmals zu diesem Zeitpunkt eine übergeordnete Versorgung durch Wasserleitungen organisiert und eine Pflasterung der Straßen vorgenommen. Anders als in Aquincum wird der Bau der Stadtmauer in Carnuntum anhand neuerer Grabungen erst in severische Zeit, um 200 n. Chr., gesetzt, wobei unklar ist, ob es eine Vorgängeranlage gab.

An monumentalen öffentlichen Bauten entstanden im Zentrum der Colonia Carnuntum der „MacellumThermen-Komplex“ mit Macellum, Schola, Palästra und Großen Thermen in frühseverischer Zeit. Wahrscheinlich um die Mitte des 3. Jahrhunderts n. Chr. datiert ein Macellum im Zentrum der Colonia Aquincum. ${ }^{104}$

Im folgenden Abschnitt werden neueste Ergebnisse zu ausgewählten Typen städtischer Infrastruktur der beiden Zivilstädte von Aquincum und Carnuntum im Überblick dargestellt.

\section{Straßen}

Der Bezug beider Hauptstädte auf ein übergeordnetes Verkehrsnetz ist naturgemäß gegeben. Für Aquincum ist das Phänomen aufzuzeigen, dass der cardo maximus nicht in voller Länge von immanenter Bedeutung war, sondern nur im südlichen Abschnitt bis zur Einbindung in den West-Ost verlaufenden decumanus maximus. Die nördliche Trasse des cardo maximus war im überregionalen Verkehrsnetz ohne Belang. Der tatsächliche Nord-Süd führende Hauptverkehrsweg, die Limesstraße, verlief östlich außerhalb der Stadt unmittelbar parallel zum rechten Donauufer.

Auch in Carnuntum ist der das Forum im Osten passierende cardo maximus von geringer Breite (Tabelle 2, $A b b .10)$. Dieser war offenkundig im alten Siedlungsgefüge von Bedeutung als Fortsetzung der aus Süden herangeführten Hauptverkehrsroute. Eine südlich des Suburbiums schräg nach Nordosten auf das Legionslager zuführende, das Auxiliarkastell im Süden passierende Stichstraße dürfte in der weiteren Entwicklung von Carnuntum als Umfahrung von größerer verkehrstechnischer Wichtigkeit gewesen sein. ${ }^{105}$

Die Entwicklung im Ausbau der Verkehrswege divergiert in den beiden pannonischen Hauptstädten, zumal in Aquincum mit einer Pflasterung der Straßen bereits in traianisch-hadrianischer Zeit gerechnet wird, während diese in Carnuntum erst frühseverisch datiert.

Aquincum. Die älteste Straße in der Zivilsiedlung von Aquincum war die Straße D (= decumanus maxi$m u s$ ), die West-Ost orientiert einem traditionsreichen Verkehrsweg folgte, der auf die topografischen Faktoren abgestimmt war. ${ }^{106}$ Ausgehend von der Donaufurt führte die Straße Richtung Westen in das Solymártal (Abb. 10). Mit $11 \mathrm{~m}$ war sie die breiteste Straße und auch die einzige, die das Stadtgebiet zur Gänze in Ost-West-Richtung durchquerte. Die besondere Bedeutung ist auch dadurch gegeben, dass ab traianisch-hadrianischer Zeit über diese Ost-

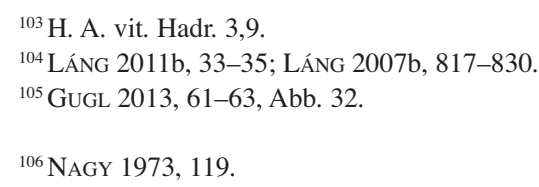

${ }^{107}$ Z. B. eine Gasse, die aus dem Ostteil der Stadt auf die Straße H im Westen zielt und eine Tabernenreihe quert. Zur Gasse mit Tabernenreihe: Póczy 2003a, 147-149, Abb. 5; zur Umgruppierung der Pilaster 19 und 24 des Aquädukts in dieser Zone: KABA 1976, 226-227, Abb. 61. 
Tabelle 2. Durchschnittliche Breite gepflasterter intraurbaner Straßen der Zivilstädte

\begin{tabular}{|c|c|c|c|c|c|}
\hline \multirow{4}{*}{\begin{tabular}{|l|} 
\\
Aquincum
\end{tabular}} & \multirow{4}{*}{$\begin{array}{c}\text { decumanus } \\
\text { maximus }\end{array}$} & \multirow{2}{*}{\multicolumn{2}{|c|}{ cardo maximus }} & \multicolumn{2}{|c|}{ Nebenstraßen und Gassen } \\
\hline & & & & \multirow{3}{*}{\begin{tabular}{|l|} 
höherer Rang \\
$5,6-6,2 \mathrm{~m}$
\end{tabular}} & \multirow{3}{*}{\begin{tabular}{|l} 
niederer Rang \\
$3,3-3,7 \mathrm{~m}$
\end{tabular}} \\
\hline & & Süden $=$ Straße C & $10,7 \mathrm{~m}$, später $7,7 \mathrm{~m}$ & & \\
\hline & & Norden $=$ Straße A & $6-6,5 \mathrm{~m}$ & & \\
\hline Carnuntum & $11,7-12 \mathrm{~m}$ & Östlich Forum & $4,5 \mathrm{~m}$ & $6-7,5 \mathrm{~m}$ & $2,4-4,1 \mathrm{~m}$ \\
\hline
\end{tabular}

West-Straße die einzige Möglichkeit einer Passage des Nord-Süd verlaufenden Aquädukts ${ }^{107}$ auch mit Fuhrwerken bestand. ${ }^{108}$ Aus diesem Grund war ein Anstieg des Niveaus von 1-1,5 m, der in anderen Arealen des Stadtzentrums festzustellen ist (z. B. bei einer Tabernenreihe ${ }^{109}$ ), im Falle der Straße D nicht zu konstatieren. Dies ist beispielsweise am Eingang von der Straße D zum Haus XXIX festzustellen, wo ein Gefälle zur Straße hin vorliegt. ${ }^{110}$ Eine Pflasterung mit Steinplatten erfolgte eventuell bereits unter Domitianus, wie dies ältere Grabungen zeigten. ${ }^{111}$ Jüngste Untersuchungen lassen auf eine etwas spätere Datierung in traianisch-hadrianische Zeit schließen. ${ }^{112}$ Von Bedeutung ist auch, dass nicht nur der decumanus maximus (Straße D) mit Pflastersteinen versehen war, sondern auch Seitenstraßen von angemessener Breite. So war eine Nord-Süd-Straße, die ausgehend von der Straße D das Nordbad (3. Thermen) im Westen flankierte, gepflastert und wurde später durch Schotterlagen erneuert.

Die südliche Trasse des cardo maximus (Straße C) war mit rund 10,7 m ursprünglich gleich breit wie der decumanus maximus (Straße D). Dieser Nord-Süd orientierte Verkehrsweg querte auf dem kürzesten Weg das Stadtgebiet. Die Orientierung des südlichen cardo maximus (Straße C) und des Aquädukts stimmten überein.

Die gepflasterte Straße A1, die parallel zum Aquädukt verlief, wurde zeitgleich mit diesem angelegt. Das messbare Breitenmaß liegt zwischen 7,3 und 8,1 m. Von vergleichbarer Breite war der nördliche Abschnitt des cardo maximus (Straße A) und die Straße an der Westseite des Nordbads (3. Thermen) mit 6,0-6,5 m und 6,4 $\mathrm{m}$ sowie die Ost-West-Straßen $\mathrm{E}^{113}$ und $\mathrm{G}^{114}$ mit 6,2 und 5,6 m. Nord-Süd orientierte Straßen abseits der Hauptverkehrswege waren schmäler, Straßen B und F mit 3,3 und 3,7 m. Diese Verkehrswege wurden spätestens in severischer Zeit gepflastert. Auch wenn die Straßenbreite zumeist nur mit annähernder Genauigkeit angegeben werden kann, basierend auf den Maßen der Rekonstruktionen und nicht auf exakten Grabungsdaten, ist ein System ablesbar. Die beiden Hauptstraßen sind mit 10-11 m breit, niederrangige Straßen messen rund $6 \mathrm{~m}$, schmale um $3 \mathrm{~m}$.

Wenig ist über die Verkehrswege im westlichen Teil der Stadt bekannt. Die Straße H ist 5-6 m breit, während eine Nord-Süd orientierte Querstraße zur schmalen Gruppe mit 3 m zählt. Diese Maßverteilung stimmt mit den Daten im östlichen Teil der Stadt überein.

Carnuntum. Im Siedlungszentrum ist als ältester, datierter Befund eine Nord-Süd orientierte geschotterte Straßentrasse zu postulieren, die rund $18 \mathrm{~m}$ westlich des jüngeren Verlaufs des cardo maximus positioniert war und durch spätere Baumaßnahmen des severischen „Macellum-Thermen-Komplexes“ überlagert wurde. Das keramische Fundmaterial aus dem Schotterstratum weist einen auffallend hohen Fragmentierungsgrad auf, die korrodierten Eisenteile sind rund verschliffen (zahlreiche Schuhnägel). Zu den ältesten Funden zählen italische Sigillaten, darunter ein Tellerfragment mit dem Stempel des Gellius der Jahre 10-50 n. Chr. (OCK 2000, Nr. 878. 13), kleinteilige Fragmente italischer Feinware sowie geglätteter Gebrauchskeramik. Eine Münze des Domitianus der Prägezeit 88/89 n. Chr. (RIC II ${ }^{2} 659$ ) definiert den t.p.q.

${ }^{108}$ PÓCZY 1995, 470.

${ }^{109}$ NÉMETH-HAJNÓCZI 1976, 423.

${ }^{110}$ LÁNG 2005, 75, Abb. 7

${ }^{111}$ Póczy 1995, 470; s. dazu auch: NAGY 1971, 76, Anm. 77: »Auf den Zeitpunkt des Ausbaues des letzteren (Straße D) wirft der Umstand ein Licht, dass unter der Steinbepflasterung des Straßenkörpers eine Münze des Domitianus zum Vorschein gekommen ist."; sowie SzILÁGYi 1943, 356-357: eine prägefrische Münze des Vespasianus wurde in einem Kanal gefunden, der parallel zur $11 \mathrm{~m}$ breiten Fortsetzung der Straße D verlief, und so nahm J. Szilágyi an, dass beide Konstruktionen, also Kanal und Straße, zeitgleich in der Regierungszeit des Vespasianus fertiggestellt waren.
${ }^{112}$ LÁNG 2007a, 120-121, Abb. 7.

${ }^{113}$ Aufgrund der Grabungsergebnisse ist Straße E später, zur Zeit der Reorganisation der Stadt im 3. Jahrhundert n. Chr., errichtet worden: NAGY 1942a, 374. Ihre Besonderheit liegt in der Reduktion der Breite von 6 auf 3 m Richtung Westen: Zsidi 2005a, 87.

${ }^{114}$ Anhand jüngster Grabungen ist festzustellen, dass der Köper der Straße G aus Pflastersteinen über zwei Schotterstraten und einer Lage Schutt bestand, jeweils mit Erdschichten dazwischen. Funde indizieren eine Nutzung noch um die Mitte des 3. Jahrhunderts n. Chr. Die Bauzeit der Straße ist ungewiss, allerdings lässt die wenig differenzierte Schichtabfolge eine kurze Nutzungszeit annehmen: LÁNG 2012a, 19-20. 
Erschlossen wird das Stadtzentrum durch den - in seinem Verlauf veränderten - cardo sowie den decumanus maximus (Abb. 10), die offenkundig beide erst in severischer Zeit gepflastert wurden. ${ }^{15}$ Der cardo maximus besaß östlich des Forums nur eine Breite von 4,5 m, im Norden der Forumsinsula war der decumanus maximus 11,7-12 m breit. ${ }^{116}$ Rund 1,1 m unter dem Pflaster des decumanus maximus im Stadtzentrum wurde ein 0,15 m hohes Kiesstratum auf einer mindestens 0,17 m hohen Lehmschicht angetroffen; dieses Schichtpaket markiert ein älteres Straßenniveau. ${ }^{177}$ Funde aus dem Lehmstratum, u. a. süd-/mittelgallische und Rheinzaberner TS, datieren dieses ältere Straßenniveau um die Mitte bzw. in die zweite Hälfte des 2. Jahrhunderts n. Chr.

Auch in der östlichen Zivilstadt lässt sich zeigen, dass nach einer mehrphasigen Nutzung geschotterter Straßenkörper ein Plattenbelag erst in severischer Zeit aufgebracht wurde. ${ }^{118}$ Ist die Breite der Hauptverkehrswege im Zentrum der Colonia Carnuntum mit bis zu $12 \mathrm{~m}$ zu beziffern, so sind 6-7,5 m für die gut ausgebauten, mit Pflasterung und integriertem Leitungssystem versehenen decumani der Randzonen der Stadt dokumentiert. ${ }^{119}$ Zentrumsnah wird ein Wohnviertel durch gepflasterte Straßen und Gassen niederer Ordnung mit Breiten zwischen $2,4-4,1$ m erschlossen. ${ }^{120}$

\section{Wasserversorgung}

Ähnlich wie im Straßenbau sind auch in der Organisation der übergeordneten Frischwasserversorgung Divergenzen zwischen den beiden pannonischen Hauptstädten zu konstatieren. Mit dem Ausbau des Legionslagers wurde nördlich von Aquincum eine Quelle gefasst und ein Aquädukt damit gespeist, der quer durch das Gebiet der Zivilsiedlung gezogen und durch Verteilerleitungen in die städtische Infrastruktur eingebunden wurde (Abb. 14). Es wird von einem Ausbau der Hauptwasserleitung in traianisch-hadrianischer Zeit ausgegangen.

Die Zivilstadt Carnuntum befand sich im Einzugsgebiet mehrerer großer Quellgebiete ( $A b b .14$ ), allerdings erfolgte die Zuleitung von Frischwasser aus diesen suburbanen Regionen durch Leitungen wahrscheinlich erst zur Zeit der severischen Infrastrukturmaßnahmen. Jedenfalls fällt ins Auge, dass die erste öffentliche Badeanlage (Abb. 14; Carnuntum: Nr. 1) hadrianisch-antoninischer Zeit in der ältesten Periode über einen örtlichen Brunnen versorgt wurde.

Aquincum. Der auf Pfeilern errichtete Aquädukt war ein spezielles charakteristisches Element der Stadtstruktur. Das Wasser wurde vom 700 m nördlich der Stadt befindlichen Quellgebiet quer durch die Zivilstadt in Richtung Legionslager im Süden geleitet. Die Brunnenhäuser am nördlichen Ausgangspunkt wurden archäologisch untersucht. Die Pilasterreihe der Bogenkonstruktion des Aquädukts konnte mehrere Kilometer lang dokumentiert werden, bis zur nördlichen Grenze der Canabae legionis. ${ }^{121}$ Aufgrund der im Quellgebiet entdeckten Funde ist von einer Konstruktion der Wasserleitung in traianisch-hadrianischer Zeit auszugehen. Klar ist, dass die Errichtung zeitgleich (oder später) mit dem Bau des permanenten Legionslagers erfolgte. ${ }^{122}$ Eine gepflasterte Gasse säumte die Basis der Pfeilerkonstruktion des Aquädukts innerhalb der Zivilstadt wie auch südlich der Stadtmauer (Abb. 12-14). ${ }^{123}$ Die Gasse wurde im Osten durch eine Tabernenreihe flankiert.

In der Frühphase des Munizipiums war eine Begehung des östlichen und westlichen Teils der Gasse unter den Bögen des Aquädukts möglich. Allerdings konnte diese Kommunikation aufgrund der geschlossenen Gebäudestrukturen nur zu Fuß erfolgen. Die Grabungsergebnisse zeigen, dass Stiegen die Tabernen mit der Gasse verbanden. ${ }^{124}$

Abzweiger des Aquädukts versorgten die westlichen wie östlichen Stadtteile mit Frischwasser. Die Kanalisation wurde parallel verlaufend zu den Frischwasserleitungen errichtet, Abwasser und Regenwasser zur Donau abgeleitet. ${ }^{125}$

${ }^{115}$ Vgl. Region 4: HuMER-KANDLER 2003, 19-20, ,Nordstraße“; der zentral unter der Straßenmitte verlaufende, gemauerte Entwässerungskanal wurde im östlichen Abschnitt bereits in hadrianischer Zeit angelegt.

${ }^{116}$ SCHEdivy 1985, 78; KANDLER 1999, 362; HumerKANDLER 2003, 9-10.

${ }^{117}$ Grabungsbefund: E. Swoboda, 1939.

${ }^{118}$ Humer 2006b, Textbd., 273-274; Humer-Radbauer 2004,42 .

${ }^{119}$ Humer 2006b, Textbd., 273-274, ,Nord- und Südstraße“.
${ }^{120}$ KANDLER 1985, 143, Abb. 1.

${ }^{121}$ Zusammenfassend mit weiterer Literatur: PÓcZY 1972; KABA 1976; Póczy 1980, 53-65.

${ }^{122}$ Laut K. Póczy bildete die Errichtung des Aquädukts eine Grundvoraussetzung für den Bau des permanenten Legionslagers: Póczy 1995, 469.

${ }^{123}$ HAVAS 2005, 52-53.

${ }^{124}$ Póczy 2003a, 148-149.

${ }^{125}$ PÓCZY 1980, 80. 
Aquincum

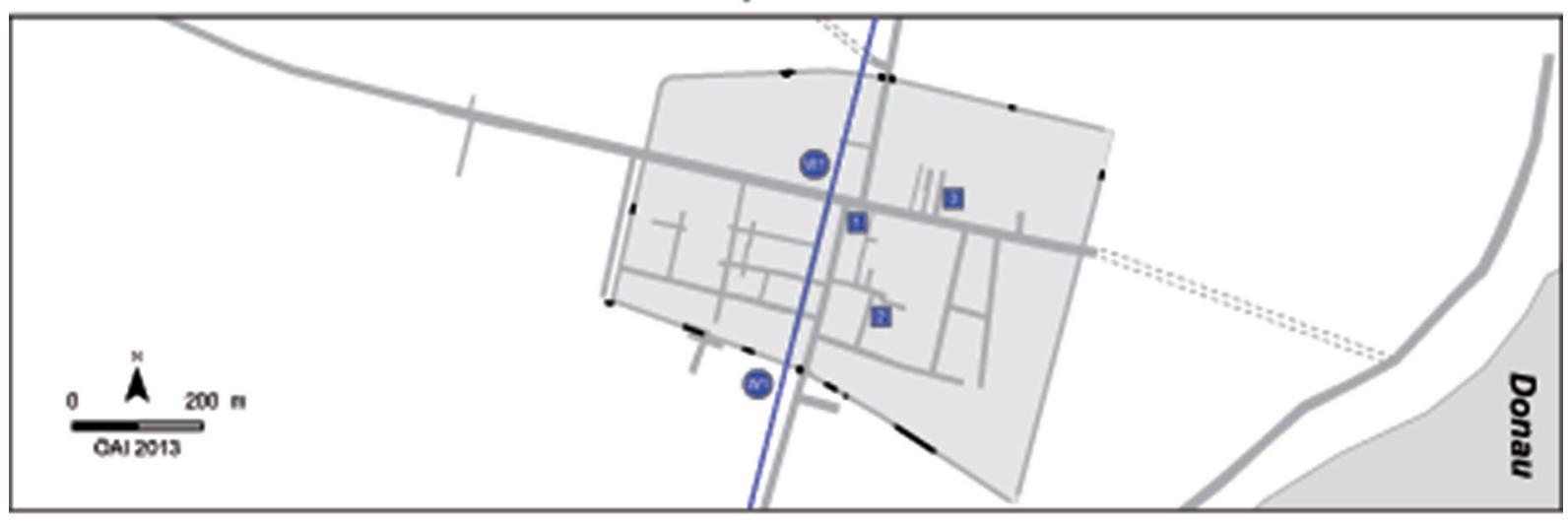

\section{Carnuntum}
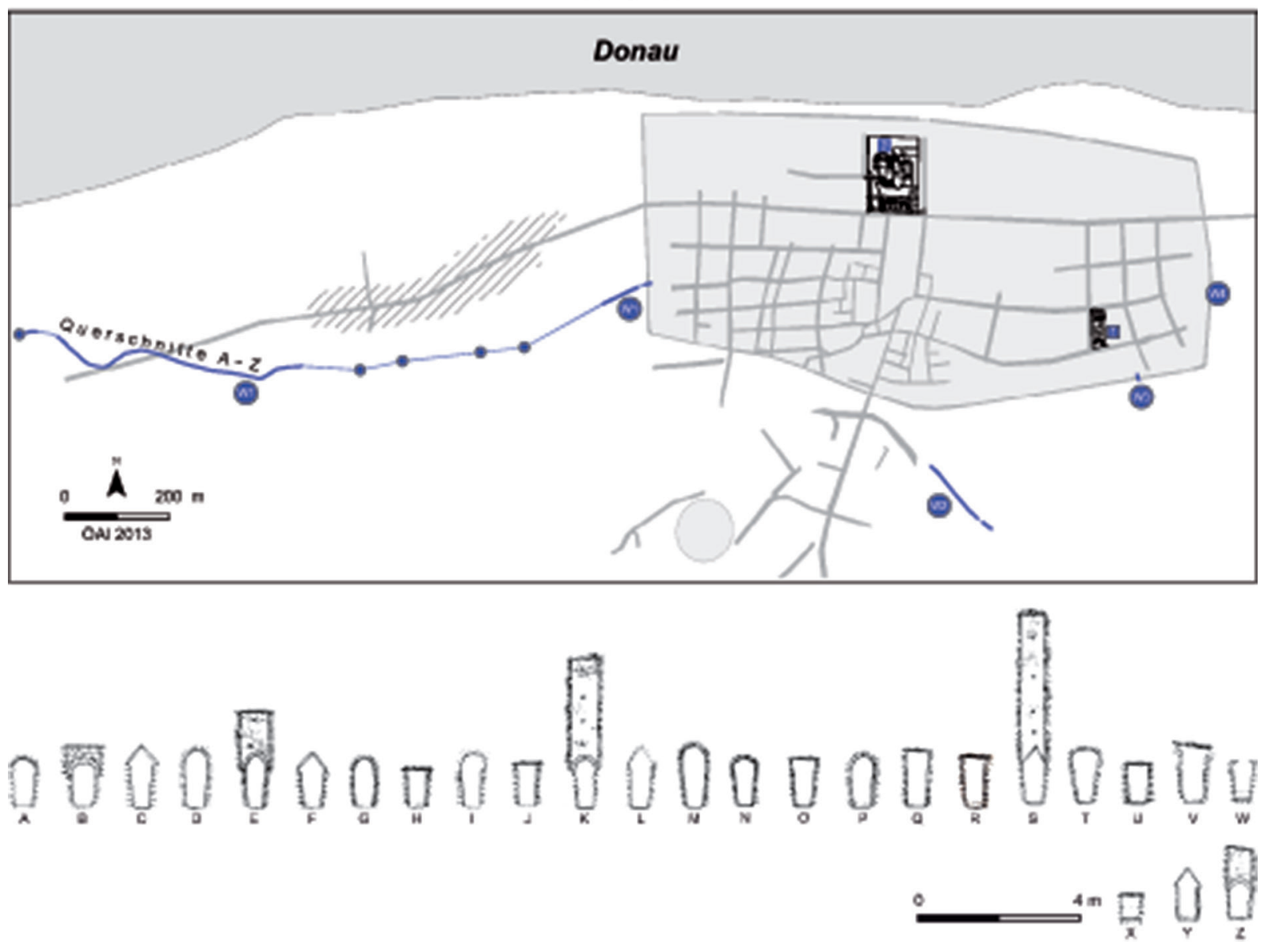

Abb. 14. Wasserversorgung. Aquincum, Verlauf des Aquädukts (W1) und Lage öffentlicher Bäder.

1: Große Thermen; 2: Doppelbad (2. Thermen); 3: Nordbad (3. Thermen). Carnuntum, Wasserleitungen außerhalb der Stadt (W1-W4) und öffentliche Bäder. 1: Thermen in Region 4; 2: Große Thermen im zentralen „Macellum-Thermen-Komplex“. Schnitte der Wasserleitung (W1) westlich von Carnuntum (ÖAI, unter Verwendung von Daten des BHM, der ÖAW und Vorlagen in: HumER-KonECNY 2009, Abb. 33; MASCHEK-HUMER 2009, Abb. 30) 
Die Lage der öffentlichen Bauten in Aquincum ist in Zusammenhang mit der Frischwasserversorgung und der Kanalisation zu sehen; es zeigt sich hier in den zusammenhängend ergrabenen Arealen eine Regelhaftigkeit. Die Verteilung der Thermen (Abb. 14; Aquincum: Nr. 1-3) deutet auf eine bewusste und sorgfältige Stadtplanung. In die frühe Phase des Munizipiums fällt die Errichtung der Großen Thermen, des Nordbads (3. Thermen) und eines suburbanen Badegebäudes nächst dem sog. deversorium (Haus XLI), während der Bestand des sog. Doppelbads (2. Thermen) für diese frühe Phase nur hypothetisch angenommen werden kann. ${ }^{126}$

Neben dem Aquädukt dienten auch Brunnen zur Wasserversorgung innerhalb der Stadt, von denen zahlreiche auch archäologisch untersucht wurden. Fünf sind in der Region 2 bekannt: drei in den Flügeln der sog. basilica (Haus I), nahe dem Stadtzentrum, ${ }^{127}$ einer in der sog. Leimsiederei (Haus XXIX) ${ }^{128}$ und östlich dieser Befunde ein weiterer zwischen Mauerstrukturen. Letzterer setzte sich aus Fassdauben zusammen, die auch Brandzeichen trugen. ${ }^{129}$

Zwei weitere Brunnen sind in der Region 4 belegt. Einer liegt im Hof des collegium-Baus im Handwerksviertel vor ${ }^{130}$ und einer, gleichfalls mit durch Brandzeichen markierten Fassdauben, wurde 1941 im Keller eines antiken Wohnhauses angetroffen, nördlich des sog. Symphorus mithraeum. ${ }^{131}$

Carnuntum. Die Wasserversorgung der Zivilstadt Carnuntum erfolgte aus Quellgebieten im Westen (Flur Gstettenbreite), ${ }^{132}$ Südwesten (Bereich Forellenteich) ${ }^{133}$ und Süden (Flur Johanniswiese) (Abb. 14; Carnuntum: W1-W4). ${ }^{134}$ Unter Berücksichtigung der aktuellen Wasservorkommen im Umfeld von Carnuntum wird deutlich, dass die Situation für eine Versorgung mit Frischwasser sehr günstig ist. Das Gelände der Zivilstadt ist durch ein merkliches Gefälle nach Norden zum Donauabbruch hin gekennzeichnet, von 186 auf 175 m ü. M. Die Quellgebiete liegen im Einzugsgebiet der Donau und sind durch einen Höhenrücken (190 m ü. M, Goldberg) von den nach Süden zu entwässernden getrennt.

Die Siedlungsbefunde im Südosten der Zivilstadt verdeutlichen, dass eine lokale Wasserversorgung durch Hausbrunnen durchgehend vom späten 1. bis in das 3. Jahrhundert n. Chr. erfolgte. ${ }^{135}$ Laut einem Befund (K 36) der „Weststraße“ wurde bereits im frühen 2. Jahrhundert n. Chr. ${ }^{136}$ ein Leitungsstrang in Stein-Ziegelbauweise errichtet, ein großräumig organisiertes übergeordnetes Leitungssystem entstand hingegen erst um $200 \mathrm{n}$. Chr. Die im Verlauf des 2. Jahrhunderts n. Chr. angelegten (Drainage-)Leitungen aus Holz wurden zu diesem Zeitpunkt durch Konstruktionen in Stein ersetzt. ${ }^{137}$ Die noch im 3. Jahrhundert n. Chr. genutzten Hausbrunnen indizieren, dass diese Wasserleitungen nicht auf die Versorgung aller Abnehmer abgestimmt waren, sondern nur auf eine partielle Verteilung des Frischwassers.

Für die Wasserversorgung der Thermen in der Region 4 von Carnuntum (Abb. 14; Carnuntum: Nr. 1) diente in der ältesten Bauperiode späthadrianischer oder antoninischer Zeit ein vor Ort befindlicher Brunnen, der erst im späten 2. Jahrhundert n. Chr. aufgegeben wurde. ${ }^{138} \mathrm{Ab}$ diesem Zeitpunkt wurde die Frischwasserversorgung über ein großräumiges Leitungsnetz organisiert.

Auf dem Bauplatz der in frühseverischer Zeit errichteten Großen Thermen im Zentrum der Zivilstadt (Abb. 14; Carnuntum: Nr. 2) wurde im Zuge der Erbauung des Gebäudes ein lokaler Brunnen aufgegeben. ${ }^{139}$ Das übergeordnete Leitungsnetz für die Versorgung der Großen Thermen ist mit hoher Wahrscheinlichkeit aus zwei

\footnotetext{
${ }^{126}$ Zsidi 2004, 192-194.

${ }^{127}$ Ausgrabung von E. Márity, 1992; die Funktion als Brunnen ist fraglich: LÁNG 2012b, 52.

${ }^{128}$ LÁNG 2007a 122.

${ }^{129}$ PETŐ 1976, 201-205; VADAY 2003, 43-44.

${ }^{130}$ KUZSINSZKY 1934, 44.

${ }^{131}$ VADAY 2003, 44; SZILÁGYI 1945, 456-458.

${ }^{132}$ STIGLitZ 2011, 101-102, Abb. 1-3.

${ }^{133}$ StigLitz 2011, 102, Bereich „Forellenteich“.

${ }^{134}$ Versorgung des Stadtzentrums: HuMER-KonECNY 2009, 426, Abb. 33 (Südost-Nordwest orientierte Wasserleitung, rund 110 m südlich der Stadtmauer); HuMER-KoNECNy 2002, 653-656, Abb. 570 (römische? Quellfassung im Bereich Scharndorfer Weg); SCHEDIVy 1985, 62-90 (zahlreiche antike bis neuzeitliche Leitungsund Kanalstränge). - Versorgung der Zivilstadt Ost (Region 4):
}

Humer-Radbauer 2004, 42, Abb. 4; MascheK-Humer 2009, 419 , Abb. 30 = MASCHEK 2011, 39, Abb. 9, 11-13; JoBST 1996, 151, Abb. $19=$ SAUER 1994,426

135 „Haus IV“: MASCHEK 2010, 29 = MASCHEK-HUMER 2009, 419 (Fassbrunnen, dendrochronologisch ab 93 n. Chr.); „Peristylhaus“: MASCHEK-HUMER 2006, 691; MASCHEK 2008, 162 (Brunnen, 2. Jahrhundert n. Chr.); „Haus V“: KonECNY 2010b, 26 (Brunnen, bis 3. Jahrhundert n. Chr.).

${ }^{136}$ Humer-RAdBAUER 2004, 42, Abb. 3-4.

${ }^{137}$ MASCHEK-Humer 2009, 419, Abb. 30; MASCHEK 2011, 38-39, Abb. 9, 11-13.

\footnotetext{
${ }^{138}$ PACHER-KONECNY 2012, 142.

${ }^{139}$ StigLitz 1969, 11.
} 
Quellgebieten südlich und westlich der Zivilstadt gespeist worden (Abb. 14; Carnuntum: W1-W2). ${ }^{140}$ Gut informiert sind wir über die unterirdische Wasserleitung des westlichen Quellgebiets in der sog. Gstettenbreite, ${ }^{141}$ deren Strang auf einer Länge von rund $550 \mathrm{~m}$ dokumentiert werden konnte und darüber hinaus durch weitere punktuelle Kartierungen oberflächlicher Aufschlüsse erfassbar ist (Abb. 14; Carnuntum: W1). Die durchschnittlich 1,6 m hohe und $0,6 \mathrm{~m}$ breite Sickerleitung ist gewölbt oder dachförmig mit Ziegeln abgedeckt und weist regelmäßig geschichtetes Mauerwerk ohne Verputz auf sowie mehrere Einstiegsschächte (Abb. 14; Carnuntum: unten). ${ }^{142}$ Ein aus dem westlichen Suburbium eventuell als Aquädukt herangeführter Strang dieser Wasserleitung wurde bis zu einem Nebentor der Westflanke der Stadtmauer dokumentiert. Die Substruktion der wahrscheinlich oberirdisch geführten Wasserleitung bestand aus einer 1,8 m breiten und mehr als 1,0 m tief fundamentierten, Südwest-Nordost orientierten Gussmauer, die von schmalen, parallel verlaufenden Mauern jeweils im Abstand von 2 m flankiert war. ${ }^{143}$

Die Position der älteren öffentlichen Bäder dezentral, im östlichen Abschnitt der Zivilstadt dürfte aus der günstigeren Lage in einem Quellgebiet resultieren, ${ }^{144}$ das ohne aufwändige wassertechnische Konstruktionen - wie sie für die Großen Thermen im Zentrum notwendig sein sollten - eine Versorgung garantierte.

\section{Stadtmauer}

Ein Befestigungsgraben umgab die Zivilstadt von Aquincum bereits im 2. Jahrhundert n. Chr. Dieser wurde durch jüngere Grabenstrukturen abgelöst (Abb. 15; Aquincum). Der Bestand des ältesten Grabens zeitgleich mit der in Stein erbauten Stadtmauer wird argumentiert. In Carnuntum ist von einem Ausbau der Stadtmauer in Stein im bislang untersuchten Abschnitt nicht vor dem späten 2. Jahrhundert n. Chr. auszugehen.

Tabelle 3. Durchschnittliche Breite des Stadtgrabens und des Fundaments der in Stein errichteten Stadtmauer

\begin{tabular}{|l|l|c|}
\hline & \multicolumn{1}{|c|}{ Stadtgraben } & \multicolumn{1}{c|}{ Stadtmauer/Fundament } \\
\hline Aquincum & Spitzgraben; maximale Abfolge von 3 Spitzgräben dokumentiert: 3,8-4,5 m & $1,5-2,2 \mathrm{~m}$ \\
\hline \multirow{2}{*}{ Carnuntum } & Spitzgraben: 2-3,7/4 m & $1,7 / 1,85-2,1 / 2,3 \mathrm{~m}$ \\
\cline { 2 - 4 } & Vorgelagerter Abschnittsgraben: $2,6-3 \mathrm{~m}$ & \\
\hline
\end{tabular}

Aquincum. Seit Beginn der archäologischen Untersuchungen in Aquincum war die Stadtmauer von Interesse. Der Verlauf ( $A b b .10, A b b .12)$ ist seit über hundert Jahren bekannt und wurde an mehr als hundert Fundstellen verifiziert. Nichtsdestotrotz sind die Bauphasen und die genaue Struktur noch zu erforschen. Die Bewertung älterer Grabungsunterlagen und zukünftige Grabungen werden mehr Aufschlüsse bieten.

Einigkeit herrscht über die Datierung der Stadtmauer. Dass die älteste Ausbaustufe bereits die munizipale Siedlung befestigte, wird von B. Kuzsinszky, ${ }^{145}$ L. Nagy, ${ }^{146}$ J. Szilágyi ${ }^{147}$ und T. Nagy postuliert. ${ }^{148}$ Die frühe Befestigung wird von L. Nagy auf strategische Gründe zurückgeführt: „die von einer Stadtmauer geschützte Stadt war auch der Garant für eine sichere Benützung der oben genannten Militärstraße (von Óbuda nach Brigetio) am Ausgang des Tals (d. h. des Solymártals)“. ${ }^{149}$ K. Póczy vertrat einen abweichenden Standpunkt. Ihrer Meinung nach wäre die erste Bauperiode später zu datieren, zumal für die Bewohner der Stadt ein Verteidigungssystem nur in der Phase der Markomannenkriege eine Notwendigkeit darstellte. ${ }^{150}$ Aufgrund der Grabungsergebnisse der 1980er Jahre

\footnotetext{
${ }^{140}$ Eine Zuleitung aus dem Quellgebiet im Süden indizieren die Befunde unter dem cardo maximus: Die östliche, annähernd mittig unter der Straße verlaufende Leitung ist als Sammelkanal anzusprechen, die knapp neben den Gebäudefundamenten im Westen verlaufende jedoch als Frischwasserleitung; vgl. SCHEDIvy 1985, 78, Abb. 30.

${ }^{141}$ STigLitz 2011, 101-102, Abb. 5-6.

${ }^{142}$ Ein Parallelbefund liegt am Südrand der Zivilstadt Ost (Region 4) vor: MASCHEK 2011, 38-39, Abb. 11-13 = MASCHEK-HUMER 2009, 419, Abb. 30. - Eine vergleichbare Sickerleitung ist für die Versorgung von Vindonissa konstruiert worden: GrewE 1988, 53, Abb. 4.
}

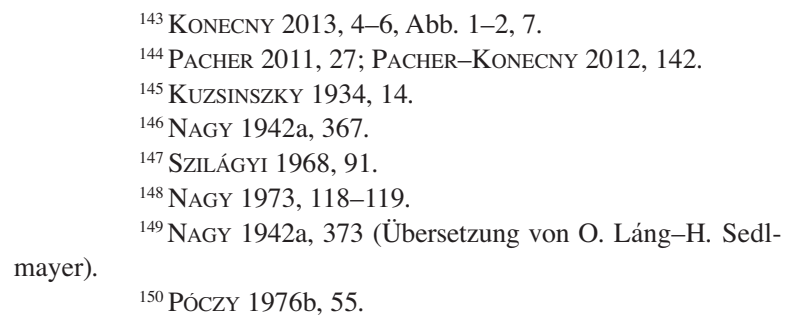




\section{Aquincum}
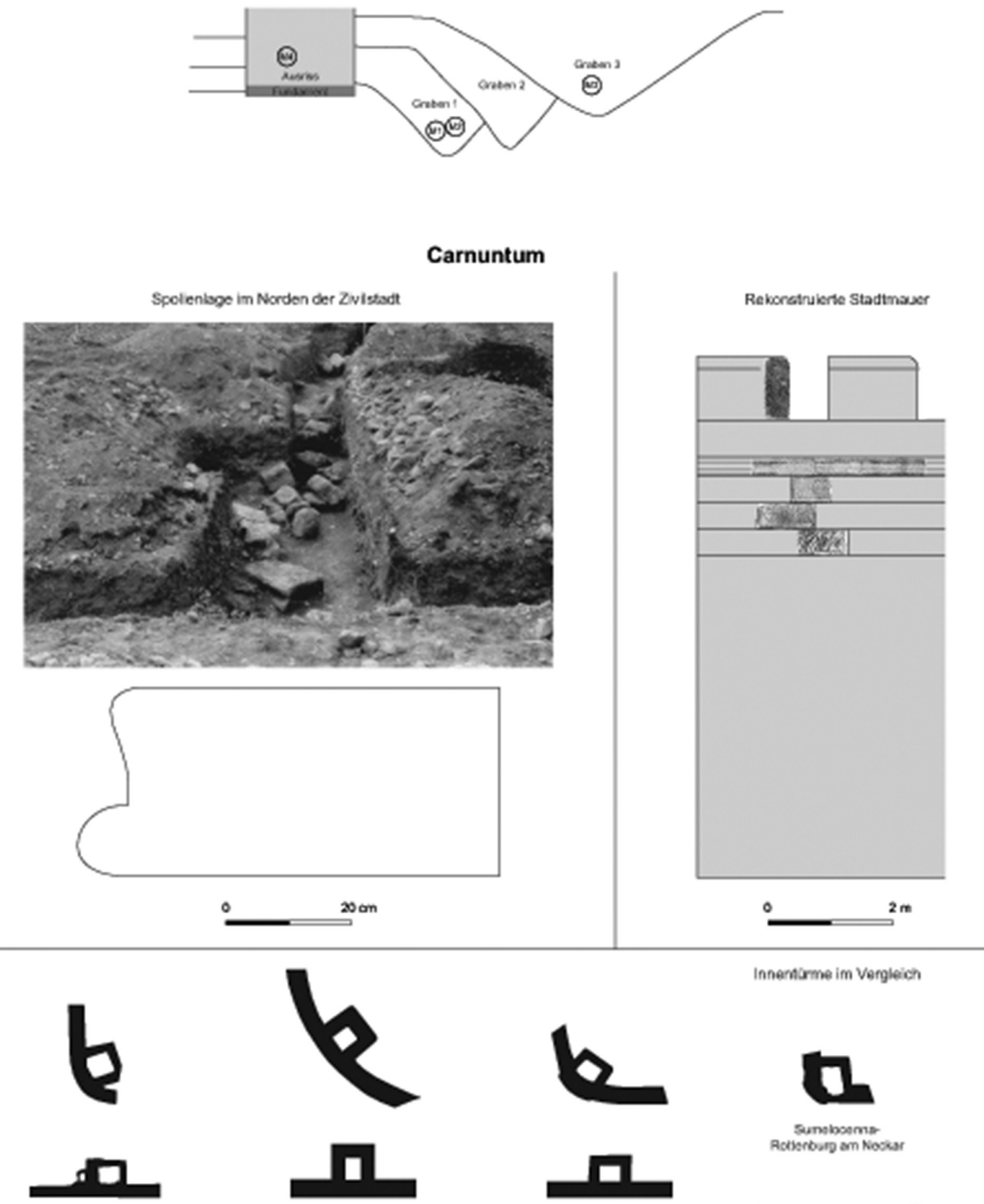

Infernorme im Vargleich

Camuthern-Putranat

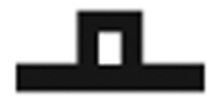

Phoch ine Famiroan
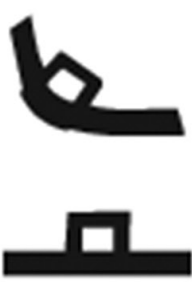

Bad Wimplos

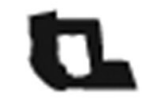

Sunghogms. Actisnoup am Nockar

0 $20 n$

Abb. 15. Stadtmauer. Aquincum: Struktur der Gräben und der bis ins Fundament abgerissenen Stadtmauer.

Die Münzen in den Verfüllschichten: M1 - 1./2. Jahrhundert n. Chr. M2 - Hadrianus; M3 - Constantius II; M4 - Hadrianus.

Carnuntum: Funde und Befunde der Stadtmauer von Carnuntum mit Vergleichsbefunden

(ÖAI, unter Verwendung von Vorlagen in: EingarTnER-Eschbaumer-Weber 1993, Beil. 14; Gairhos 2008, Abb. 65; Koch 1986, Abb. 65;

KoneCNy 2013, Abb. 1; MASCHEK-Humer 2009, Abb. 30; MAScheK 2012, Abb. 3; Zsidi 1990, Abb. 11) 
ließ sie von dieser Argumentation ab und befürwortete gleichfalls eine Errichtung in der ältesten Munizipiumsperiode. ${ }^{151}$ Trotz der starken Zerstörung der Stadtmauer durch Steinraub lieferten die Grabungen der 1980er Jahre Informationen zur ältesten Phase der Mauer, deren Errichtung mit der Verleihung des munizipalen Rangs in Verbindung gebracht wird. ${ }^{152}$

Der älteste Graben (fossa) wurde im Westabschnitt der südlichen Stadtmauer 1986/1990 untersucht, in dem eine kompakte schwarze Verfüllung festgestellt wurde mit einer Münze des Hadrianus und einer nicht näher bestimmbaren Prägung des 1./2. Jahrhunderts n. Chr. als einzigen Funden (Abb. 15; Aquincum). ${ }^{153}$ Am Nordrand dieses älteren Grabens wurde die Mauer in Stein errichtet, der Graben wurde bewusst verfüllt und ein jüngerer Graben wurde in die ältere Struktur eingetieft. ${ }^{154}$ Die Verfüllung des älteren Grabens und die Errichtung der Mauer stehen wahrscheinlich in einem Zusammenhang. Ein Gebäude, das nahe dem südöstlichen Abschnitt der südlichen Stadtmauer gegen Ende des 2. Jahrhunderts n. Chr. errichtet wurde, war in die Verfüllung des Grabens fundamentiert worden. ${ }^{155}$ Stadtmauer und zugehöriger Graben mussten also früher angelegt worden sein.

Die Datierung der Bauperioden der Stadtmauer gestaltet sich schwierig, da diese nicht an allen Seiten die gleiche Struktur aufweist. ${ }^{156}$ Abschnittsweise ist eine unterschiedliche Baugeschichte wahrscheinlich. Die Breite des Fundaments schwankt zwischen 1,5-2,2 m, die des Grabens zwischen 3,8-4,5 m (Tabelle 3). Der Westabschnitt ist besser ausgebaut mit regelmäßigen Zwischen- und runden Ecktürmen. Der lange Abschnitt im Süd- und Nordosten verblieb hingegen ohne Türme. Teile des Grabens wurden jüngst im Osten der Stadt untersucht ${ }^{157}$ und somit kann auch der Verlauf der östlichen Stadtbefestigung komplettiert werden. Bekannt ist die Position des Nord- und Südtores, deren Grundrisse unterschiedlich sind. Die beiden Türme des nördlichen Stadttores sind rechteckig, während die des südlichen rund sind. Das Westtor weist überhaupt nur einen Turm auf und dieser wurde über dem Verlauf der Straße H errichtet.

Carnuntum. Für die Zivilstadt Carnuntum wird postuliert, dass die Stadtmauer um 200 n. Chr. errichtet wurde ${ }^{158}$ und somit in direktem Zusammenhang mit der Erhebung zur Colonia unter Septimius Severus stand. Durch diese - abschnittsweise auch quer durch verbautes Siedlungsgebiet geführte ${ }^{159}$ - Begrenzung des rund 52 ha großen Pomeriums wird deutlich ( $A b b .10, A b b .12)$, dass das geophysikalisch prospektierte Forum tatsächlich die Stadtmitte definierte. Der Verlauf der im Fundamentbereich bis 2,3 m breiten Stadtmauer (Tabelle 3) ist für den West-, Süd- und Ostteil gesichert. ${ }^{160}$ Der in Stein errichteten Mauer war ein Spitzgraben vorgelagert, dem parallel im Vorfeld abschnittsweise ein weiterer Spitzgraben folgte (Tabelle 3). ${ }^{161}$ Ein Innenturm im südöstlichen Abschnitt maß $3 \times 5$ m. ${ }^{162} \mathrm{Im}$ Westabschnitt wurde ein Nebentor von rund $3 \mathrm{~m}$ Weite festgestellt ${ }^{163}$ und unweit davon, in der Südwestecke ein weiterer, innen liegender Turm von $4 \times 5$ m verifiziert. ${ }^{164}$ Vergleichsbefunde innen liegender Ecktürme sind für die Stadtmauern von Sumelocenna-Rottenburg am Neckar, Phoebiana-Faimingen und Bad Wimpfen beizubringen (Abb. 15), deren Errichtung um 200 bzw. im ersten Drittel des 3. Jahrhunderts n. Chr. angenommen wird. ${ }^{165}$ Innentürme, die noch keine Mauervorsprünge aufweisen, sind in vergleichbarer Form an der zwischen 180 und 190 n. Chr. errichteten Befestigung des Legionslagers Lauriacum-Enns festzustellen. ${ }^{166}$

Für die Stadtmauer von Carnuntum ist ausschließlich der Verlauf im Norden unklar. H. Stiglitz meinte in Geländeformationen am Donauabbruch einen Turm der Nordwestecke und den nördlichen West-Ost-Verlauf der Stadtmauer zu erkennen. ${ }^{167}$ Während der Grabungen 1939 wurden 38 lose, 0,3 × 0,68 × 0,9 m große, profilierte

1990, 143-169.

${ }^{151}$ PócZY 1984, 20

${ }^{152}$ Zusammenfassung der Grabungsergebnisse: ZsIDI

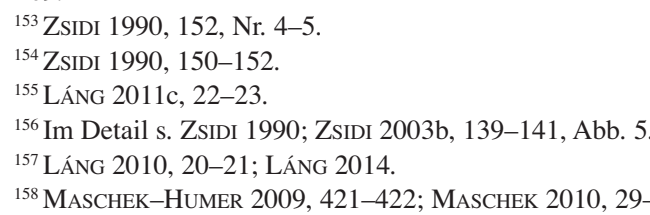

31; PACHER 2009-2011, 175-176. - Eine Vorlage des für die Datierung des Mauerbaus signifikanten Fundmaterials ist noch nicht erfolgt.

${ }^{159}$ KANDLER 2004, 38, Abb. 18.

${ }^{160}$ Süden: ScHEDIVy 1985, 60, Abb.1-2; MASCHEK-HUMER 2009, 421-422, Abb. 30 = MASCHEK 2010, 29-31, Abb. 5; HUMER-
Konecny 2009, 424, Abb. 33; MascheK 2012, 289-293. Westen: SCHEDIVy 1985, 95, 115, Abb. 52-53; KonECNy 2013, 4-6, Abb. 1 und 8. Osten: PACHER 2009-2011, 173-178. 2012,290

${ }^{161}$ Humer-Konecny 2009, 424, Abb. 33; MAscheK

${ }^{162}$ MascheK-Humer 2009, Abb. 30.

${ }^{163}$ KANDLER 2004, 38.

${ }^{164}$ KoneCNy 2013, 4-6, Abb. 1, 4, 8.

$1995,443-444$

${ }^{165}$ Gairhos 2008, 102-103, 109-110, Abb. 65; Weber 313 mit Abb

${ }^{166}$ Lauriacum-Enns, vor 191 n. Chr.: PeTROvitsch 2006,

${ }^{167}$ STIGLITZ 1987, 3-4. 
Quadersteine 16,5 m nördlich der Umfassungsmauer des „Macellum-Thermen-Komplexes“ dokumentiert (Abb. 15). ${ }^{168}$ Vergleichbare Stücke konnten bei einer Begehung des Jahres 2007 unter dem Donauabbruch im Bereich der aufgegebenen neuzeitlichen Mühle verifiziert werden. Ein Zusammenhang dieser Spolien mit der Nordflanke der Stadtmauer könnte postuliert werden, zumal Quadersteine mit vergleichbaren Profilierungen aufgrund archäologischer Evidenzen gesichert der Südflanke zuzuordnen sind. ${ }^{169}$ D. Maschek erstellte eine Rekonstruktion des Aufgehenden der südlichen Befestigung mit einer Zone profilierter Gesimsblöcke (Höhe: 0,3 m, Breite: 1,1$1,2 \mathrm{~m})$ unter dem zinnenbewehrten Wehrgang $(A b b .15) .{ }^{170}$

\section{Amphitheater}

Die Errichtung der Amphitheater in den Zivilstädten von Aquincum und Carnuntum dürfte spätestens in die zweite Hälfte des 2. Jahrhunderts n. Chr. fallen. ${ }^{171}$ Die beiden Amphitheater von Aquincum werden mit einer spitz zulaufenden elliptischen Arena gebaut; jene in Carnuntum besitzen langrechteckige Arenen mit annähernd halbrundem Abschluss. Sie entsprechen dem Typ des Amphitheaters ,,a structure pleine“ mit „,avea supporté par des remplais compartimentés". ${ }^{172}$

Obgleich jeweils demselben Bautyp zuzuordnen, unterscheiden sich die Amphitheater der Zivilstädte von Aquincum und Carnuntum deutlich hinsichtlich ihrer Größe. Dabei fällt auf, dass in Aquincum für die Zivilstadt ein kleineres Amphitheater (5060 $\mathrm{m}^{2}$ Grundfläche) geplant wurde, für die Canabae hingegen ein deutlich größeres mit $10390 \mathrm{~m}^{2}$ (Abb. 16, Tabelle 4). ${ }^{173}$ In Carnuntum ist das Verhältnis genau umgekehrt. Hier besitzt die Zivilstadt das deutlich monumentalere Bauwerk mit $9770 \mathrm{~m}^{2}$ Grundfläche, im Vergleich zu dem (nur) $7060 \mathrm{~m}^{2}$ messenden Amphitheater der Canabae.

Tabelle 4. Größenvergleich der Amphitheater und Siedlungsareale der Zivilstädte und Canabae von Aquincum und Carnuntum (Werte gerundet)

\begin{tabular}{|c|c|c|c|c|}
\hline & $\begin{array}{l}\text { Amphitheater: } \\
\text { Fläche }\left(\mathbf{m}^{2}\right)\end{array}$ & $\begin{array}{c}\text { Siedlung: } \\
\text { Fläche }\left(\mathbf{m}^{2}\right)\end{array}$ & $\begin{array}{c}\text { Amphitheater/Siedlung- } \\
\text { Verhältnis }\end{array}$ & Anzahl der Plätze \\
\hline Aquincum Zivilstadt & 5060 & 330390 & $1: 65$ & 8617 \\
\hline Aquincum Canabae & 10390 & 1740000 & $1: 167$ & 16049 \\
\hline Carnuntum Zivilstadt & 9770 & 516740 & $1: 53$ & 18449 \\
\hline Carnuntum Canabae & 7060 & 1200000 & $1: 170$ & 8343 \\
\hline
\end{tabular}

Stellt man eine Beziehung zwischen den Flächen der Amphitheater und jenen der korrespondierenden Siedlungsareale her, so zeigt sich, dass die beiden Amphitheater der Zivilstädte und jene der Canabae in einem annähernd regelhaften Verhältnis zur Siedlungsfläche stehen: In den Zivilstädten beträgt dieses Verhältnis (intra muros) 1:53 in Carnuntum und 1:65 in Aquincum sowie in den Canabae 1:167 in Aquincum und 1:170 in Carnuntum (Tabelle 4). Die Anzahl der Sitzplätze ist in den kleinen Amphitheatern annähernd gleich und variiert bei den großen um ca. 1500 Plätze. ${ }^{174}$ Für die Zivilstadt von Carnuntum ist demnach offensichtlich als Zentralort mit einem sehr großen Besucherzustrom zu rechnen, was auch durch den Neufund einer in $80 \mathrm{~m}$ Entfernung zum Amphitheater

${ }^{168}$ Unpubliziert; Informationen aus Grabungstagebüchern von E. Swoboda zum 3. 5. 1939 und 8. 5. 1939.

${ }^{169}$ Die einheitliche Höhe von 0,3 m der Blöcke aus den Suchgräben a-d nördlich des „Macellum-Thermen-Komplexes“ entspricht dem Maß der Profilsteine aus den Grabungen im Abschnitt der südlichen Stadtmauer: MASCHEK 2012, 291, Abb. 3-4. - Zu Ansammlungen von Bausteinen einer Stadtmauer, so beispielsweise Gesimsplatten in der Verfüllung eines Wehrgrabens in Sumelocenna-Rottenburg am Neckar, s. GAIRHOS 2008, 97, Abb. 61.

${ }^{170}$ MAscheK 2012, 291, Abb. 3-4.

${ }^{171}$ Golvin 1988, 136-138, Nr. 123, 125; LÁNG 2011b, 32; Beutler 2013, 32. Zum Amphitheater in den Canabae von Carnun- tum: BoulasiKIS 2008 datiert die Umbauphase des ersten hölzernen Amphitheaters in Stein in den Canabae von Carnuntum in die zweite Hälfte des 2. Jahrhunderts n. Chr., wohingegen BEUTLER 2013, 32-33 und Gugl 2013, 164 den Bau eines Amphitheaters in Steinbauweise in flavische Zeit stellen.

${ }^{172}$ Golvin 1988, 109.

48, Abb. 17.

${ }^{173}$ Zur Größe der Canabae von Aquincum: NÉMETH 2010 ,

${ }^{174}$ Golvin 1988, 268, Tab. 29

${ }^{175}$ Neubauer 2012, 22-27. 


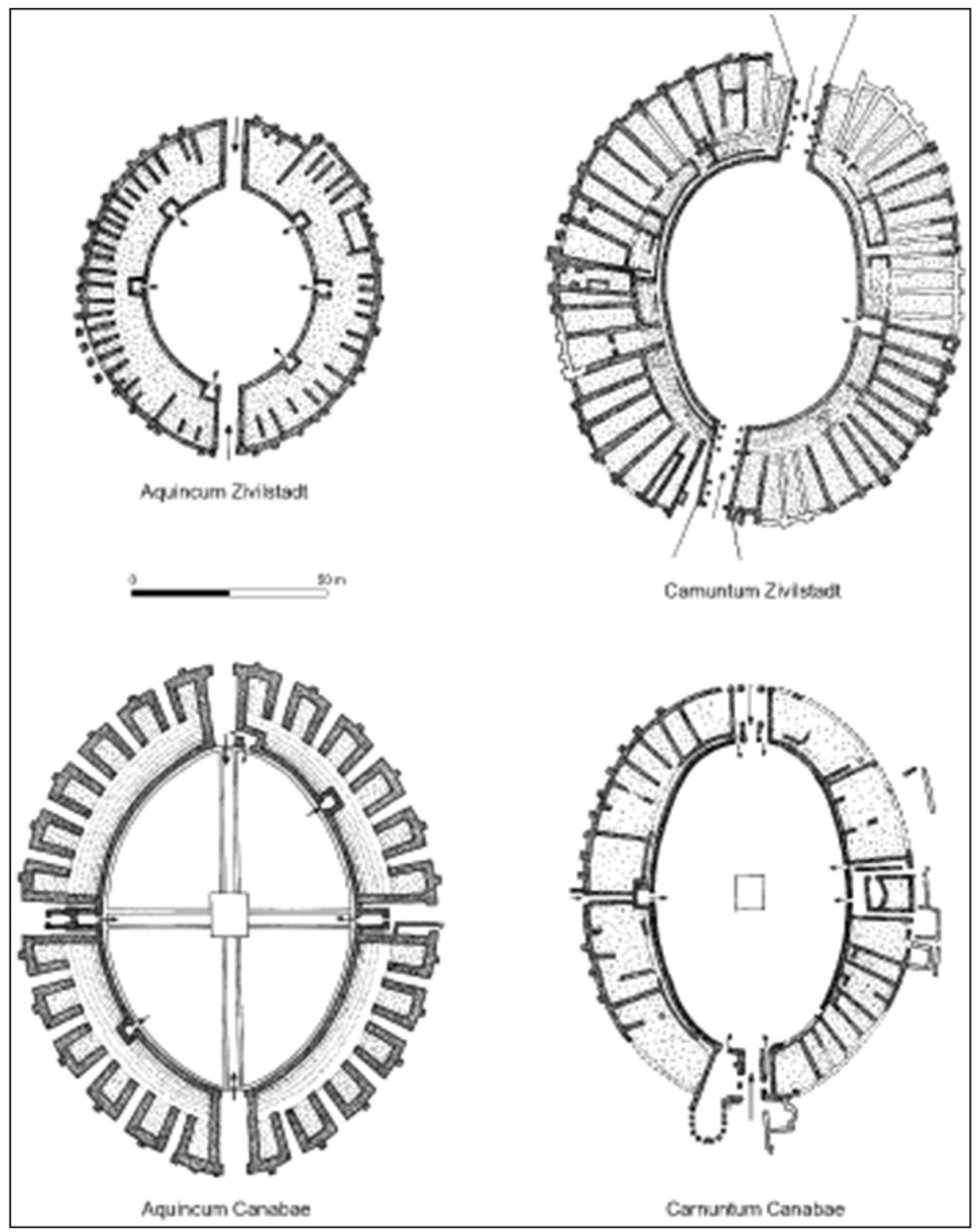

Abb. 16. Amphitheater der Zivilstädte und Canabae von Aquincum und Carnuntum (ÖAI, unter Verwendung von Vorlagen in: Golvin 1988, Taf. 14. 4-6, 8)

gelegenen Gladiatorenschule erklärt werden könnte. ${ }^{175}$ Die in Bezug zur Siedlungsfläche relative Kleinheit der Amphitheater in den Canabae kann vielleicht mit beschränktem Zugang von nur Teilen der Bevölkerung zu den Spielen erklärt werden, wohingegen die zivilen Amphitheater ein weiteres Einzugsgebiet zu versorgen hatten. Das zur Zivilstadt von Carnuntum in ca. 50 km Entfernung nächst gelegene, zivile Amphitheater ist jenes des Munizipiums Scarbantia-Sopron. ${ }^{176}$

Aquincum. Das Amphitheater der Zivilstadt Aquincum wurde außerhalb und zugleich nahe der Stadtbefestigung errichtet $(A b b .4, A b b$. 16). Die Längsachse entsprach weder der Ausrichtung der Stadtmauer noch jener

${ }^{176}$ GÖMÖRI 1994, 251-261; GROH 2005, 95-96, Abb. 11. 
des Straßensystems. L. Nagy erklärte diese Abweichung aus der westlichen Biegung der Straße, die durch das nördliche Stadttor führte und deren Orientierung sich in der Achse des Amphitheaters widerspiegelt. ${ }^{177}$ Die Errichtung des Amphitheaters in Stein ist in die Zeit des Antoninus Pius zu datieren, basierend auf einem epigraphischen Indiz aus dem an der Westseite befindlichen Nemesisheiligtum. ${ }^{178}$ Eine Inschrift des Jahres $162 \mathrm{n}$. Chr. überliefert, ${ }^{179}$ dass M. Ulpius Zosimus der Göttin einen Altar stiftete, und lässt darauf schließen, dass zu diesem Zeitpunkt das Heiligtum bereits existierte. Zumal auch das Militäramphitheater aufgrund einer Bauinschrift von $145 \mathrm{n}$. Chr. in die Regierungszeit des Antoninus Pius datiert, ${ }^{180}$ kann davon ausgegangen werden, dass die beiden Amphitheater von Aquincum zeitgleich entstanden. Eine weitere, Nemesis gewidmete Inschrift belegt, dass das Heiligtum des zivilen Amphitheaters 259 n. Chr. noch existierte. ${ }^{181}$

Die zeitgleiche Entstehung bedingte aber keine übereinstimmende Bauqualität. Das Amphitheater der Zivilstadt war einfacher und von geringerem Aufwand in der Struktur. Die Radialmauern waren unregelmäßig errichtet und Stiegenaufgänge auf einer außen angebrachten Rampe führten zu den Sitzplätzen. Steinbänke waren unmittelbar auf einer Erdanschüttung installiert; einige der Blöcke tragen die Namen der Inhaber der Sitzplätze. Das östliche Tor stellte die porta pompae dar, die mit der durch das nördliche Stadttor geführten Straße kommunizierte. Die porta Libitinae befand sich an der Westseite des Gebäudes.

Die gegenüber dem Westeingang in einem großen eingezäunten Areal positionierten Bauten werden als Unterkünfte der Gladiatoren und Trainingsareal bestimmt. ${ }^{182}$ Der Gebäudekomplex liegt $20-25 \mathrm{~m}$ westlich des Amphitheaters und hatte eine Ausdehnung Nord-Süd von annähernd $100 \mathrm{~m}$ und Ost-West von $150 \mathrm{~m}$. Die Westbegrenzung wurde bislang nicht gefunden. Ein rechteckiges Fundament in der Mitte des Hofs wurde von L. Nagy als Turm interpretiert. Der östliche Zugang des Areals lag unmittelbar gegenüber dem westlichen Eingang des Amphitheaters. Über die Gebäude im Inneren des Komplexes liegen keine genaueren Informationen vor, allerdings lassen schmale, ergrabene Mauerzüge auf eine partielle Verbauung schließen. Aufgrund einer jüngst formulierten Forschungsmeinung wird, basierend auf Inschriften und topografischen Parallelen, das Zentrum des Kaiserkults der Provinz Unterpannonien in Aquincum, und zwar in diesem weitläufigen Areal mit rechteckiger, in der Mitte gelegener Baustruktur postuliert, direkt neben dem zivilstädtischen Amphitheater. ${ }^{183}$

\section{LITERATUR}

ALFÖLDI et al. 1942

ALTEKAMP-SCHÄFER 2001

BAIER 2008

BESZÉDES 2011

BEUTLER 2013

BIRÓ 2009

BORHY 2013

BOULASIKIS 2008

CENCIC 2003

DILKE 1991

Doneus 2013
= A. ALFÖLDI-L. NAGY-Gy. LÁsZló (Hrsg.): Budapest története [Geschichte von Budapest] I-II. Budapest 1942.

$=\mathrm{S}$. AlteKAMP-A. SCHÄFER (Hrsg.): The Impact of Rome on the Settlements in the Northwestern and Danube Provinces. BAR IntSer 921. Oxford 2001.

$=$ CH. BAIER: Frühe Baubefunde im Areal von Haus II der Zivilstadt Carnuntum. In: GrabHERR-KaINRATH 2008, 27-36.

= J. BESZÉDES: Az albertfalvi római tábor és település kutatásának eredményei Nagy Tibor tevékenysége után (Ausgrabungsergebnisse von dem römischen Lager und der Siedlung in Albertfalva nach der Tätigkeit von Tibor Nagy). BudRég 44 (2011) 58-74.

= F. BEUTLER: Die zwei Amphitheater von Carnuntum und deren Datierung. In: ECK-FeHÉR-KovÁCS 2013, 19-37.

= Sz. BIRÓ (Hrsg.): Ex Officina...Studia in honorem Dénes Gabler. Győr 2009.

$=$ L. BoRHY: Amphitheatralia Pannonica I. Die sog. Bauinschrift des Militäramphitheaters von Aquincum. In: ECK-FEHÉR-KovÁcs 2013, 51-58.

= D. BoulASIKIs: Neue Grabungen am Nemeseum des Amphitheaters I von Carnuntum. Forum Archaeologiae 46/III/2008 (http://farch.net) (Zugriff: 12. 6. 2013).

= J. CENCIC: Römische Wohnbauten in Carnuntum. CarnuntumJb 2003, 9-116.

= O. A. W. DiLKE: Mathematik, Maße und Gewichte in der Antike. Stuttgart 1991.

= M. Doneus: Luftbildarchäologische Datenherstellung in Carnuntum. In: Doneus-GugL-Doneus 2013, 20-28.

\footnotetext{
${ }^{177}$ NAGY 1942a, 370.

${ }^{178}$ TORMA 1881, 82; SZILÁGYI 1968, 127-128; NAGY 1973, 119; PócZy 1976b, 42.

${ }^{179}$ CIL III 10441.
}

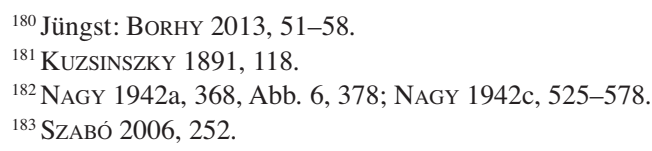

${ }^{180}$ Jüngst: BORHY 2013, 51-58.

${ }^{182}$ NAGY 1942a, 368, Abb. 6, 378; NAGY 1942c, 525-578.

${ }^{183}$ SZABó 2006, 252. 
Doneus-GugL-Doneus 2013

DRURY 1982

ECK-FEHÉR-KOVÁCS 2013

EINGARTNER-ESCHBAUMER-WEBER 1993

FILGIS 2001

GABLER 1977

GAIRHOS 2008

GoLvIN 1988

GÖMÖRI 1994

GRABHERR-KAINRATH 2008

GREWE 1988

GROH 2005

GROH 2009

GROH 2013

GUGL 2012

GUGL 2013

HaVAS 2005

HUMER 2006a

HUMER 2006b

HUMER-KANDLER 2003

HUMER-KONECNY 2002

HUMER-KONECNY 2009

HUMER-KONECNY 2011

HUMER-KONECNY-MASCHEK 2004

HUMER-RADBAUER 2004

JoBST 1996

JOBST-RUDOLF 1987

KABA 1976

KANDLER 1985

KANDLER 1999

KANDLER 2000
= M. Doneus-Ch. Gugl-N. Doneus: Die Canabae von Carnuntum - eine Modellstudie der Erforschung römischer Lagervorstädte. RLiÖ 47. Wien 2013.

$=$ P. J. DRURY: Form, function and the interpretation of the excavated plans of some large secular Romano-British buildings. In: P. J. Drury (ed.): Structural Reconstruction. Approaches to the Interpretation of the Excavated Remains of the Buildings. BAR British Ser. 110. Oxford 1982, 289-308.

= W. ECK-B. FeHÉR-P. KovÁcs (Hrsg.): Studia Epigraphica in memoriam Géza Alföldy. Bonn 2013.

J. EINGARTNER-P. EschbaUmeR-G. Weber: Faimingen-Phoebiana I. Der römische Tempelbezirk in Faimingen-Phoebiana. Limesforschungen 24. Mainz am Rhein 1993.

= M. N. FILGIS: Ausgewählte Baubefunde des Handwerks und Gewerbes im römischen Vicus von Wimpfen. In: ALTEKAMP-SCHÄFER 2001, 19-37.

= D. GABLER: A dunai limes I-II. századi történetének néhány kérdése (Some remarks on the history of the Danubian limes of the first and second century). ArchÉrt 104 (1977) 145-175.

= S. GAIRHos: Stadtmauer und Tempelbezirk von Svmelocenna. FBBW 104. Stuttgart 2008.

= J. CL. Golvin: L'amphithéâtre romain. Paris 1988.

= J. GÖMÖRI: Recent archaeological finds concerning the topography of Scarbantia. In: G. Hajnóczi (Hrsg.): La Pannonia e l'impero romano. Annuario dell'accademia d'Ungheria. Rom 1994, 251-261.

= G. GRABHERR-B. KAINRATH (Hrsg.): Akten des 11. Österreichischen Archäologentages in Innsbruck. 23.-25. März 2006. Innsbruck 2008.

= K. GREwE: Römische Wasserleitungen nördlich der Alpen. In: Frontinus-Gesellschaft (Hrsg.): Die Wasserversorgung antiker Städte. Geschichte der Wasserversorgung 3. Mainz am Rhein 1988, 43-97.

= ST. GroH: Amphitheater in Noricum. ÖJh 74 (2005) 85-129.

$=$ ST. GroH: Neue Forschungen an der Bernsteinstraße in Nordwestpannonien - Die römischen Militärlager und der Vicus von Strebersdorf und Frankenau/Frakanava (Mittelburgenland, Österreich). In: BIRÓ 2009, 175-188.

= ST. GroH: Die Infrastruktur der Bernsteinstraße in Pannonien. In: St. Groh-H. Sedlmayer-Cs. V. Zalka: Die Straßenstationen von Nemescsó und Sorokpolány an der Bernsteinstraße (Pannonien, Ungarn). ZEA 3. Wien 2013, 173-184.

= CH. GUGL: Leugengrenzen und juristischer Status von canabae-Siedlungen. In: REINHOLDT-WOHLMAYR 2012, 413-420.

= CH. Gugl: Die Carnuntiner canabae - Luftbilder und Grabungsbefunde im Vergleich. Die Carnuntiner Canabae - Ein Modell für römische Lagervorstädte? In: DonEUs-GuGL-DonEus 2013, 41-215.

= Z. Havas: Az aquincumi aquaeductus új aspektusai (New approach to the aqueduct of Aquincum). BudRég 39 (2005) 51-70.

= F. Humer (Hrsg.): Legionsadler und Druidenstab. Katalog zur Sonderausstellung »2000 Jahre Carnuntum«. Katalog des Niederösterreichischen Landesmuseums N. F. 462. Text- und Katalogbd. St. Pölten 2006.

= F. Humer: Die Entstehung des Municipium Aelium Karnuntum. In: HumER 2006a, Textbd., 270-279.

= F. HuMER-M. KANLDER: Carnuntum. AÖ 14/1 (2003) 4-27.

= F. HuMer-A. L. Konecny: Petronell. FÖ 41 (2002) 653-661.

= F. Humer-A. KonECNY: Petronell. FÖ 48 (2009) 422-426.

= F. Humer-A. Konecny (Hrsg.): Römische Thermen. Akten des internationalen Kolloquiums. Archäologischer Park Carnuntum und Gesellschaft der Freunde Carnuntums. 17.-18. 9. 2009. Kulturfabrik Hainburg. Hainburg 2011.

= F. Humer-A. KoneCNY-D. MascheK: Zivilstadt Carnuntum - Haus I. CarnuntumJb 2004, 89-177.

= F. HuMER-S. RADBAUER: Die Ausgrabungen an der Weststraße in der Zivilstadt von Carnuntum. AÖ $15 / 2(2004) 40-44$

= W. JoBst: Archäologischer Park Carnuntum. Tätigkeitsbericht 1994. CarnuntumJb 1995 (1996) $123-152$.

= W. Jobst-E. Rudolf: Die Ausgrabung. In: W. Jobst-E. Rudolf-A. Dinstl-D. Gabler-K. KnibbeA. Rauchenwald: Carnuntum - Zivilstadt 1986-87. CarnuntumJb 1987 (1988) 151-240.

= M. KABA: Az aquincumi aquaeductus pilléreinek 1975. évi kutatása (elözetes jelentés) (The 1975 excavations of the Piers of the aqueduct at Aquincum. Preliminary report). BudRég 24 (1976) 225-230.

= M. KAndLER: Das Heiligtum des Silvanus und der Quadriviae im Petroneller Tiergarten. ÖJh 56 (1985) 143-168.

= M. Kandler: Das Forum der Colonia Carnuntum. In: P. Scherrer-H. Taeuber-H. Thür (Hrsg.) Steine und Wege. FS Dieter Knibbe. SoSchr ÖAI 32. Wien 1999, 359-368.

= M. KAndLER: Zur Bautätigkeit in Carnuntum unter den Severern. In: J. Bouzek-H. FriesingerK. Pieta-B. Komoróczy (Hrsg.): Gentes, Reges und Rom. FS Jaroslav Tejral. Spisy Archeologického Ústavu AV ČR Brno 16. Brünn 2000, 43-52. 
KANDLER 2004

KANDLER et al. 2006

КосH 1986

KoneCNy 2008

KONECNY 2010a

KONECNY 2010b

KONECNY 2011

KONECNY 2013

KORTÜM 2005

KovÁCS 1997-1998

KovÁCs 1999

KRONBERGER 2009

KUZSINSZKY 1890

KUZSINSZKY 1891

KUZSINSZKY 1934

LÁNG 2005

LÁNG 2007a

LÁNG 2007b

LÁNG 2009a

LÁNG 2009b

LÁNG 2010

LÁNG 2011a

LÁNG 2011b

LÁNG 2011c

LÁNG 2012a

LÁNG 2012b

LÁNG 2013a

LÁNG 2013b
= M. KAndler (mit Beiträgen von F. Humer und H. ZABehlicky): Carnuntum. In: M. Šašel Kos-P. Scherrer (Hrsg.): Die autonomen Städte in Noricum und Pannonien. Pannonia 2. Situla 42. Ljubljana 2004, 11-66.

= M. Kandler-A. Eder-Hinterleitner-K. Löcker-W. Neubauer-P. Melichar-S. S. Seren: Das unsichtbare Forum In: HuMER 2006a, Textbd., 280-286.

= R. Koсн: Bad Wimpfen im Tal. In: Ph. Filtzinger-D. Planck-B. Cämmerer (Hrsg.): Die Römer in Baden-Württemberg. Stuttgart-Aalen 1986, 217-221.

= A. KonECNY: Untersuchungen im so genannten „Valetudinarium“ in der Zivilstadt von Carnuntum. AÖ 19/2 (2008) 28-29.

= A. KoneCnY: Untersuchung im Bereich des projektierten Parkplatzes am westlichen Ortsrand von Petronell-Carnuntum: die Kampagne 2009. AÖ 21/1 (2010) 31-32.

= A. Konecny: Die Arbeiten in Haus V und auf der Südstraße in der Zivilstadt Carnuntum 2009 und 2010. AÖ 21/2 (2010) 25-27.

= A. KonECnY: Die Thermenanlage im Freilichtmuseum »Spaziergarten « in der Zivilstadt Carnuntum. In: HUMER-KONECNY 2011, 11-21.

= A. Konecny: Neues aus der Zivilstadt Carnuntum. Acta Carnuntina 3/1 (2013) 4-9.

= K. KoRTüM: Städte und kleinstädtische Siedlungen. In: Archäologisches Landesmuseum BadenWürttemberg (Hrsg.): Imperium Romanum. Katalog der Ausstellung des Landes Baden-Württemberg im Kunstgebäude Stuttgart. 1. Oktober 2005-8. Januar 2006. Stuttgart 2005, 154-164.

= P. KovÁcs: Civitas Eraviscorum. Antaeus 24 (1997-1998) 278-295.

= P. KovÁcs: Vicus és castellum kapcsolata az alsó-pannoniai limes mentén [Die Verbindung zwischen vicus und castellum am unterpannonischen Limes]. Studia classica 1. Piliscsaba 1999.

= M. KRONBERGER: Vindobona, das römische Wien. Wien 2009.

= B. KuZSINSZKY: Az aquincumi ásatások, 1881-1884 és 1889 [Ausgrabungen in Aquincum]. BudRég 2 (1890) 75-160.

= B. KUZSINSZKY: Az aquincumi amfiteátrum [Das Amphitheater von Aquincum]. BudRég 3 (1891) 81-122.

= V. KuZSINSZKY: Ausgrabungen und Funde. Budapest 1934.

= O. LÁNG: A „Peristyl-ház”: hitelesítő feltárás az aquincumi polgárváros északkeleti részén (The "Peristyle house": authenticating excavation in the Northeast part of the Aquincum Civil Town). AqFüz 11 (2005) 68-80.

= O. LÁNG: „Átriumos hosszúház - lakótraktus”: hitelesítő feltárás az aquincumi polgárváros északkeleti részén II ("Strip house with an atrium-residence wing": authentication excavation in the northeastern part of the Aquincum Civil Town II). AqFüz 13 (2007) 117-128.

= O. T. LÁNG: Did the Cosinii build macella ? The possible builder of the macellum in Aquincum. In: M. Mayer-G. Baratta-A. Guzmán Almagro (Hrsg.): Acta XII congressvs internationalis epigraphiae graecae et latinae. Barcelona, 3-8 September 2002. Barcelona 2007, 817-830.

= O. LÁNG: "Unpleasant to live, yet it makes the city rich": Functions of strip-buildings in the Aquincum Civil Town in the light of new discoveries. In: BIRÓ 2009, 271-286.

= O. LÁNG: Gazdagon díszített épület az aquincumi polgárváros nyugati részén (Richly decorated building in the western part of the Civil Town of Aquincum). AqFüz 15 (2009) 18-29.

= O. LÁNG: Feltárások az aquincumi polgárváros keleti határán (Excavations on the eastern edge of the Civil Town of Aquincum). AqFüz 16 (2010) 19-24.

= O. LÁNG: Indigenous sanctuary in the northeastern zone of the Aquincum Civil Town - was it ever there at all? In: I. Lazar (Hrsg.): Akten des 4. Internationalen Symposiums über römische Städte in Noricum und Pannonien. Koper 2011, 143-156.

= O. LÁNG: The civilian Town of Aquincum. In: Zs. Visy (ed.): Romans on the Danube. Pécs 2011, 29-36.

= O. LÁNG: Hitelesítő ásatás az ún. Festőház és környezetének területén, az aquincumi polgárváros déli városfalánál (Control excavation on the territory of the so-called Painter's House and its surroundings by the southern town wall of Aquincum Civil Town). AqFüz 17 (2011) 18-35.

= O. LÁNG: Új eredmények az aquincumi polgárváros délkeleti régiójának kutatásában - az úgynevezett Festőház és közvetlen környezete (New results in research on the southeastern part of the Civil Town in Aquincum - the so-called "Painter's House" and its surrounds). AqFüz 18 (2012) 17-36.

= O. LÁNG: Urbanistic Problems in the Civil Town of Aquincum. The so-called "Northern stripe". [Unpubl. Diss. Eötvös Lorand Universität.] Budapest 2012.

= O. LÁNG: Is it the basilica? New data on building no. I in the Aquincum Civil Town. CarnuntumJb 2014, 99-115.

= O. LÁNG: The rise and fall of a riverside building: New data on the Aquincum segment of the limes. BudRég 46 (2013) 117-127. 
LÁNG 2013c

LÁNG 2014

LASSÁNYI 2005

LASSÁNYI 2013

LASSÁNYI-BECHTOLD 2006

MADARASSY 1991

MÁRITY 1992

MASCHEK 2008

MASCHEK 2010

MASCHEK 2011

MASCHEK 2012

MASCHEK-HUMER 2006

MASCHEK-HUMER 2009

MOSSER et al. 2011

MÜLLER-MADER et al. 2011

NAGY 1937

NAGY 1942a

NAGY 1942b

NAGY $1942 c$

NAGY 1943

NAGY 1948

NAGY 1964

NAGY 1971

NAGY 1973

NÉMETH 1973

NÉMETH 2010

NÉMETH-HAJNócZI 1976

Neubauer 2012

PACHER 2011

PACHER 2009-2011

PACHeR-Konecny 2012
= O. LÁNG: Urban problems in the Civil Town of Aquincum: the so-called "northern band". Dissertationes Archaeologicae 3/1. Budapest 2013, 231-250.

$=$ O. LÁNG: New results in the research of the Northern stripe of the Aquincum Civil Town and surroundings. The Budapest-Esztergom railway reconstruction (Arbeitstitel). AqFüz 20 (2014) (in Vorbereitung).

= G. LASSÁNYI: Feltárások az Aranyhegyi-patak menti temetöben (Excavations in the cemetery on the Aranyhegyi Stream). AqFüz 11 (2005) 81-90.

= G. LASSÁNYI: Kutatások az Aquincum polgárvárosától nyugatra épülő baseballpályán (Research on the territory of the future baseball park west of the Civil Town of Aquincum). AqFüz 19 (2013) 19-31.

= G. LASSÁNYI-E. BECHTOLD: Újabb feltárások az Aranyhegyi-patak menti temetőben (Recent excavations in the cemetery along the Aranyhegyi Stream). AqFüz 12 (2006) 73-78.

= O. MADARAsSY: Nr. 64/10. RégFüz I/43 (1991) 33 .

= E. MÁrity: Chronological problems and special features in the structure of the Civilian City of Aquincum. CommArchHung 1992, 65-73.

= D. MASChEK: Neue Untersuchungen im sog. „Peristylhaus der Zivilstadt Carnuntum“. In: GRABHERR-KAINRATH 2008, 159-166.

= D. MASCHEK: Archäologie und Bauforschung im Bereich von ,Haus IV b-c' der Zivilstadt von Carnuntum: Ergebnisse der Grabungskampagne 2009. AÖ 21/1 (2010) 29-31.

= D. MASCHEK: Die Therme des Zivilstadtviertels im Archäologischen Park Carnuntum in ihrem urbanistischen Kontext: Neue Befunde zur Parzellierung und Wasserversorgung des Wohnstadtviertels. In: HUMER-KONECNY 2011, 33-45

= D. MASCHEK: »Ad aeternitatem perfectus habeatur sine vitio murus« (Vitr. I,5). In: ReINHOLDTWOHLMAYR 2012, 289-296.

= D. MASCHEK-F. HuMER: Petronell. FÖ 45 (2006) 690-693.

= D. MASCHEK-F. HuMER: Petronell. FÖ 48 (2009) 417-422.

= M. MOSSER-S. JäGER-WERSONIG-K. ADLER-WÖLFL: Zur Peripherie der römischen Zivilsiedlung. FW 14 (2011) 202-217.

= M. MÜLLER-I. MADER-R. ChineLLI-S. JÄGER-WERSONIG-S. SAKL-OBERTHALER-U. EISENMENGERS. Czeika-C. Litschauer-C. Öllerer-E. Eleftheriadou: Entlang des Rennwegs. Die römische Zivilsiedlung von Vindobona. Wien 2011.

= L. NAGY: Az Aquincumi Múzeum kutatásai és gyarapodása az 1923-1935. években [Untersuchungen und Neuerwerbungen des Aquincum Museums in den Jahren 1923-1935]. BudRég 12 (1937) 261275 .

= L. NAGY: Topográfia, polgárváros [Topographie und Zivilstadt]. In: ALFÖLDI et al. 1942, 366-385.

= L. NAGY: Agyagmüvesség [Töpferkunst]. In: ALFÖLDI et al. 1942, 627-650.

= L. NAGY: Családi és társadalmi élet [Familien- und gesellschaftliches Leben]. In: ALFöLDI et al. 1942, 525-578.

= T. NAGY: A Fővárosi Régészeti és Ásatási Intézet jelentése az 1938-1942. évek között végzett kutatásairól (Bericht des Archäologischen Institutes von Budapest über die Forschungen der Jahre 1938-1942). BudRég 13 (1943) 359-400, 537-558.

= T. NAGY: A modern szállodák egy antik előde Aquincumból [Ein antiker Vorgänger der modernen Hotels aus Aquincum]. Új Építészet 3 (1948) 121-122.

$=$ T. NAGY: Perióduskutatások az aquincumi polgárváros területén (Die Erforschung der Perioden im Zentral-Gebiet der Zivilstadt von Aquincum). BudRég 21 (1964) 9-54.

$=$ T. NAGY: Der Vicus und das Municipium von Aquincum. ActaArchHung 23 (1971) 59-81.

$=$ T. NAGY: Budapest története. I-II: Római kor [Geschichte von Budapest I-II: Römerzeit]. Hrsg. von L. Gerevich. Budapest 1973.

= M. NÉMETH: Újonnan összeállított falfestmény Aquincumból (Neu zusammengestelltes Wandgemälde aus Aquincum). BudRég 23 (1973) 115-120.

= M. NÉMETH: A város helye és szerepe Pannonia provincia történetében [Die Stelle und Rolle der Stadt in der Geschichte der Provinz Pannonien]. In: H. K. Kérdő-F. Schweitzer (Hrsg.): Aquincum, ókori táj - ókori város. Budapest 2010, 47-54.

= M. NÉMETH-Gy. HAJNócZI: Nr. 111. Szentendrei út 139 (Előzetes jelentés) [Vorbericht]. BudRég 24 (1976) 423

= W. NeUBAUER (Hrsg.): ArchPro Carnuntum. Wien 2012.

= M. W. PACHER: Eine Brunnenstube aus der Therme im Freilichtmuseum Petronell-Carnuntum. In: HUMER-KONECNY 2011, 23-32.

= M. W. PACHER: Die Stadtmauer von Carnuntum in ihrem östlichen Verlauf. CarnuntumJb 2009-2011 (2011) 173-178.

= M. W. PACheR-A. KoneCnY: Die Thermenanlage im so genannten Spaziergarten von Carnuntum. In: TRAXLER-KASTLER 2012, 129-145. 
PeTIT 2001

PETŐ 1976

Petrovitsch 2006

PetZnek 2006

PISO 1991

PócZY 1956

PócZY 1967

PócZY 1970

PócZY 1972

PócZY 1976a

PócZY 1976b

PócZY 1976c

PócZY 1980

PócZY 1984

PócZY 1995

PócZY 2003a

PócZY 2003b

PócZY 2004

PócZY-HAJNócZi 1968

PócZY-HAJNócZI 1971

PÓCZY-ZSIDI 1992

RAUCHENWALD 2006

REINHOLDT-WOHLMAYR 2012

RORISON 2001

RUPNIK 2013

SAUER 1994

SCHEDIVY 1985

SOMMER 1988

SOMMER 1999

STIGLitZ 1969

STIGLITZ 1987

STIGLITZ 2011

Swoboda-Milenović 1959

SZABÓ 2006

SZILÁGYI 1943

SZILÁGYI 1945

SZILÁGYI 1950

SZILÁGYI 1968

TORMA 1881
= J.-P. PETIT: Architecture et urbanisme dans une agglomération secondaire de la Gaule Belgique au Haut-Empire. In: AlteKAMP-SCHÄFER 2001, 37-56.

= M. PETÕ: A legújabb aquincumi fahordó-lelet (The latest Aquincum wooden cask find). BudRég 24 (1976) 201-205.

= H. Petrovitsch: Legio II Italica. Forschungen in Lauriacum 13. Linz 2006.

= B. PetZneK: Ausgewählte Gefäßkeramik aus Haus I in der Zivilstadt Carnuntum. CarnuntumJb 2006, 135-279.

= I. PIso: Die Inschriften vom Pfaffenberg und der Bereich der Canabae legionis. Tyche 6 (1991) 131-169.

= K. Sz. Póczy: Die Töpferwerkstätten von Aquincum. ActaArchHung 7 (1956) 73-136.

= K. Póczy: Nr. 38. RégFüz 20 (1967) 32-33.

= K. PóczY: Anwendung neuerer Ausgrabungsergebnisse bei der Ruinenkonservierung in der Bürgerstadt Aquincum. ATASH 67 (1970) 177-194.

= K. PóczY: Aquincum első aquaeductusa (Le premier aqueduc d'Aquincum). ArchÉrt 99 (1972) 15-32.

= K. Póczy: Nr. 116. Pók u.-Szentendrei út sarok (Elözetes jelentés) [Vorbericht]. BudRég 24 (1976) 424.

= K. Póczy: Pannoniai városok [Städte Pannoniens]. Budapest 1976.

= K. Póczy: Nr. 53/37. RégFüz 29 (1976) 33-36.

= K. PóczY: Közművek a római kori Magyarországon (Kommunalwerke der Römerzeit in Ungarn). Budapest 1980.

= K. PóczY: Aquincum - castra, canabae, colonia. BudRég 25 (1984) 15-34.

= K. PóczY: Der Aquädukt im Stadtbild des Munizipiums von Aquincum (Pannonien). In: F. E. Koenig-S. Rebetz (Hrsg.): Arcvliana. FS H. Bögli. Avenches 1995, 469-477.

= K. PócZY: Wasserver- und entsorgung, Gebäude des Stadtzentrums. In: ZsIDI 2003a, 144-149.

= K. PócZY: Veränderung des Rechtsstatus der Siedlung. In: ZsIDI 2003a, 125-126.

= K. PóczY: Aquincum, Budapest római kori történelmi városmagja [Aquincum, der historische römische Stadtkern von Budapest]. Budapest 2004.

= K. Póczy-Gy. HajNóczi: Nr. 29. RégFüz 21 (1968) 22-23.

= K. PóczY-Gy. HajNóczi: Nr. 35. RégFüz 24 (1971) 26-27.

= K. PócZY-P. Zsidi: Nr. 47/14. RégFüz 44/2 (1992) 32.

$=$ A. Rauchenwald: Ausgewählte Fundgruppen aus Haus I in der Zivilstadt Carnuntum. CarnuntumJb 2006, 281-362.

= C. Reinholdt-W. Wohlmayr (Hrsg.): Akten des 13. Österreichischen Archäologentages, ParisLodron-Universität Salzburg, 25.-27. 2. 2010. Wien 2012.

= M. RoRISOn: Vici in Roman Gaul. BAR IntSer 933. Oxford 2001.

= L. RUPNIK: Római kori vaseszköz-lelet a baseballpálya alatt (A Roman Period iron tool find unter the baseball park). AqFüz 19 (2013) 32-42.

= F. SAUER: Petronell. Jahresbericht 1994. Die Abteilung für Bodendenkmale des Bundesdenkmalamtes. FÖ 33 (1994) 426.

= E. SchEDIvY: Notgrabung im Tiergarten des Schlosses Petronell. Plan der Zivilstadt von Carnuntum. CarnuntumJb 1985 (1986) 60-101, 111-118.

= S. SOMMER: Kastellvicus und Kastell. FBBW 13 (1988) 457-708.

= S. SOMmer: Vom Kastell zum Municipium - zur Struktur von Arae Flaviae. In: N. Hanel-C. Schucany (Hrsg.): Colonia - Municipium - Vicus. Struktur und Entwicklung städtischer Siedlungen in Noricum, Raetien und Obergermanien. BAR IntSer 783. Oxford 1999, 59-64.

= H. STIGLITZ: Grabung Carnuntum 1968. Pro Austria Romana 19/3-6 (1969) 10-11.

= H. STIGLITZ: Geländebegehung im Tiergarten des Schlosses Petronell. Pro Austria Romana 37 (1987) 3-4.

= H. StiglitZ: Zur Wasserversorgung der Zivilstadt von Carnuntum. In: Humer-KoneCNy 2011, 101-105.

= R. M. SwobodA-Milenović: Grabungsbericht 1959. CarnuntumJb 1959 (1961) 31-39.

= Á. SZABÓ: Pannoniciani sacerdotes. A szervezett vallási élet principatus kori vezetői [Pannoniciani sacerdotes. Vorstände des organisierten Religionslebens in der Prinzipatszeit]. Pécs 2006.

= J. SzILÁGYI: Az Aquincumi Múzeum kutatásai és gyarapodása az 1936-1942. évek folyamán (Die Forschungen und Neuerwerbungen des Museums von Aquincum in den Jahren 1936-1942). BudRég 13 (1943) 337-357, 528-536.

= J. SZILÁGYI: A Fővárosi Múzeum rómaikori kutatásai és az Aquincumi Múzeum gyarapodása az 1943-1944. években (The Roman research of the Municipal Museum and the new acquisitions of the Museum of Aquincum in the years 1943-1944). BudRég 14 (1945) 451-468.

= J. SZILÁGYi: Az aquincumi (egyszerü) lakóház-típusok (Les types de maison d'habitation d'Aquincum). AÉrt 77 (1950) 84-90.

= J. SZILÁGYI: Aquincum. RE Suppl. IX. Stuttgart 1968, 61-136.

= K. TORMA: Az aquincumi amfiteátrum [Das Amphitheater von Aquincum]. Budapest 1881 . 
TRAXLER-KASTLER 2012

VADAY 2003

VÁMOS 2010

WEBER 1995

ZIELING 1995

ZSIDI 1990

ZsIDI 2002

ZSIDI 2003a

ZSIDI $2003 \mathrm{~b}$

ZSIDI 2003c

ZSIDI 2003 d

ZsIDI 2004

ZSIDI $2005 \mathrm{a}$

ZSIDI $2005 b$

ZsIDI 2007

ZSIDI 2008

ZsIDI 2011

ZSIDI-LASSÁNYI 2014
= S. TraXler-R. KASTLER (Hrsg.): Colloquium Lentia 2010. Römische Bäder in Raetien, Noricum und Pannonien. Beiträge zur Tagung im Schlossmuseum Linz. 6.-8. Mai 2010. Studien zur Kulturgeschichte von Oberösterreich 27. Linz, 2012.

= A. VADAY: Wells excavated in the Carpathian basin during a decade. Antaeus 26 (2003) 25-68.

= P. VÁmos: Types of pottery kilns in Aquincum. RCRFActa 41 (2010) 67-73.

= G. WeBER: Faimingen. In: W. Czysz et al. (Hrsg.): Die Römer in Bayern. Stuttgart 1995, 441-444.

= N. Zieling: Die Zukunft archäologischer Forschung - ein Ausblick. In: Archäologischer Park/Regionalmuseum Xanten (Hrsg.): Tatort CUT. Führer und Schriften des Archäologischen Parks Xanten 17. Xanten 1995, 119-121.

= P. ZsIDI: Aquincum polgárvárosának városfala és védművei az újabb kutatások tükrében (Stadtmauer und Verteidigungssystem der Zivilstadt von Aquincum im Spiegel der neuesten Forschungsergebnisse). CommArchHung 1990, 143-169.

= P. ZsIDI: Aquincum polgárvárosa [Die Zivilstadt von Aquincum]. Budapest 2002.

= P. ZsIDI (Hrsg.): Forschungen in Aquincum 1969-2002. Aquincum Nostrum II/2. Budapest 2003.

= P. ZsIDI: Verkehrsverbindungen, Wehranlagen, Straßennetz. In: ZsIDI 2003a, 137-143.

= P. ZsIDI: Baugeschichtliche Skizze der Zivilstadt. In: ZSIDI 2003a, 127-135.

= P. Zsidi: Die Bebauung außerhalb der Stadtmauer. In: Zsidi 2003a, 156-159.

= P. Zsidi: Aquincum topográfiája [Die Topographie von Aquincum]. SpecN 18 (2004) 167-226.

= P. ZsIDI: Az aquincumi polgárváros. Vezető az Aquincumi Múzeum romkertjében [Die Zivilstadt von Aquincum. Führer durch den Ruinengarten des Aquincum Musums]. Budapest 2005.

= P. ZsIDI: Die Spuren der vormunizipalen Wehranlagen in der Zivilstadt von Aquincum. In: L. BorhyP. Zsidi (Hrsg.): Die norisch-pannonischen Städte und das römische Heer im Lichte der neuesten archäologischen Forschung. Aquincum Nostrum II/3. Budapest 2005, 101-111.

= P. Zsidi: A Duna szerepe Aquincum topográfiájában (Die Rolle der Donau in der Topographie von Aquincum). BudRég 41 (2007) 57-83.

= P. ZsIDI: Wohnhaustypen und Stadtstruktur in der Zivilstadt von Aquincum. In: P. Scherrer (eds): Domus. Das Haus in den Städten der römischen Donauprovinzen. SoSchr ÖAI 44. Wien 2008, 251-270.

= P. ZsIDI: The role of the Danube in the topography of Aquincum. In: Gy. Kovács-G. Kulcsár (Hrsg.): Ten Thousand Years along the Middle Danube. Varia Archaeologica Hungarica 26. Budapest 2011, 241-264.

= P. ZsIDI-G. LASSÁNYI: III. Óbuda, Aquincum, Hrsz: 19668/4. AqFüz 2014 (in Druckvorbereitung). 